Sergio Andrés Chaparro Moreno

\title{
Projeto de LNAs CMOS para Radiofrequência usando Programação Geométrica
}

Dissertação apresentada à Escola Politécnica da Universidade de São Paulo para obtenção do Título de Mestre em Ciências. 
Sergio Andrés Chaparro Moreno

\section{Projeto de $L N A$ s CMOS para Radiofrequência usando Programação Geométrica}

Dissertação apresentada à Escola

Politécnica da Universidade de São

Paulo para obtenção do Título de Mestre

em Ciências.

Área de concentração:

Microeletrônica

Orientador:

Prof. Dr. Wilhelmus A. M. Van Noije 
Este exemplar foi revisado e alterado em relação à versão original, sob responsabilidade única do autor e com a anuência de seu orientador.

São Paulo, 03 de Setembro de 2013

Assinatura do autor

Assinatura do orientador

Ficha Catalográfica

Moreno, Sergio Andrés Chaparro

Projeto de LNAs CMOS para Radiofrequência usando Programação

Geométrica / S.C. Moreno - ed. rev. - São Paulo, 2013.

$101 \mathrm{p}$.

Dissertação (Mestrado) - Escola Politécnica da Universidade de São Paulo. Departamento de Engenharia de Sistemas Eletrônicos.

1. Redes locais de computadores (projeto) 2. Programação geométrica 3. Radiofrequência I. Universidade de São Paulo. Escola Politécnica. Departamento de Engenharia de Sistemas Eletrônicos II. t. 
A mis queridos padres Esperanza y Gonzalo, y a mi churrita hermosa. 


\section{AGRADECIMENTOS}

Agradezco a mis padres por su cariño, orientación y apoyo incondicional, además por darme todas las herramientas necesarias para ir por la vida. A mis hermanos por creer siempre en mis capacidades y ser un buen ejemplo a seguir. A mi churrita por todo su cariño, comprensión, y apesar de la distancia, estar siempre pendiente animándome durante el desarrollo de este trabajo.

Agradeço ao professor de Wilhelmus pela confiança e orientação que levou este trabalho a bom termo.

Agradeço ao pessoal do LSI e do LSITEC. Em especial quero expressar minha gratidão a Silvana, Elisa, Tarciso, Jair, Paulo, Stelvio e ao Cícero da conceição (descanse em paz meu amigo), por me ajudar muitas vezes na edição de documentos, as medições dos chips, além dos problemas técnicos e burocráticos.

Gracias a mi colega y amigo Armando Ayala por toda la ayuda y orientación. A mis compañeros y colegas del CIDIC-LSI, Juan José Carrillo, Jorge Oliveros, Johanny Saenz, Tiago Weber, Fabian Cabrera y Hugo Hernandez. También agradezco al profesor Jose Amaya por sus aportes, y a todos los que directa o indirectamente contribuyeron en el desarrollo de este trabajo.

Por último agradezco a Diana Caro, Olga Rodríguez, Angelica Mora, Leidy Chaparro, Cesar Martínez, Marisol Martínez y Jennifer Zarate por continuar en contacto apesar de la distancia y los años. 


\section{Resumo}

O objetivo desta dissertação é propor o projeto de amplificadores de baixo ruído (LNAs) do tipo banda estreita e banda larga em tecnologia CMOS. O projeto de $L N A$ s de banda estreita é representado através de um método de otimização conhecido como programação geométrica. Também, neste trabalho foi projetada uma topologia para $L N A$ s de banda larga, aplicando a programação geométrica durante a fase inicial de projeto. Os layouts de ambos os circuitos foram desenhados e fabricados usando três processos CMOS diferentes.

O aumento da utilização de circuitos digitais, está reduzindo e substituindo a quantidade de circuitos analógicos implementados nos sistemas atuais. Nos transceptores de radiofrequência, a maior parte dos circuitos foi substituída por circuitos digitais equivalentes. A razão para esta substituição é devido a sua escalabilidade, variações PVT (Process, Voltage and Temperature) baixas, e menor tempo de projeto, resultado de um fluxo altamente automatizado. A redução do tempo de projeto representa um time-to-market menor e custos mais baixos. No entanto, o amplificador de baixo ruído é um dos blocos de radiofrequência que permanecem principalmente no domínio analógico, tornando a redução do tempo de projeto mediante a otimização do fluxo analógico como um bom foco de estudo.

O LNA deve ser capaz de receber um sinal de baixa potência e alta frequência, e amplificá-lo adicionando o menor ruído possível, mantendo o casamento de impedâncias, baixo consumo de potência, e uma linearidade adequada a fim de evitar a distorção. Nesta dissertação, a maioria das especificações de desempenho citadas são formuladas rigorosamente e descritas como um programa geométrico. Além disso, vários scripts são escritos de forma a automatizar o fluxo de projeto. A programação geométrica é considerada como uma boa opção porque se o problema de otimização tem solução, o resultado é o ponto de otimização global, e pode ser atingido rapidamente (na ordem de segundos). Para um LNA fonte comum de banda estreita, o problema de projeto é completamente formulado como um programa geométrico, e alguns parâmetros normalmente desprezados, como as não idealidades dos indutores $C M O S$ e a capacitância portadreno do transistor $M O S$ são considerados no projeto. O problema de otimização é resolvido em minutos e testado em cinco processos CMOS diferentes, e para diferentes frequências de operação entre $1,5 \mathrm{GHz}$ e $5 \mathrm{GHz}$. Os resultados são comparados e validados através de simulações, e dois layouts de $L N A$ s para $2,45 \mathrm{GHz}$ foram desenhados, fabricados e testados usando dois processos de $0,18 \mu \mathrm{m}$ diferentes. Neste trabalho, também foi formulado um $L N A$ de banda larga com cancelamento de ruído, e um bloco $L N A$-Misturador de banda larga é projetado incluindo a programação geométrica no cálculo da impedância de entrada e o cancelamento de ruído. Os layouts de dois protótipos diferentes do bloco LNA-Misturador de banda larga, operando na faixa de frequência entre $1 \mathrm{GHz}$ e $5 \mathrm{GHz}$, foram desenhados e fabricados usando um processo de $0,18 \mu \mathrm{m}$.

Palavras-chave: LNA, Programação geométrica, Radiofrequência, frequência, Automação de projeto, Figura de ruído, Casamento de impedância, $C A D, C M O S$. 


\section{Abstract}

This dissertation proposes the design of CMOS narrowband and wideband low noise amplifiers. The design problem of narrowband LNAs is represented as an optimization problem known as geometric programming. Furthermore, a topology for wideband LNAs is designed including the geometric programming in an early stage of the design. Both type of circuits were layouted and fabricated using three different CMOS processes.

The tendency to increase the number of applications for digital-intensive circuitry, is reducing and replacing the amount of analog circuits implemented on systems nowadays. In radiofrequency transceivers, most of the circuits have been replaced by a digital-intensive counterpart. Digital circuitry is preferred over the analog one due to its scalability, low PVT (Process, Voltage and Temperature) variations, and shorter designing time result of a highly automated flow. The reduction of the designing time represents a faster time-to-market and lower costs. However, the low noise amplifier is one of the radiofrequency blocks that remain mainly in the analog domain, thus reducing its designing time by optimizing an analog design flow become a good focus of study.

The LNA should be capable of receiving a low power and high frequency signal and amplify it adding the minimum noise possible, while maintaining good impedance matching, low power consumption and an adequate linearity in order to avoid distortion. In this dissertation, most of the performance parameters aforementioned are formulated rigorously and described as a geometric program. Moreover, various scripts are written in order to automate the design flow. The geometric programming is considered a good option because if the optimization problem is feasible, the result is the global optimum and can be obtained in seconds. For a common source narrowband LNA, the design problem is fully formulated as a geometric program and some parameters commonly neglected, as the CMOS inductors non-idealities and the gate-drain capacitance of MOS transistor are considered. The optimization problem is solved in minutes and tested on five different CMOS processes at different operating frequencies between 1.5 $\mathrm{GHz}$ and $5 \mathrm{GHz}$. The results are compared and validated through simulations, and two layouts for $2.45 \mathrm{GHz}$ LNAs are drawn, fabricated and tested using two different $0.18 \mu \mathrm{m}$ processes. In addition, a noise canceling wideband LNA is formulated, and a wideband LNA-Mixer cell is designed by including the geometric programming to estimate the input impedânce matching and assure the noise cancelation. The layouts of two different prototypes of the wideband LNA-Mixer cells for the $1 \mathrm{GHz}-5 \mathrm{GHz}$ frequency band are drawn and fabricated using a 0.18 $\mu \mathrm{m}$ process.

Key words: LNA, Geometric Programming, Radiofrequency, Frequency, Design Automation, Noise Figure, Impedance matching, CAD, CMOS. 


\section{Lista de Figuras}

1.1 Estágios para casamento da impedância de entrada: (a) $C S$ com resistência em paralelo; (b) $C S$ com realimentação resistiva; (c) $C G$; (d) $C S$ com degeneração

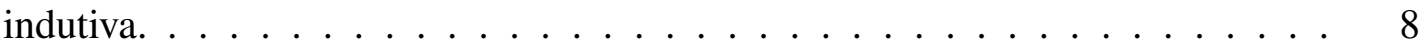

1.2 Técnica de $N C$ : (a) Funcionamento da técnica; (b) $L N A$ usando $N C$. . . . . . 9

1.3 Técnica de $C C C$ : (a) Estágio $C G$ com aumento da transcondutância; (b). Estágio de entrada de um $L N A$ usando $C C C$. . . . . . . . . . . . . . . . . . 10

1.4 Realimentação resistiva: (a) Estágio $C S \operatorname{com} \operatorname{ResF}$; (b). LNA usando ResF. . . . 11

1.5 Método DS: (a) Método DS modificado; (b) Sumidouro de IMD3 PMOS; (c) Método com duplo DS; (d) Coeficientes de terceira ordem da série de potências. 13

$1.6 \quad$ LNA banda larga usando amplificadores distribuídos. . . . . . . . . . . . . . . 14

1.7 Outros $L N A$ s: (a) Estágio porta comum com $D F$; (b) $L N A$ usando $D F$; (c) $L N A$ banda larga usando inversores. . . . . . . . . . . . . . . . . . 15

2.1 LNA-CS com degeneração indutiva. . . . . . . . . . . . . . . . . . . . . . 19

2.2 Modelo do circuito de banda estreita para análise de pequenos sinais. . . . . . . 20

2.3 Cálculo de $Z_{\text {in }}$ : (a) Teorema de Miller; (b) Modelo equivalente para o LNA. . . 21

2.4 Modelo do LNA de banda estreita para a análise de ruído. . . . . . . . . . . . . 25

2.5 Modelo para a análise de ruído das resistências. . . . . . . . . . . . . . . . 28

2.6 Resultados de simulação variando-se a tensão $V_{g s}$ de $M_{1}$ : (a) Ponto de interceptação de terceira ordem; (b) potência dissipada. . . . . . . . . . . . . . . 30

2.7 Comparação das equações formuladas: (a) Parte real da impedância de entrada; (b) Parte imaginária da impedância de entrada; (c) Fator de ruído; (d) Ganho de tensão. . . . . . . . . . . . . . . . . . . . . . . . . . . . . 34

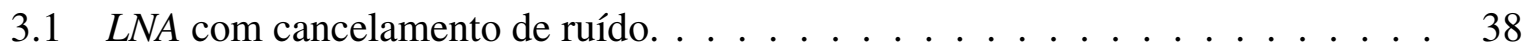

3.2 Modelo do circuito de banda larga para análise de pequenos sinais. . . . . . . . 39 
3.3 Modelo do LNA de banda larga para a análise de ruído. . . . . . . . . . . . . . 46

3.4 Comparação das equações formuladas: (a) Parte real da impedância de entrada; (b) Parte imaginária da impedância de entrada; (c) Fator de ruído; (d) Ganho de tensão. . . . . . . . . . . . . . . . . . . . . 52

4.1 Diagrama de fluxo da metodologia de projeto usando programação geométrica. 57

4.2 Esquemático do $L N A$ de banda estreita usando nas simulações. . . . . . . . . . 58

4.3 Resultados principais para um $L N A$ de banda estreita projetado para $1,5 \mathrm{GHz}$ usando o processo da TowerJazz. . . . . . . . . . . . . . . . . . . . . 61

4.4 Resultados principais para um $L N A$ de banda estreita projetado para $1,8 \mathrm{GHz}$ usando o processo da $X F A B \ldots \ldots \ldots$

4.5 Resultados principais para um $L N A$ de banda estreita projetado para 2,45 GHz usando o processo da $A M S \ldots \ldots$. . . . . . . . . . . . . . . . 62

4.6 Resultados principais para um $L N A$ de banda estreita projetado para 3,5 GHz usando o processo de $0,18 \mu \mathrm{m}$ da $I B M \ldots \ldots$. . . . . . . . . . . . 63

4.7 Resultados principais para um $L N A$ de banda estreita projetado para $5 \mathrm{GHz}$ usando o processo de $0,13 \mu \mathrm{m}$ da $I B M$.

4.8 Resultados de simulação de $L N A$ s projetados para diferentes frequências de operação:(a) Figura de ruído; (b) Ganho de tensão; (c) Coeficiente de reflexão de entrada; (d) Interceptação de terceira ordem; (e) Consumo de potência; (f) Isolamento reverso . . . . . . . . . . . . . . . . . . . . . . . 64

4.9 Esquemático do $L N A$ de banda larga usado nas simulações. . . . . . . . . . . . 66

4.10 Resultados de simulação dos LNAs de banda larga projetados:(a) Figura de ruído; (b) Ganho; (c) Coeficiente de reflexão de entrada; (d) Coeficiente de reflexão de saída; (e) Parte real da impedância de entrada; (f) Parte imaginária da impedância de entrada. . . . . . . . . . . . . . . . . . .

4.11 Vista esquemática completa do LNA de banda estreita implementado. . . . . . . 
4.13 Resultados pós-layout do $L N A$ de banda estreita projetado no processo da XFAB: (a) Figura de ruído e coeficiente de reflexão da entrada; (b) Ganho e coeficiente de reflexão da entrada; (c) Interceptação de terceira ordem; (d) Fator e medida de estabilidade. . . . . . . . . . . . . . . . . . . . . . . . . . 74

4.14 Layout do LNA de banda estreita usando o processo TS018SL-5M1L da TowerJazz. 76

4.15 Resultados pós-layout do LNA de banda estreita projetado no processo da TowerJazz: (a) Figura de ruído e coeficiente de reflexão da entrada; (b) Ganho e coeficiente de reflexão da entrada; (c) Interceptação de terceira ordem; (d) Fator e medida de estabilidade. . . . . . . . . . . . . . . . . . . . . 76

4.16 Vista esquemática completa do bloco $L N A$-misturador de banda larga projetado. 77

4.17 Layouts dos protótipos dos blocos LNA-misturador de banda larga usando o processo cmrf7sf da IBM: (a) Versão sem indutor; (b) Versão com indutor. . . . 78

4.18 Resposta transiente dos blocos $L N A$-misturador de banda larga: (a) Sinal de sáida sem cancelamento do $L O$; (b) Sinal de sáida com cancelamento do $L O$. .

4.19 Resultados pós-layout dos blocos $L N A$-misturador de banda larga projetadas no processo da IBM: (a) Figura de ruído de banda lateral única; (b) Ganho de tensão; (c) Coeficiente de reflexão da entrada; (d) Interceptação de terceira ordem. 80

4.20 Microfotografia dos LNAs de banda estreita: (a) XFAB; (b) TowerJazz. . . . . . 81

4.21 Microfotografia dos blocos $L N A$-misturador de banda larga usando o processo da IBM: (a) Versão sem indutor; (b) Versão com indutor.

4.22 Resultados experimentais parciais do LNA da Towerjazz: (a) Figura de ruído e coeficiente de reflexão da entrada; (b) Ganho e coeficiente de reflexão da saída; (c) Set up de medida.

4.23 Resultados experimentais parciais do $L N A$ da XFAB: (a) Figura de ruído e coeficiente de reflexão da entrada; (b) Ganho e coeficiente de reflexão da saída; (c) Set up de medida; (d) Vista do analisador de redes. . . . . . . . . . . . . . . 83

A.1 Metodologia proposta para a exploração automática do espaço de projeto do $L N A$ de banda estreita.

A.2 Figura de ruído resultado de diferentes simulações. . . . . . . . . . . . . . . . 91

A.3 Ganho resultado de diferentes simulações. . . . . . . . . . . . . . . . . . 92 
A.4 Interceptação de terceira ordem resultado de diferentes simulações. . . . . . . . 92

A.5 Consumo de potência resultado de diferentes simulações. . . . . . . . . . . . . 93

A.6 Casamento da impedância de entrada garantido nas diferentes simulações. . . . 93

A.7 Indutância de porta obtida para casar a impedância de entrada nas simulações. . 94

A.8 Indutância de degeneração obtida para casar a impedância de entrada nas simulações. . . . . . . . . . . . . . . . . . . . . . . . . . . . . 94

A.9 Casamento da impedância de saída garantido nas diferentes simulações. . . . . 95

A.10 Isolamento reverso resultado de diferentes simulações. . . . . . . . . . . . . . 95 


\section{Lista de Tabelas}

1.1 Estado da arte dos $L N A$ s banda estreita. . . . . . . . . . . . . . . . . . . 4

1.2 Estado da arte dos $L N A$ s banda larga. . . . . . . . . . . . . . . . . . . 6

4.1 Restrições dos dispositivos segundo o processo usado. . . . . . . . . . . . . . . 56

4.2 Resultados dos PGs resolvidos para diferentes tecnologias e frequências de operação. . . . . . . . . . . . . . . . . . . . . . . . . 59

4.3 Dimensões dos dispositivos obtidas nos PGs resolvidos. . . . . . . . . . . . . 60

4.4 Resultados das variáveis do transistor modeladas. . . . . . . . . . . . . . . . . 60

4.5 Resultados de PGs resolvidos para LNAs de banda larga em diferentes tecnologias. 66

4.6 Resultados de algumas das variáveis dos transistores modeladas para os LNAs de banda larga. . . . . . . . . . . . . . . . . . . . . . . 67

4.7 Dimensões dos dispositivos obtidas nos PGs resolvidos para os LNAs de banda

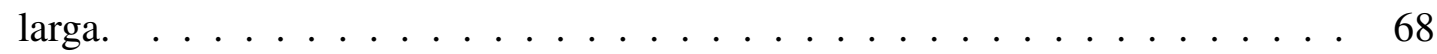

4.8 Dimensionamento do $L N A$ de banda estreita em $X F A B$. . . . . . . . . . . . . . . 72

4.9 Resultados de projeto do $L N A$ de banda estreita em $0,18 \mu \mathrm{m}$ da XFAB . . . . . . 73

4.10 Dimensionamento do LNA de banda estreita em TowerJazz. . . . . . . . . . . . 75

4.11 Resultados de projeto do LNA de banda estreita em 0,18 $\mu \mathrm{m}$ da TowerJazz. . . 75

4.12 Dimensionamento dos blocos LNA-Misturador em IBM. . . . . . . . . . . . . 78

4.13 Resultados pós-layout dos blocos $L N A$-misturador de banda larga em 0,18 $\mu \mathrm{m}$ da $I B M . \ldots \ldots \ldots \ldots$

4.14 Resultados parciais das medidas do chip da TowerJazz. . . . . . . . . . . . . 83

4.15 Resultados parciais das medidas do chip da XFAB . . . . . . . . . . . . . 84 


\section{Lista de abreviaturas e siglas}

ADC Analog-to-Digital Converter-Conversor analógico-digital

AMS Austria MicroSystems

ASITIC Analysis and Simulation of Spiral Inductors and Transformers for ICs - Análise e simulação de indutores em espiral e transformadores para circuitos integrados

CAD Computer-Aided Design - Projeto assistido por computador

CCC Capacitive Cross-Coupling - Acoplamento capacitivo cruzado

CG Common Gate - Porta comum

CMOS Complementary Metal-Oxide Semiconductor - Semicondutor metal-óxido complementar

CR Cognitive Radio - Rádio cognitivo

CS Common Source - Fonte comum

CVX MATLAB Software for Disciplined Convex Programming - Software do MATLAB para programação convexa disciplinada

DA Distributed Amplifier - Amplificador distribuído

DF Dual Feedback - Dupla realimentação

DS Derivative Superposition - superposição derivada

ESD Electrostatic Discharge - Descarga eletrostática

GAMS General Algebraic Modeling System - Sistema de modelagem algébrica geral

IBM International Business Machines - Negócio internacional de máquinas

IMD3 Third Order Intermodulation Distortion - Distorsões por intermodulação de terceira ordem 
LNA Low Noise Amplifier - Amplificador de baixo ruído

LVS Layout Versus Schematic - Layout contra esquemático

NC Noise Canceling - Cancelamento de ruído

NMOS N-type Metal-Oxide Semiconductor - Semicondutor metal-óxido do tipo N

PA Power Amplifier - Amplificador de potência

PG Programa geométrico ou programação geométrica

PLL Phase-Locked Loop - Malha de captura de fase

PMOS P-type Metal-Oxide Semiconductor - Semicondutor metal-óxido do tipo P

ResF Resisitve-Feedback - Realimentação resistiva

RF Radiofrequência

RR Reconfigurable Radio - Rádio reconfigurável

SDR Software-Defined Radio - Rádio definido por software

TOMLAB Optimization Environment for Fast and Robust Large-Scale Optimization in $M A T L A B$ - Ambiente de otimização para otimização rápida e robusta em larga escala em MATLAB

UWB Ultra-Wide Band - Banda ultra larga

VCO Voltage-Controlled Oscillator - Oscilador controlado por tensão

VPCD Virtuoso Passive Component Designer - Desenhador de componentes passivos do Virtuoso

WLAN Wireless Local Area Network - Rede de área local sem fio 


\section{Lista de símbolos}

$f_{T} \quad$ Frequência de ganho unitário de corrente do transistor

NF $\quad$ Figura de ruído

$P_{I I P 3} \quad$ Ponto de interceptação de terceira ordem referido à entrada

$S_{11} \quad$ Coeficiente de reflexão na entrada

$Z_{\text {in }} \quad$ Impedância de entrada

$g_{m i} \quad$ Transcondutância do transistor $i$

$C_{g s i} \quad$ Capacitância porta-fonte do transistor $i$

$L_{S} \quad$ Indutor de degeneração

$L_{g} \quad$ Indutor ligado à porta de um transistor

$M_{i} \quad$ Transistor $M O S i$

$R_{f} \quad$ Resistência de realimentação

$V_{g s i} \quad$ Tensão porta-fonte do transistor $i$

$g_{3} \quad$ Componente de terceira ordem da corrente de dreno do transistor

$R_{S} \quad$ Resistência característica da fonte do sinal de entrada

$f_{o}(x) \quad$ Função objetivo de um programa geométrico

$f_{i}(x) \quad$ Função restrição tipo desigualdade de um programa geométrico

$g_{j}(x) \quad$ Função restrição tipo igualdade de um programa geométrico

$L_{d} \quad$ Indutor de carga

$C_{L} \quad$ Capacitância de carga

$v_{\text {inRF }} \quad$ Fonte do sinal de entrada tipo RF

$Z_{L g} \quad$ Impedância equivalente do indutor de porta

$Z_{L s} \quad$ Impedância equivalente do indutor de degeneração

$r_{g i} \quad$ Resistência de porta do transistor $i$

$Z_{C g s i} \quad$ Impedância equivalente da capacitância porta-fonte do transistor $i$

$Z_{C g d i} \quad$ Impedância equivalente da capacitância porta-dreno do transistor $i$

$Z_{C g b i} \quad$ Impedância equivalente da capacitância porta-corpo do transistor $i$

$g_{m b i} \quad$ Transcondutância de corpo do transistor $i$

$r_{d s i} \quad$ Resistência porta-dreno do transistor $i$

$V_{s b i} \quad$ Tensão fonte-corpo do transistor $i$ 
$C_{g b i} \quad$ Capacitância porta-corpo do transistor $i$

$C_{g d i} \quad$ Capacitância porta-dreno do transistor $i$

$A_{m i} \quad$ Ganho de Miller do transistor $i$

$Z_{\text {Lsrefi }} \quad$ Impedância de degeneração referida ao nó $i$

$\operatorname{Re}\left\{Z_{i n}\right\} \quad$ Parte real da impedância de entrada

$R_{L g} \quad$ Resistência série do indutor de porta

$R_{L s} \quad$ Resistência série do indutor de degeneração

$\operatorname{Im}\left\{Z_{\text {in }}\right\}$ Parte imaginária da impedância de entrada

$\omega \quad$ Frequência angular

$i_{o} \quad$ Corrente de saída do circuito

$i_{o i} \quad$ Corrente de saída percorrendo o transistor $i$

$I_{i} \quad$ Corrente através da impedância porta-dreno do transistor $i$

$G_{L N A} \quad$ Ganho de transcondutância do amplificador de baixo ruído

$Z_{\text {out }} \quad$ Impedância de saída

$A_{v_{L N A}} \quad$ Ganho de tensão do amplificador de baixo ruído

$f \quad$ Frequência

$i_{n i, g} \quad$ Raiz do valor quadrático médio da corrente de ruído da porta do transistor $i$

$i_{n i, d} \quad$ Raiz do valor quadrático médio da corrente de ruído do canal do transistor $i$

$F_{M i} \quad$ Fator de ruído do estágio formado pelo transistor $i$

$\overline{i_{n, o}^{2}} \quad$ Densidade espectral de potência da corrente de ruído total na saída

Densidade espectral de potência da corrente de ruído na saída devido à fonte do sinal de entrada

Densidade espectral de potência da corrente de ruído do canal do transistor $i$

Densidade espectral de potência da corrente de ruído de porta do transistor $i$

Fator de correlação entre o ruído de porta e o ruído de canal do transistor

$\Delta f \quad$ Largura de banda de ruído

$\gamma \quad$ Fator de excesso de ruído no dreno do transistor

$\delta \quad$ Fator de excesso de ruído induzido na porta do transistor

K $\quad$ Constante de Boltzmann

$T \quad$ Temperatura

$g_{d s 0 i} \quad$ Condutância do transistor $i$ quando $V_{D S}=0$

$g_{d s i} \quad$ Condutância dreno-fonte do transistor $i$

$\overline{v_{n, R s}^{2}}$

Densidade espectral de potência da tensão de ruído da fonte de sinal de entrada

$i_{n, o} \quad$ Raiz do valor quadrático médio da corrente de ruído total na saída

$\overline{v_{n, R}^{2}}$

Densidade espectral de potência da tensão de ruído de uma resistência

$F_{R i} \quad$ Fator de ruído devido à resistência $i$ 
$F_{L N A} \quad$ Fator de ruído do amplificador de baixo ruído

$N F_{L N A} \quad$ Figura de ruído do amplificador de baixo ruído

$Q_{L i} \quad$ Fator de qualidade do indutor $i$

$I_{D i} \quad$ Corrente do dreno do transistor $i$

$W_{i} \quad$ Largura do canal do transistor $i$

$R_{s q} \quad$ Resistência por quadrado do material de porta do transistor

$n_{f i} \quad$ Número de dedos do layout do transistor $i$

$L_{i} \quad$ Comprimento do canal do transistor $i$

$P_{D} \quad$ Potência dissipada

$V_{D D} \quad$ Tensão de alimentação

$R_{O} \quad$ Resistência de saída

$W_{f i} \quad$ Largura dos dedos do transistor $i$

$R_{L d} \quad$ Resistência série do indutor de carga

$R_{o L d} \quad$ Resistência equivalente em paralelo do indutor de carga

$Z_{\text {inM }} \quad$ Impedância de entrada do estágio formado pelo transistor $i$

$R_{1} \quad$ Resistência de carga do estágio de entrada do $L N A$ com cancelamento de ruído

$R_{L} \quad$ Resistência de carga do estágio de saída do $L N A$ com cancelamento de ruído

$G_{M i} \quad$ Ganho de transcondutância do estágio formado pelo transistor $i$

$i_{n i, o} \quad$ Raiz do valor quadrático médio da corrente de ruído do estágio formado pelo transistor $i$

$\overline{i_{n M 1, o}^{2}} \quad$ Densidade espectral de potência da corrente de ruído na saída devido ao estágio formado pelo transistor $M_{1}$

$\overline{i_{n i, o}^{2}} \quad$ Densidade espectral de potência da corrente de ruído do estágio formado pelo transistor $i$ 


\section{Sumário}

1 Introdução 1

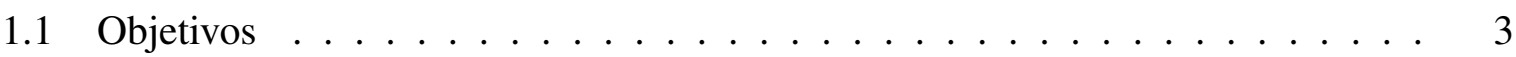

1.2 Estado da arte . . . . . . . . . . . . . . . . . . 3

1.2.1 LNAs de banda estreita . . . . . . . . . . . . . . . . 3

1.2.2 LNAs de banda larga ..................... 5

1.3 Topologias e técnicas para projeto de $L N A s \quad \ldots \ldots \ldots \ldots$

1.3.1 Compromisso máxima transferência de potência - figura de ruído . . 7

1.3.2 Cancelamento de ruído . . . . . . . . . . . . . . . . . 9

1.3.3 Acoplamento usando capacitores cruzados . . . . . . . . . . . . . 10

1.3.4 Realimentação resistiva . . . . . . . . . . . . . . . . . . 11

1.3.5 Método de superposição derivada . . . . . . . . . . . . . . . 12

1.3.6 Outras topologias . . . . . . . . . . . . . . . . . . . 14

1.4 Estrutura do texto . . . . . . . . . . . . . . . . . . 16

2 Formulação de projeto de um LNA de banda estreita usando programação $\begin{array}{ll}\text { geométrica } & 17\end{array}$

2.1 Programação Geométrica . . . . . . . . . . . . . . . . . . . . . 17

2.2 Forma padrão de um programa geométrico . . . . . . . . . . . . . . . . . 18

2.3 Formulação de projeto de um LNA de banda estreita . . . . . . . . . . . . . . . 19

2.3.1 Análise de pequenos sinais . . . . . . . . . . . . . . . 19

2.3.2 Análise de ruído . . . . . . . . . . . . . . . . . . . 24 
2.4 Considerações para aplicar a programação geométrica no projeto do $L N A$ de banda estreita . . . . . . . . . . . . . . . . . . . . . . . 29

2.4 .1 Linearidade . . . . . . . . . . . . . . . . . . . 29

2.4.2 Modelagem do transistor . . . . . . . . . . . . . . . 30

2.4 .3 Outras considerações . . . . . . . . . . . . . . . . 31

2.5 Resumo da formulação de projeto do LNA de banda estreita . . . . . . . . . . . 33

2.6 Forma padrão do $\mathrm{PG}$ para o $L N A$ de banda estreita . . . . . . . . . . . . . . . . 35

3 Formulação de projeto de um $L N A$ de banda larga usando programação $\begin{array}{ll}\text { geométrica } & 37\end{array}$

3.1 Formulação de projeto de um $L N A$ de banda larga . . . . . . . . . . . . . . . 37

3.1 .1 Análise de pequenos sinais . . . . . . . . . . . . 38

3.1 .2 Análise de ruído . . . . . . . . . . . . . . . . . . 45

3.2 Considerações para aplicar programação geométrica no projeto do LNA de banda $\operatorname{larga} \ldots \ldots \ldots$. . . . . . . . . . . . . . . . . . . 50

3.3 Resumo da formulação de projeto do $L N A$ de banda larga . . . . . . . . . . . . 52

3.4 Forma padrão do PG para o $L N A$ de banda larga . . . . . . . . . . . . . . . . . 54

4 Projeto, simulação e fabricação dos $L N A s$

4.1 Resultados do LNA de banda estreita . . . . . . . . . . . . . . . 56

4.1 .1 Automação de projeto . . . . . . . . . . . . . 56

4.1.2 Resultados dos diferentes $L N A$ s projetados $\ldots \ldots \ldots$

4.1.3 Resumo dos resultados . . . . . . . . . . . . . . . . . . . . . 64

4.2 Resultados do LNA de banda larga . . . . . . . . . . . . . . . . 65

4.3 Layouts e resultados pós-layout . . . . . . . . . . . . . . . . . . 70

4.3.1 Resultados pós-layout dos LNAs de banda estreita . . . . . . . . . . . . 71

4.3.2 Resultados pós-layout dos blocos LNA-misturador de banda larga usando o processo de $0,18 \mu \mathrm{m}$ da $I B M \ldots \ldots \ldots$. . . . . . . . 77 
4.4 Chips fabricados . . . . . . . . . . . . . . . . 80

4.4.1 Resultados parciais de medida dos LNAs de banda estreita . . . . . . . 81

5 Conclusões e trabalhos futuros

Apêndice A - Exploração do espaço de projeto do $L N A$ de banda estreita 


\section{Introdução}

Nos últimos anos a idéia de ter transceptores versáteis, tais como aqueles usados para os rádios definidos por software (SDR, Software-Defined Radio), rádios cognitivos (CR, Cognitive Radio) e rádios reconfiguráveis ( $R R$, Reconfigurable Radio) tem se tornado uma realidade. Como consequência, a necessidade de transceptores para radiofrequência (RF) predominantemente digitais (Digital-Intensive) e operando no domínio do tempo, aumentou e tornou-se um foco interessante de estudo para diferentes pesquisadores na área acadêmica e na indústria [1-7]. Como mencionado em [3]: "In a deep-submicron CMOS process, time-domain resolution of a digital signal edge transition is superior to voltage resolution of analog signals," o que significa que, à medida que as tensões de alimentação diminuem e os transistores tornam-se mais rápidos, considera-se mais adequado manipular a informação no domínio do tempo discreto do que no domínio da tensão e o tempo contínuo. Além disso, em comparação com os circuitos analógicos, os circuitos digitais são menos sensíveis às variações do processo, facilmente dimensionados a partir de uma tecnologia para outra, e o seu fluxo de projeto está altamente automatizado. Assim, o tempo de colocação no mercado (Time to Market) de uma solução completamente digital ou majoritariamente digital, é menor do que uma solução analógica/RF, diminuindo os custos.

Até agora, a maioria dos circuitos do transceptor foram convertidos para o domínio digital, até mesmo alguns dos circuitos do Front-End [3-5]. Existem algumas abordagens para osciladores controlados por tensão (VCO, Voltage Controlled Oscillator) e amplificadores de potência (PA, Power Amplifier), usando circuitos predominantemente digitais, loops de controle além de comutação e armazenamento em capacitores para criar ou manipular sinais discretos [4-7]. Nestes trabalhos e nos anteriores, alguns conceitos novos foram introduzidos, como por exemplo, a conversão RF-para-digital e digital-para-RF. O primeiro é conseguido através de um misturador de subamostragem, ou um conversor analógico-digital (ADC, Analog-to-Digital Converter) baseado em um VCO. O segundo, através da integração do $A D C$, o misturador de up-conversion e o amplificador de potência em um único bloco. Além disso, em [3] o primeiro sintetizador de frequência completamente digital é apresentado. No entanto, na cadeia 
de recepção o amplificador de baixo ruído (LNA, Low Noise Amplifier) é necessário, assim como o bloco predominantemente analógico restante continua a ser um importante foco de pesquisa, seja para encontrar uma solução mais adequada para os novos requerimentos nos transceptores (por exemplo em [2]), ou substituí-lo usando a conversão RF-para-digital nos sinais de baixa potência e alta frequência que provém da antena.

O LNA é o primeiro bloco na cadeia de recepção. Ele está encarregado de receber o sinal de baixa potência que provém da antena e amplificá-lo adicionando o menor ruído possível, mantendo um casamento da impedância de entrada adequado, ganho alto e um comportamento linear $[8,9]$. Este bloco afeta a faixa dinâmica do receptor inteiro, já que a figura de ruído define o mínimo nível do sinal de entrada permitido para garantir uma relação sinal-ruído adequada na saída, e a linearidade define o máximo nível do sinal de entrada permitido sem ter uma saída distorcida. Assim, um LNA deve ter uma figura de ruído baixa, com ganho elevado em toda a banda de interesse, alta linearidade em termos do ponto de interceptação de terceira ordem, casamento de impedâncias adequado a fim de ter uma transferência de potência ótima com a antena, e isolamento entre as portas de entrada e saída, consumindo o mínimo de potência e área, que são preocupações em cada circuito integrado hoje em dia. Sobre estas bases, a busca de novas topologias e técnicas para melhorar o desempenho e diminuir o tempo de projeto no domínio analógico ainda são importantes, que é o propósito principal deste trabalho.

O projeto de um amplificador de baixo ruído envolve muitos aspectos dependendo da aplicação, das especificações exigidas e do processo de fabricação. Mesmo assim, a função de cada $L N A$ permanece igual: amplificar o sinal de baixa potência da antena. Como mencionado anteriormente, têm sido propostas diferentes topologias para atingir os requisitos dos diferentes padrões de comunicação e considerando os diferentes comportamentos existentes (banda estreita, banda larga, banda ultra larga e multi-padrão). Por exemplo, para aplicações de potência ultra baixa (tensão de alimentação baixa), o uso de transformadores é comum porque a queda de tensão através de dispositivos passivos não pode ser permitida. Outro exemplo é que para aplicações de banda estreita e baixo ruído, amplificadores de fonte comum são mais usados do que os de porta comum, que são mais adequados para banda larga [10]. Também o uso de indutores é comum, mas nos últimos anos com as novas tecnologias Submicron com alta $f_{T}$ (frequência na qual o ganho de corrente cai para a unidade), as propostas sem indutores apareceram a fim de evitar tratar com o baixo fator de qualidade dos indutores integrados e o seu alto consumo de área não-escalável [1].

Através dos aspectos levantados, neste trabalho é proposto o projeto de amplificadores de baixo ruído para aplicações de banda estreita e banda larga, usando ferramentas para o projeto 
assistido por computador (CAD, Computer Aided Design). A utilização destas ferramentas no fluxo de projeto reduz consideravelmente o tempo de projeto e consequentemente o custo. Neste caso em particular, será utilizada a programação geométrica como meio para alcançar um ponto de partida otimizado e trabalhar com maior facilidade e menor tempo com o problema N-dimensional de projetar um circuito analógico de radiofrequência. Além disso, se uma descrição matemática adequada do comportamento do circuito é feita, alguns dos compromissos mais importantes serão observados com maior precisão entre a matemática e as simulações posteriores.

\subsection{Objetivos}

- Formular o problema de projeto de um amplificador de baixo ruído de banda estreita em tecnologia CMOS como um programa geométrico, considerando o ruído, o ganho, o casamento de impedância de entrada, a linearidade e as não idealidades dos indutores nesta tecnologia.

- Projetar um amplificador de baixo ruído de banda larga em tecnologia $C M O S$ e analisar a implementação da programação geométrica no fluxo de projeto.

- Desenhar os layouts para ambos LNAs e realizar as simulações pós-layout.

- Testar protótipos de LNAs fabricados.

\subsection{Estado da arte}

Para atualizar o estado-da-arte de trabalhos anteriores e ter uma visão sobre novas propostas e tendências, nesta seção são apresentados alguns trabalhos publicados recentemente e que envolvem o projeto de amplificadores de baixo ruído. A revisão é feita em dois grupos; $\mathrm{Na}$ tabela 1.1 são apresentados alguns projetos de banda estreita, e na tabela 1.2 são mostrados LNAs de banda larga e banda ultra larga (UWB, Ultra Wide Band).

\subsubsection{LNAs de banda estreita}

No trabalho relacionado [11], é apresentado um LNA diferencial com topologia cascode. Neste trabalho, o amplificador é tratado como uma cascata de dois estágios, sendo um primeiro estágio de fonte comum (CS, Common Source) e um segundo de porta comum (CG, Porta comum). 
Tabela 1.1: Estado da arte dos $L N A$ s banda estreita.

\begin{tabular}{||c||ccccccc||}
\hline Referência & {$[11]$} & {$[12]$} & {$[13]^{*}$} & {$[13]^{* *}$} & {$[14]$} & {$[15]$} & {$[16]$} \\
\hline \hline Processo [nm] & 350 & 180 & 130 & 130 & 180 & 180 & 32 \\
Frequência [GHz] & 2,2 & 5 & 2,4 & 2,4 & 2,4 & 1,2 & 2,5 \\
$N F[\mathrm{~dB}]$ & 1,92 & 4,1 & 2 & 1,2 & 3,9 & 1,8 & 3,5 \\
Ganho $[\mathrm{dB}]$ & 8,6 & 10,23 & 24 & 29 & 12,9 & $30,4^{\mathrm{a}}$ & 11 \\
$P_{I I P 3}[\mathrm{dBm}]$ & $-2,55$ & -15 & $-11^{\mathrm{b}}$ & $-11^{\mathrm{b}}$ & $\mathrm{NA}$ & $\mathrm{NA}$ & 5 \\
$S_{11}[\mathrm{~dB}]$ & $<-13$ & $-17,9$ & $-10,7$ & $-7,6$ & $<-8$ & $<-14$ & $<-13$ \\
Potência $[\mathrm{mW}]$ & 16,2 & 0,8 & $2,6^{\mathrm{b}}$ & $2,3^{\mathrm{b}}$ & 14,4 & 3,6 & 19,8 \\
Área $\left[\mathrm{mm}^{2}\right]$ & 1,3 & 0,792 & 0,6 & 0,578 & $\mathrm{NA}$ & 0,66 & 0,35 \\
Ano & 2008 & 2009 & 2009 & 2009 & 2009 & 2010 & 2011 \\
\hline
\end{tabular}

${ }^{a}$ Ganho de Tensão.

${ }^{\mathrm{b}}$ Dados do core.

Pelo fato de que os estágios $C G$ têm maior ruído do que os $C S$, e também que o segundo estágio de uma cascata é importante para definir a linearidade, a redução do ruído e a melhora na linearidade é feita neste estágio usando o acoplamento com capacitores cruzados. O circuito apresenta uma figura de ruído baixa para a tecnologia, mas com alta dissipação de potência e consumo de área elevada devido ao uso de indutores OnChip. Por outro lado, a técnica de polarização direta do corpo e reutilização de corrente proposta em [12], permite ao amplificador operar com tensões de alimentação baixas diminuindo a dissipação de potência. A polarização direta do corpo consiste em aplicar uma tensão positiva no corpo do transistor NMOS, para reduzir a tensão de limiar e fazê-lo operar em inversão forte usando uma tensão porta-fonte menor. A técnica de reutilização de corrente usada consiste no empilhamento de dois estágios num mesmo caminho de corrente. O circuito apresenta a menor dissipação de potência relatada na tabela mas com uma figura de ruído alta.

Em [13] são apresentados dois $L N A$ s projetados usando realimentação resistiva, a fim de reduzir o número de indutores usados pela topologia cascode com degeneração indutiva. Esta topologia tem três indutores dos quais dois são usados para garantir casamento da impedância de entrada com baixo ruído. A realimentação resistiva permite obter casamento de impedâncias usando apenas um indutor, além de aumentar o ganho e manter uma figura de ruído baixa. A versão * está totalmente integrada e a ** possui uma rede externa para o casamento da impedância de entrada. Devido ao fator de qualidade baixo dos indutores $C M O S$, a versão totalmente integrada tem um ruído maior e menor ganho do que a versão com componentes externos. No artigo relacionado [14], é proposta uma topologia $C G$ diferencial usando indutores diferenciais OnChip para reduzir a área. Nesta topologia o ruído é reduzido por meio de duas técnicas: o acoplamento com capacitores cruzados, e a otimização do comprimento do canal. A primeira consiste no aumento da transcondutância do estágio para obter o casamento de 
impedância na entrada com menor ruído. A segunda consiste em aumentar o comprimento do canal dos transistores de entrada cuidadosamente a fim de modificar o valor do fator de efeito de canal curto que têm influência sobre o ruído total.

Na referência [15] é apresentado um LNA com entrada simples e saída diferencial também conhecido como balun ativo. Este amplificador é adequado para a maioria das propostas de misturador que têm entradas e saídas diferenciais. Outra vantagem de usar ramos de sinal diferenciais em receptores é obter um ganho de tensão maior, evitar o ruído de modo comum e reduzir o efeito de algumas parasitas. Normalmente os baluns são implementados externamente, mas usá-los produz degradação do ganho e aumento do ruído. Assim, no trabalho relacionado, com uma correta polarização de ambos os ramos podem ser obtidos sinais com ganho igual e diferença de fase adequada. O circuito tem uma figura de ruído baixa, e consumo de potência menor do que os outros amplificadores diferenciais relacionados na tabela 1.1. Finalmente [16] introduz uma topologia de amplificador Push-Pull diferencial, além do uso de indutores acoplados um dentro do outro (Nested). A estrutura Push-Pull é produzida pelo empilhamento de dois LNAs com degeneração indutiva; um NMOS e um PMOS. Esta configuração melhora a linearidade aproveitando que a combinação das respostas complementares destes transistores gera uma transcondutância constante às mudanças na tensão de entrada. Os indutores são usados um dentro do outro a fim de reduzir a área e ter casamento da impedância de entrada adequado com baixo nível de ruído. O circuito Push-Pull atinge a menor área dos trabalhos relatados na tabela e a mais alta linearidade, mas com uma penalidade no consumo de potência.

\subsubsection{LNAs de banda larga}

Uma vez expostos alguns trabalhos do estado-da-arte dos amplificadores de baixo ruído banda estreita, em seguida serão apresentadas as topologias, técnicas e contribuições de diferentes autores para o projeto de amplificadores de banda larga e banda ultra larga.

No trabalho relacionado [17] é mostrado um LNA de dois estágios diferenciais para operar nas bandas de WLAN, Bluetooth e $U W B$. O circuito tem um estágio de entrada com reutilização de corrente e realimentação, seguido por um estágio par diferencial com um indutor ativo como carga para compensar o ganho e reduzir consideravelmente o consumo de área. O estágio de reutilização de corrente consiste de um transistor NMOS e um PMOS empilhados, a fim de aumentar a transcondutância para um ponto de operação fixo. O circuito apresenta um alto ganho, coeficente de reflexão na entrada abaixo de $-10 \mathrm{~dB}$ na faixa de frequência desejada, o 
Tabela 1.2: Estado da arte dos $L N A$ s banda larga.

\begin{tabular}{||c||ccccccc||}
\hline Referência & {$[17]$} & {$[18]$} & {$[2]$} & {$[19]$} & {$[20]$} & {$[21]_{v 1}$} & {$[21]_{v 2}$} \\
\hline \hline Processo [nm] & 65 & 130 & 65 & 180 & 90 & 65 & 65 \\
Frequência [GHz] & $1-10,5$ & $3,1-10,6$ & $0,05-10$ & $1,5-7$ & $0,002-2,3$ & $0,1-10$ & $0,1-5,2$ \\
$N F[\mathrm{~dB}]$ & $3,9-5$ & $2,7-3,7$ & $2,9-5,9$ & $3-3,7$ & $1,4_{\min }$ & $2,7-3,3$ & $2,9-5,4$ \\
Ganho $[\mathrm{dB}]$ & 16,5 & 12,4 & $18-20^{\mathrm{b}}$ & 15 & $21^{\mathrm{b}}$ & 10,5 & 10,7 \\
$P_{I I P 3}[\mathrm{dBm}]$ & -5 & $-3,8$ & $-11,2 /-7$ & -4 & $-1,5$ & $-3,5$ & -6 \\
$S_{11}[\mathrm{~dB}]$ & $<-10$ & $<-7,3$ & $<-10$ & $<-10$ & $<-10^{\mathrm{a}}$ & $<-10$ & $<-5$ \\
Potência $[\mathrm{mW}]$ & 36 & 14,4 & 22 & 15 & 18 & 13,7 & 7 \\
Área $\left[\mathrm{mm}^{2}\right]$ & 0,021 & 0,031 & 0,002 & 0,98 & 0,06 & 0,02 & 0,03 \\
Ano & 2009 & 2010 & 2010 & 2011 & 2011 & 2012 & 2012 \\
\hline
\end{tabular}

a Até $1,6 \mathrm{GHz}$.

${ }^{\mathrm{b}}$ Ganho de tensão.

que indica um casamento de impedâncias na entrada adequado, mas possui um alto consumo de potência. No artigo [18] é apresentado um amplificador com realimentação resistiva e reutilização de corrente. Os autores utilizaram um indutor de valor pequeno a fim de aumentar a largura de banda em $23 \%$, e reduzir a figura de ruído em cerca de $1 \mathrm{~dB}$ na frequência de 10,6 GHz. O circuito usa um estágio seguidor de fonte no caminho de realimentação, e consegue operar com consumo de potência baixo para uma aplicação de $U W B$, com uma figura de ruído baixa e plana na banda (cerca de $1 \mathrm{~dB}$ de variação), mas nas frequências altas o casamento da impedância de entrada degrada.

$\mathrm{Na}$ referência [2] é apresentado um amplificador para rádio cognitivo que explora o cancelamento da capacitância equivalente na entrada de um amplificador fonte comum, usando o efeito indutivo de conectar um amplificador em realimentação negativa, o que permite obter um casamento de impedância adequado em uma faixa de frequências ampla. O circuito consiste de três estágios a fim de aumentar o ganho e permitir a realimentação negativa. Como resultado é obtido um amplificador com largura de banda de uma década e a menor área entre os trabalhos relacionados na tabela 1.2. Por outro lado, em [19] um amplificador com realimentação resistiva e reutilização de corrente é proposto para aplicações de banda larga. Este tipo de realimentação é comumente usado para ter um casamento de impedâncias na entrada de banda larga, mas devese escolher com cuidado para obter um fator de qualidade correto na rede de entrada e assim, garantir uma figura de ruído plana. O circuito também usa um indutor no ramo de reutilização de corrente para aumentar a largura de banda. Devido ao uso de indutores, este circuito tem a maior área dos trabalhos relatados na tabela, mas com um ganho alto e figura de ruído plana na banda de operação.

Em [20], propõe-se uma topologia nova para um LNA de banda larga. A topologia consiste 
em um par diferencial formado por transistores PMOS e NMOS com ligações cruzadas, a fim de aumentar o ganho e ao mesmo tempo reduzir o ruído. A proposta permite o cancelamento parcial do ruído produzido pelo par de entrada, incluindo as frequências em torno de $100 \mathrm{MHz}$ onde o ruído Flicker é predominante. Cada metade do par consiste de um transistor PMOS e um NMOS com realimentação resistiva, empilhados e conectados a sinais de polaridade diferentes. O bloco apresenta uma figura de ruído baixa em comparação com os outros circuitos relatados, mas também tem a menor largura de banda com um alto consumo de potência. Finalmente no trabalho relacionado [21], dois amplificadores de banda larga diferentes foram projetados usando a técnica de cancelamento de ruído com aumento do ganho. Esta técnica consiste em adicionar um amplificador de tensão para aumentar o ganho sem afetar o casamento de impedância nem a figura de ruído. O primeiro circuito $(v 1)$ consiste de um amplificador de fonte comum com realimentação resistiva. Este amplificador opera em $U W B$ com uma figura de ruído baixa e plana, além de um baixo consumo de potência em comparação com os outros trabalhos reportados na tabela 1.2 para a mesma faixa de frequência. O segundo circuito (v2) é um amplificador de porta comum que possui um ganho semelhante ao primeiro, com a metade do consumo de potência, mas com a metade da largura de banda e uma figura de ruído não tão plana. Ambos os circuitos têm um consumo de potência e área baixos, além de uma linearidade adequada. A primeira versão tem uma figura de ruído baixa e plana, e a segunda versão tem alguns problemas de acoplamento de impedâncias na faixa inferior de frequências.

\subsection{Topologias e técnicas para projeto de $L N A \mathrm{~s}$}

Depois de analisar alguns trabalhos relevantes publicados recentemente, algumas das técnicas e topologias mencionadas e outras usadas para projetar amplificadores de baixo ruído de banda estreita e banda larga serão brevemente descritas. Dentre as técnicas a serem relatadas existem opções para melhorar o casamento de impedâncias na entrada, o produto ganho-largura de banda, a figura de ruído, a linearidade e o consumo de área, abrangendo cada um dos parâmetros e aspectos importantes no projeto de amplificadores de baixo ruído para radiofrequência.

\subsubsection{Compromisso máxima transferência de potência - figura de ruído}

De acordo com a análise mostrada em [8], a impedância da fonte de entrada de sinal necessária para atingir o fator de ruído ótimo em um transistor MOS deve ser indutiva. No entanto, esta condição não coincide com a impedância puramente resistiva necessária para garantir a máxima transferência de potência, e como o transistor tem idealmente uma impedância de entrada 


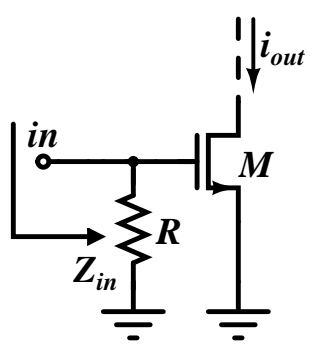

(a)

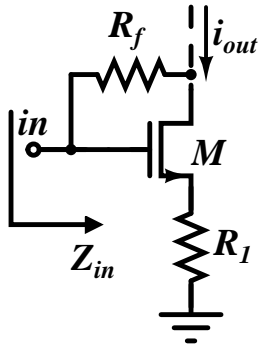

(b)

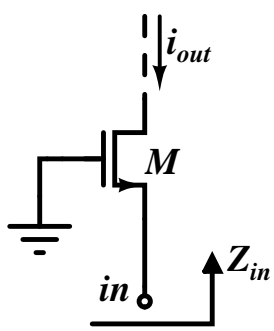

(c)

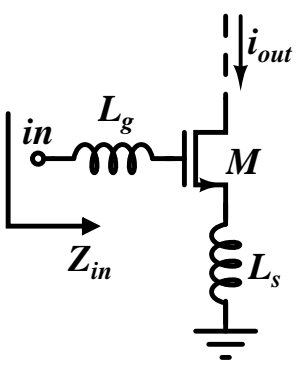

(d)

Figura 1.1: Estágios para casamento da impedância de entrada: (a) $C S$ com resistência em paralelo; (b) $C S$ com realimentação resistiva; (c) $C G$; (d) $C S$ com degeneração indutiva.

meramente capacitiva (vista a partir da porta), é difícil atingir casamento de impedâncias sem degradar o desempenho de ruído.

Existem diversas maneiras de atingir casamento de impedâncias na entrada, entre elas a mais simples é aumentar a parte resistiva da impedância de entrada do transistor usando um estágio fonte comum com uma resistência em paralelo (figura 1.1(a)), no entanto adicionar esta resistência aumenta o ruído consideravelmente é reduz o sinal de entrada à metade. Na figura 1.1(b) é mostrado um estágio fonte comum com realimentação resistiva, esta proposta atinge casamento de impedância de banda larga e degrada menos o ruído do que a proposta anterior, mas a figura de ruído continua alguns decibéis acima do valor mínimo que pode ser alcançado. Uma outra proposta é usar um estágio porta comum (figura 1.1(c)) aproveitando que a impedância vista a partir da fonte do transistor é aproximadamente igual ao inverso da transcondutância $\left(Z_{\text {in }} \approx \frac{1}{g_{m}}\right)$, e assim obter acoplamento na entrada independente da frequência (idealmente). Neste caso, o valor definido ou limitado de transcondutância para atingir acoplamento limita diretamente à frequência de ganho unitário do trasistor $\left(f_{T} \approx \frac{g_{m}}{2 \pi C_{g s}}\right.$, $) \mathrm{e}$ portanto limita o ganho máximo e fator de ruído mínimo atingidos.

As três propostas anteriores sofrem de degradação da figura de ruído devido à presença de resistências no caminho do sinal. Para diminuir tal degradação, uma solução adequada é implementar a parte real da impedância de entrada usando dispositivos que adicionem menos ruído. O estágio $C S$ com degeneração indutiva mostrado na figura 1.1(d) atinge este propósito. O indutor $L_{s}$ permite controlar o valor da parte real da impedância e $L_{g}$ controla a frequência à qual este valor é puramente resistivo. Estes controles permitem ao estágio atingir casamento de impedâncias com uma figura de ruído próxima do mínimo. No entanto, este comportamento é alcançado em uma faixa de frequências muito pequena e portanto a implementação deste é apropriada para aplicações de banda estreita. Para aplicações de banda larga podem ser usados os primeiros três estágios mencionados, ou modificações deles para melhorar o desempenho 


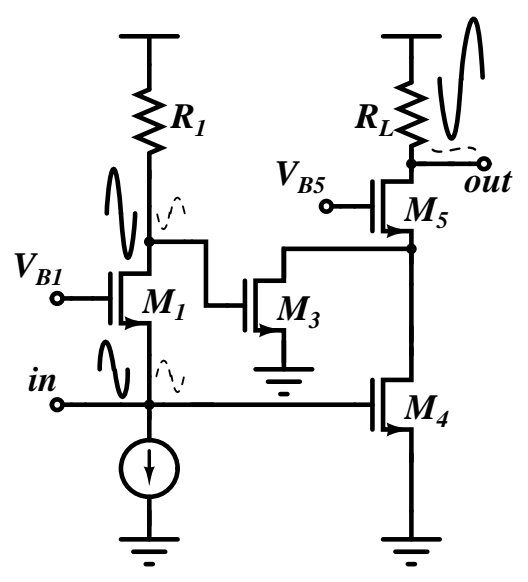

(a)

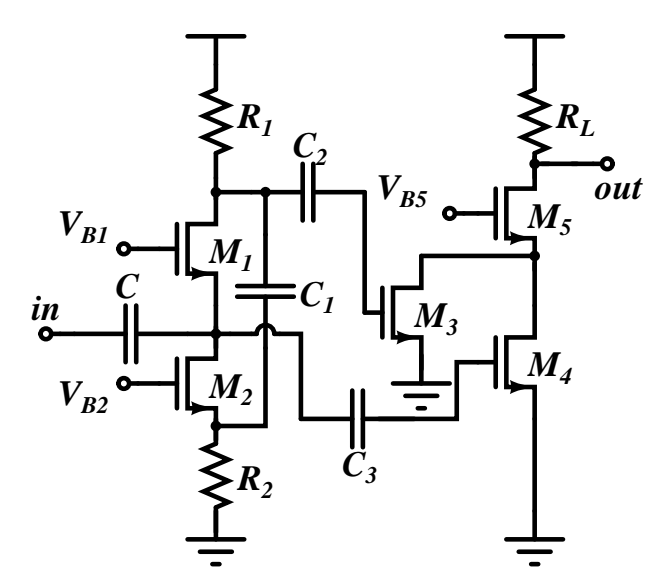

(b)

Figura 1.2: Técnica de $N C$ : (a) Funcionamento da técnica; (b) $L N A$ usando $N C$.

de ruído. Por esse motivo, são apresentadas algumas técnicas que utilizam os estágios mencionados e alguns outros para implementar amplificadores de baixo ruído de banda estreita e banda larga.

\subsubsection{Cancelamento de ruído}

A técnica de cancelamento de ruído (NC, Noise Canceling) foi inicialmente proposta em [22], a fim de alcançar um casamento de impedâncias na entrada de banda larga com uma figura de ruído sub-3 dB, evitando redes de realimentação globais que têm um baixo ganho e são propensas à instabilidade. A técnica consiste em criar um caminho novo de sinal, a fim de cancelar a contribuição do ruído na saída do estágio usado para o casamento de impedâncias, sem degradar a transferência do sinal. Para fazer o cancelamento, três blocos funcionais principais são necessários: um estágio amplificador para casamento de impedâncias, um estágio amplificador para sensoriamento de tensão, e uma rede que combina as saídas dos estágios anteriores [22]. O estágio amplificador usado para acoplamento garante uma impedância de entrada real. Entretanto, o amplificador para sensoriamento de tensão faz o sensoriamento do sinal de tensão e de ruído, para que finalmente, o estágio somador ou combinador adicione os sinais de tensão à medida que cancela as contribuições sobre o ruído. Esta técnica pode ser usada para qualquer configuração de amplificadores se eles são colocados de acordo com os três estágios principais descritos. Esta técnica também permite o cancelamento da distorção do estágio para casamento de impedâncias [22].

Na figura 1.2(a) é mostrada como funciona a técnica usada num amplificador porta comum para o casamento de impedâncias na entrada. O esquemático é representado a partir de [23], onde o estágio porta comum é usado como estágio para casamento de impedância e de 


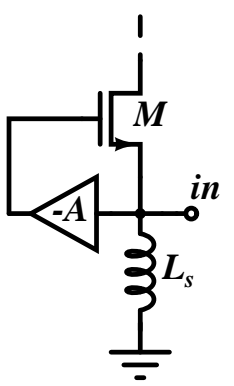

(a)

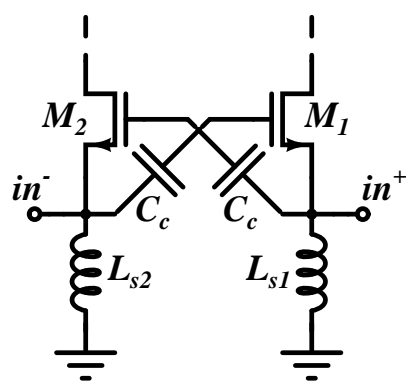

(b)

Figura 1.3: Técnica de $C C C$ : (a) Estágio $C G$ com aumento da transcondutância; (b). Estágio de entrada de um $L N A$ usando $C C C$.

sensoriamento de tensão, e o segundo estágio formado pelos transistores $M_{3}-M_{5}$ é o somador. Os circuitos de porta comum permitem aos sinais de tensão de entrada e saída estarem em fase (linhas sólidas), enquanto que os sinais de tensão de ruído estão $180^{\circ}$ defasados (linhas tracejadas), permitindo ao estágio somador adicionar os sinais de tensão e cancelar o ruído. Na figura 1.2(b) é mostrado o esquemático completo do LNA banda larga projetado em [23]. Existem muitos outros trabalhos publicados usando esta técnica como relatados em [21] e [24].

\subsubsection{Acoplamento usando capacitores cruzados}

A técnica de acoplamento capacitivo cruzado (CCC, Capacitive Cross-Coupling) permite melhorar a figura de ruído do amplificador porta comum. Embora o amplificador fonte comum tem um desempenho de ruído melhor e maior ganho (com casamento da impedância de entrada adequado para aplicações banda estreita), ele tem alguns problemas de linearidade, precisa de redes de acoplamento externas, ou no caso de serem implementadas OnChip, o consumo de área é maior e torna-se muito sensível as variações do processo. Comparado com o $C S$, o amplificador $C G$ tem uma figura de ruído maior (acima de $3 \mathrm{~dB}$ ) para as frequências mais baixas, uma vez que para alcançar um acoplamento adequado precisa-se de um valor definido de transcondutância. No entanto, como as novas aplicações precisam de circuitos operando em frequências e largura de banda maiores, o $C G$ torna-se uma opção necessária já que apresenta um melhor desempenho de ruído em altas frequências, impedância de entrada meramente resistiva (idealmente) o que garante acoplamento em uma faixa ampla de frequência, além de possuir uma melhor linearidade e estabilidade $[25,26]$.

A técnica de $C C C$ usa o amplificador com laço de realimentação mostrado na figura 1.3(a), para tratar com o valor fixo de transcondutância necessário para atingir casamento da impedância de entrada no estágio $C G$ e, em seguida, reduzir a contribuição de ruído deste. $\mathrm{O}$ 


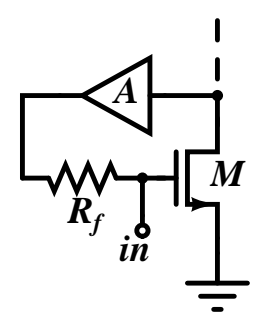

(a)

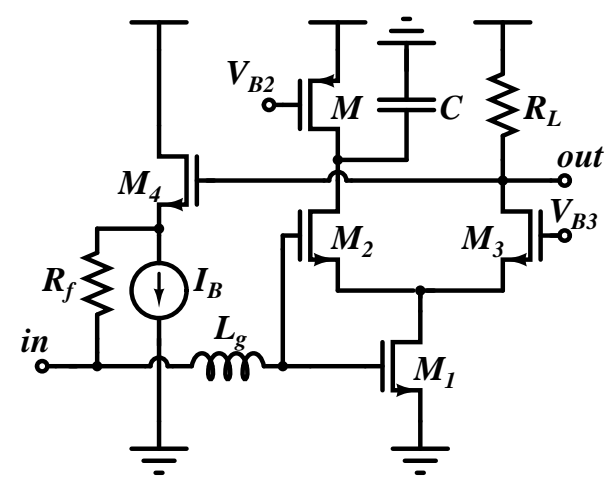

(b)

Figura 1.4: Realimentação resistiva: (a) Estágio $C S \operatorname{com} \operatorname{ResF}$; (b). LNA usando ResF.

ganho do laço de realimentação garante o casamento de impedância com uma transcondutância menor do transistor. Se o ganho de laço é igual à unidade, a transcondutância equivalente é o dobro do valor disponibilizado pelo transistor, o que permite ao estágio $C G$ ter uma entrada acoplada com figura de ruído e consumo de potência menor. A implementação do ganho no laço deve ser feita por meio de dispositivos passivos para obter uma solução que adicione o menor ruído possível. O circuito da figura 1.3(b), mostra a solução proposta pelos autores em [25], onde o acoplamento capacitivo tem um ganho de laço quase unitário adicionando pouco ruído, e a conexão cruzada é implementada para que este ganho seja negativo. Outro amplificador usando esta técnica é apresentado em [11].

\subsubsection{Realimentação resistiva}

Amplificadores de baixo ruído com realimentação resistiva (ResF, Resisitve-feedback) e sem indutores, têm mostrado ser uma opção viável para a implementação de receptores multibanda em vez de vários $L N A$ s sintonizados que requerem numerosos indutores e ocupam demasiada área. Estes circuitos ocupam pouca área e podem ser implementados em processos CMOS digitais sem melhorias adicionais para RF. com esta abordagem pode reduzir significativamente o custo da implementação do Front-End sem fio. Com a ResF é possível atingir um ganho acima de $10 \mathrm{~dB}$, largura de banda em torno de $10 \mathrm{GHz}$, e figura de ruído em torno ou inferior a $3 \mathrm{~dB}$, mas com uma penalidade no consumo de potência e a linearidade [18,27].

Na figura 1.4(a) é mostrada a configuração básica de um amplificador com realimentação resistiva e um buffer de tensão no laço de realimentação. Usar ResF passiva tem um compromisso forte entre o casamento de impedâncias e a figura de ruído, de modo que para relaxar esta condição um buffer de tensão é necessário. Este buffer permite reduzir a figura de ruído através do aumento da transcondutância do transistor, e o acoplamento pode ser mantido 
escolhendo valores corretos para as resistências de realimentação e carga. Em adição, na figura 1.4(b) é apresentada a topologia proposta em [18]. O circuito consiste de um estágio de fonte comum com reutilização de corrente formado pelos transistores $M_{1}$ e $M_{2}$, em cascata com um estágio porta comum como cascode $M_{3}$. A Res $F$ é implementada pela resistência $R_{f}$ e o seguidor de fonte $M_{4}$ usado como buffer de tensão. O indutor $L_{g}$ é usado para aumentar a largura de banda em aproximadamente $20 \%$ atingindo quase os $14 \mathrm{GHz}$. Outro circuito implementado usando esta técnica é mostrado na referência [27], onde em vez de usar um indutor na porta, a largura de banda é aumentada substituindo a resistência de carga por um indutor.

\subsubsection{Método de superposição derivada}

Esta técnica permite o projeto de amplificadores com distorção por intermodulação de terceira ordem reduzida. Em geral, a distorção de terceira ordem é a maior preocupação para o projetista, pois ela conduz a geração de sinais de interfêrencia que estão perto aos tons principais. O método de superposição derivada (DS, Derivative Superposition) foi usado em amplificadores inicialmente pelos autores em [28]. Em seguida um método modificado para LNAs banda estreita foi proposto em [29] (Figura 1.5(a)) o que posteriormente levou à publicação de outras mudanças tais como as apresentadas em [30] e [31] (figuras 1.5(b) e 1.5(c) respectivamente).

O método $D S$ consiste em adicionar um transistor operando em sublimiar ou inversão fraca, paralelo ao transistor de entrada de um LNA fonte comum, com o propósito de cancelar ou reduzir as não-linearidades de terceira ordem. Este cancelamento é obtido aproveitando a mudança do sinal da componente de terceira ordem da corrente $\left(g_{3}\right)$, resultado das variações na tensão de polarização do transistor $\left(V_{G S}\right)$. A mudança do sinal ocorre quando o transistor $M O S$ faz a transição de inversão fraca ou moderada para inversão forte. Assim, se um transistor com componente de terceira ordem positiva é colocado em paralelo com outro de componente com sinal negativo, a componente total de terceira ordem do estágio é reduzida ou cancelada melhorando a linearidade do amplificador [29]. Um exemplo do efeito de cancelamento pode ser observado na figura 1.5(d) (tomada a partir de [29]), onde para tensões entre $0,5 \mathrm{~V}$ e $0,55 \mathrm{~V}$ o efeito do componente de terceira ordem é quase cancelado. O componente de terceira ordem do transistor de entrada $\left(M_{A}\right)$ é representado pela linha tracejada; a linha pontilhada representa o componente do transistor adicionado em paralelo $\left(M_{C}\right)$, e no transistor $\left(M_{B}\right)$, pode-se observar a soma de ambas as componentes, mostrada por uma linha contínua.

Os autores de [30] afirmam que os métodos $D S$ e $D S$ modificado têm dificuldades para controlar o fator de qualidade na rede de entrada, tornando difícil manter o equilíbrio entre o casamento de impedâncias e o ruído. Como resultado é proposta uma técnica de pós- 


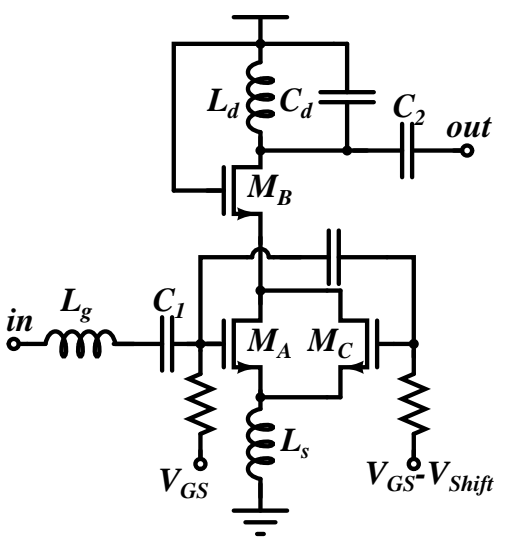

(a)

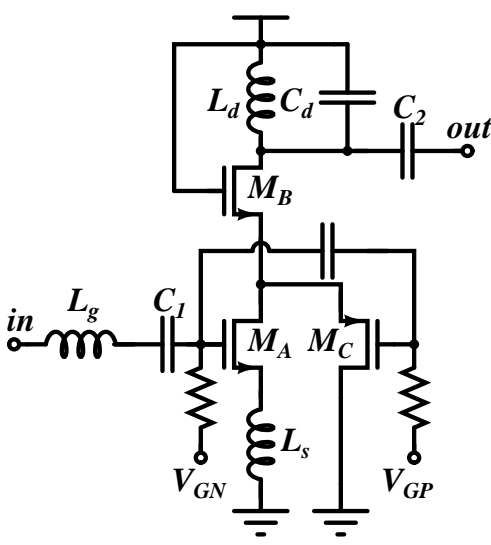

(b)

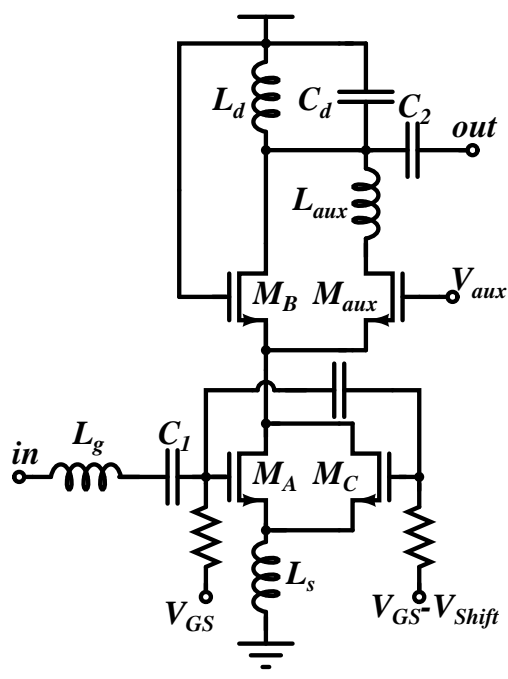

(c)

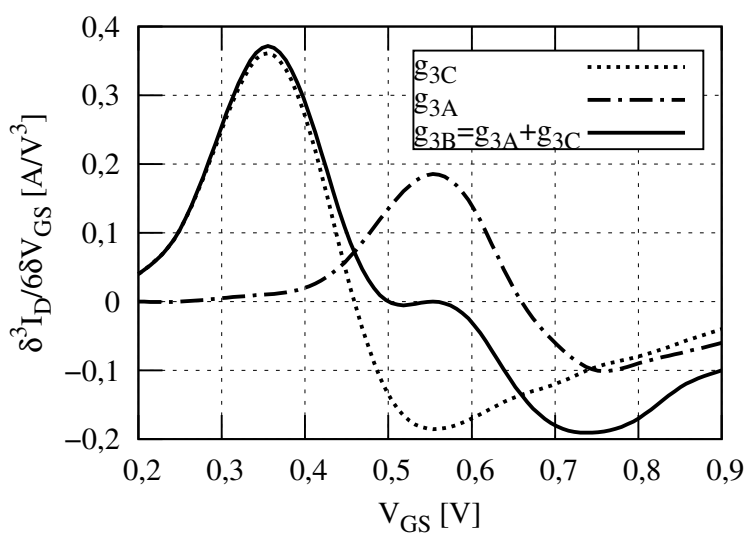

(d)

Figura 1.5: Método DS: (a) Método $D S$ modificado; (b) Sumidouro de IMD3 PMOS; (c) Método com duplo $D S$; (d) Coeficientes de terceira ordem da série de potências.

linearização, conhecida como sumidouro das distorsões por intermodulação de terceira ordem (IMD3, Third Order Intermodulation Distortion). Esta técnica é implementada acrescentando um transistor PMOS como é mostrado na figura 1.5(b), operando em inversão forte a fim de absorver as não-linearidades de terceira ordem do transistor de entrada. No entanto, este também absorve um pouco da componente de primeira ordem reduzindo o ganho, mas devido aos valores baixos da mobilidade e a transcondutância do transistor PMOS, a contribuição de ruído e a redução do ganho são pequenas.

Finalmente, o circuito mostrado na figura 1.5(c) é proposto em [31] a fim de melhorar ainda mais a linearidade em comparação com o método $D S$ modificado, reportando uma melhora de 9 $\mathrm{dBm}$ no ponto de interceptação de terceira ordem, que avalia a linearidade do circuito respeito às componentes de terceira ordem. $\mathrm{O}$ circuito usa um estágio adicional porta comum com um 


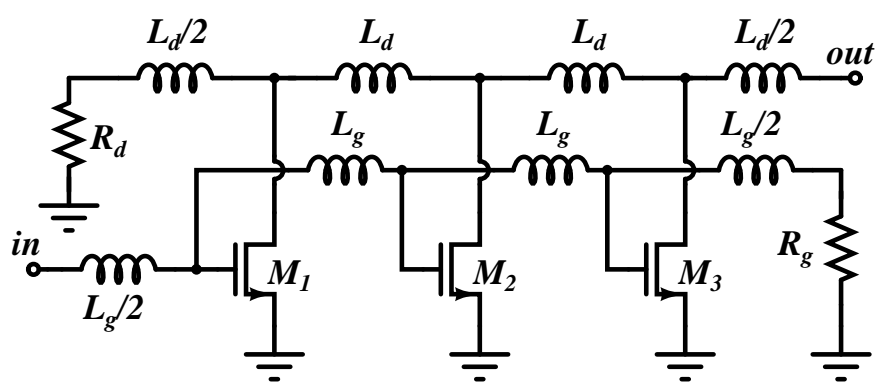

Figura 1.6: $L N A$ banda larga usando amplificadores distribuídos.

indutor sintonizado, usado para reduzir as componentes IMD3 geradas pela realimentação de alguns harmônicos de segunda ordem através do indutor de degeneração $L_{s}$. Neste circuito, os transistores em paralelo devem estar em inversão fraca igual ao circuito com $D S$ modificado. As três propostas acima mencionadas melhoram a linearidade sem afetar consideravelmente o desempenho de ruído do $L N A$, preservando a baixa figura de ruído e casamento de impedância adequado característico do estágio de fonte comum com degeneração indutiva.

\subsubsection{Outras topologias}

Além das técnicas e topologias acima mencionadas, há uma grande quantidade de propostas na literatura para melhorar diferentes parâmetros em amplificadores de baixo ruído banda larga, banda estreita e banda ultra larga. Alguns outros que merecem menção são mostrados nas figuras 1.6, 1.7(b) e 1.7(c). Na figura 1.6 é apresentado um amplificador distribuído de banda larga. Os amplificadores distribuídos (DA, Distributed Amplifier) são uma solução possível para aplicações de banda larga, começando em frequências perto de zero. Eles possuem um produto ganho-largura de banda alto e bom casamento de impedâncias, mas sofrem de alto consumo de potência e área, além de uma figura de ruído relativamente alta (normalmente maior de $3 \mathrm{~dB}$ ). Em [32] é mostrado um $D A$ de três estágios projetado para atingir baixo consumo de potência. Em comparação com outros $L N A$ s de banda larga (por exemplo os relatados na tabela 1.2), este amplificador tem baixo consumo de potência, com alta linearidade, além de um ganho plano e programável sobre $6 \mathrm{GHz}$ de largura de banda. No entanto, este ganho é baixo comparado aos reportados, a figura de ruído mínima é superior a $4 \mathrm{~dB}$, e o consumo de área é alto devido à implementação de vários indutores integrados.

No circuito da figura 1.7(b), o princípio de dupla realimentação (DF, Dual Feedback) mostrado na figura 1.7(a) é aplicado. A dupla realimentação negativa atinge simultaneamente o casamento de impedâncias e a figura de ruído baixa, sem comprometer os outros parâmetros de projeto de um amplificador $C G$ [33]. A técnica tem por objetivo atingir o casamento de impedâncias usando um valor arbitrário de transcondutância do transistor de entrada e, em 


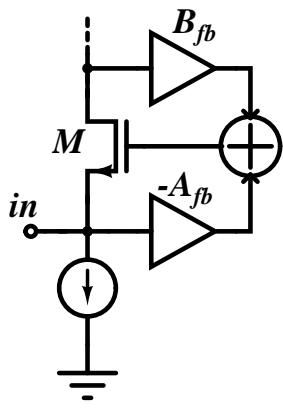

(a)

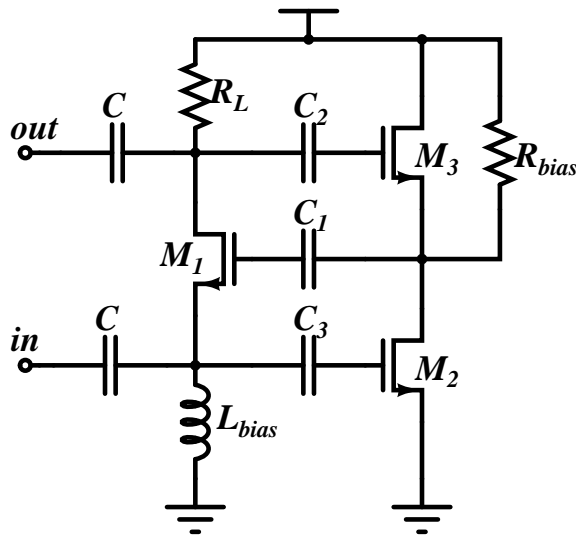

(b)

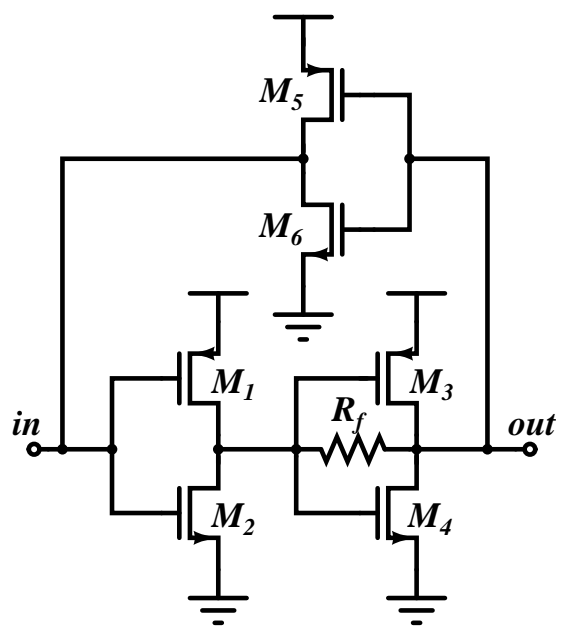

(c)

Figura 1.7: Outros $L N A$ s: (a) Estágio porta comum com $D F$; (b) $L N A$ usando $D F$; (c) $L N A$ banda larga usando inversores.

seguida, diminuir a figura de ruído e incrementar o ganho deste estágio. A $D F$ parece ser uma boa solução em comparação com o $C C C$ que ainda limita o valor de transcondutância a um valor mínimo, no melhor dos casos $g_{m}=\frac{1}{2 R_{s}}$. Comparando as figuras 1.7 (a) e 1.7(b), o estágio de casamento de impedâncias e ganho é implementado pelo transistor $M_{1}$ conectado na configuração $C G$. O amplificador $A_{f b}$ é implementado por um estágio $C S$ usando o transistor $M_{2}$. Este amplificador aumenta a transcondutância do estágio de entrada. O seguidor de fonte implementado com $M_{3}$ controla a impedância de entrada e regula o efeito da resistência de carga $\left(B_{f b}\right)$. O LNA projetado em [33] usando esta técnica, alcança uma largura de banda de $2 \mathrm{GHz}$ com linearidade alta, casamento da impedância de entrada adequado, ocupando pouca área e com uma figura de ruído médio sub $3 \mathrm{~dB}$ ao longo da banda.

Por outro lado, o amplificador da figura 1.7(c) proposto em [34], tem um inversor como amplificador principal devido a sua escalabilidade em área e tensão de alimentação. Além disso, o inversor pode ter uma faixa dinâmica na saída rail-to-rail. Para alcançar o comportamento de banda larga, o circuito utiliza dois inversores em cascata utilizando a configuração CherryHooper; um estágio de transcondutância seguido por um amplificador de transimpedância. Igualmente, um inversor pequeno de realimentação é implementado a fim de aumentar a largura de banda, sem o uso de dispositivos passivos como condensadores ou indutores que consomem uma área maior e reduzem a escalabilidade. A escalabilidade é testada projetando o circuito utilizando dois processos diferentes $(180 \mathrm{~nm}$ e $90 \mathrm{~nm})$. Os circuitos conseguem atingir larguras de banda de 4,8 GHz e 6,7 GHz usando $180 \mathrm{~nm}$ e $90 \mathrm{~nm}$ respectivamente, com ganho alto, consumo de área muito baixo e uma figura de ruído média em comparação com outros $L N A$ s com largura de banda semelhante $[19,21]$. No entanto, possuem baixa linearidade, consumo de 
potência elevado, e a versão de $180 \mathrm{~nm}$ tem alguns problemas com o casamento da impedância de entrada nas frequências acima de $3 \mathrm{GHz}$.

\subsection{Estrutura do texto}

O primeiro capítulo traz uma introdução ao problema de projeto de circuitos para radiofrequência, em seguida apresentam-se os objetivos deste trabalho, e posteriormente é feita uma revisão do estado-da-arte e algumas técnicas de projeto para LNAs.

No capítulo 2, é descrita a formulação de projeto de um LNA de banda estreita usando programação geométrica. A formulação é apresentada através de diferentes análises matemáticas e de circuito, a fim de obter expressões precisas para representar os diferentes parâmetros de desempenho. Finalmente são apresentadas algumas considerações necessárias para conseguir formular o problema de projeto do circuito como um programa geométrico, e a forma padrão do problema a ser resolvido é apresentada.

Posteriormente, no capítulo 3 são desenvolvidas diferentes análises para um $L N A$ de banda larga com cancelamento de ruído. Os principais parâmetros de desempenho são formulados, e algumas considerações são feitas a fim de formular o problema de projeto na forma padrão de un programa geométrico.

No Capítulo 4, os resultados dos diferentes programas geométricos para cinco tecnologias diferentes e das respectivas simulações são comparados. Além disso, os layouts de dois LNAs e dois misturadores de baixo ruído (ou blocos $L N A$-misturador) fabricados, os resultados das simulações pós-layout, e alguns resutados experimentais são apresentados.

Finalmente, no capítulo 5 as conclusões da dissertação e algumas recomendações para futuros trabalhos são apresentadas. 


\section{Formulação de projeto de um $L N A$ de banda estreita usando programação geométrica}

Durante o capítulo anterior foi apresentada uma introdução ao projeto de amplificadores de baixo ruído baseada em algumas técnicas e topologias propostas em trabalhos encontrados durante a revisão bibliográfica. As vantagens e desvantagens de cada proposta foram explicadas e os principais compromissos existentes foram discutidos. Neste capítulo será introduzida uma metodologia que também pode ser aplicada no projeto destes circuitos a fim de tratar os compromissos mediante a utilização de ferramentas $C A D$. A metodologia será aplicada em um amplificador de fonte comum com degeneração indutiva comumente utilizado para aplicações de banda estreita como mencionado no capítulo anterior. Desta forma, durante o desenvolvimento do presente capítulo primeiro serão introduzidos os princípios básicos da programação geométrica, e em seguida, os parâmetros de desempenho do LNA fonte comum serão extraídos por meio de diferentes análises, e finalmente será apresentada a formulação do circuito usando programação geométrica.

\subsection{Programação Geométrica}

A programação geométrica é um tipo de problema de otimização matemática não-linear descrito a cerca de cinquenta anos atrás [35], mas implementado posteriormente porque não existiam algoritmos eficientes para resolvê-lo. O que torna a programação geométrica uma boa opção para resolver problemas não lineares com múltiplas variáveis, é o fato que esta pode ser transformada em um problema de otimização convexa mediante a uma mudança de variável e, em seguida, obter algumas vantagens. As principais vantagens são a rápida convergência dos algoritmos e atingir o ótimo global independente do ponto de partida (no caso da solução existir) [36]. A principal desvantagem sobre a utilização da programação geométrica é que a função objetivo e as restrições devem pertencer a uma família particular de funções conhecidas 
como posinômios. Uma função posinômio está formada pela soma de monômios com a forma:

$$
f(x)=\varsigma x_{1}^{a_{1}} x_{2}^{a_{2}} \ldots x_{n}^{a_{n}}
$$

onde $\varsigma \geq 0$ e $a_{i}$ é qualquer número real [36,37]. A organização das expressões descritas usando apenas posinômios e monômios, cujas variáveis serão obtidas usando a programação geométrica é chamado de programa geométrico (PG).

\subsection{Forma padrão de um programa geométrico}

Um programa geométrico é um problema de otimização da forma:

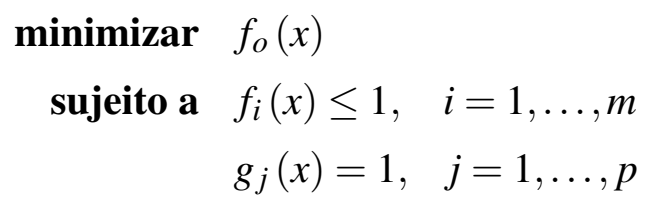

onde $f_{o}(x)$ é chamada de função objetivo ou função a otimizar, $f_{i}(x)$ são funções restrição do tipo desigualdade, e $g_{j}(x)$ são funções restrição do tipo igualdade. O $f_{0}(x)$ pode ser um posinômio ou um monômio igual do que $f_{1}(x), \ldots, f_{m}(x)$, as funções $g_{1}(x), \ldots, g_{p}(x)$ estão restritas a ser monômios, e finalmente $x=\left(x_{1}, \ldots, x_{n}\right)$ representam as variáveis de otimização.

Como foi mencionado, um programa geométrico pode ser transformado em um problema de otimização convexa através de uma mudança de variável e, em seguida, ser resolvido utilizando ferramentas computacionais em um curto período de tempo (alguns segundos). Este tipo de algoritmos tornaram-se populares e são encontrados com frequência em pacotes $E D A$ comerciais de software livre de otimização como MOSEK (usado por GAMS), CVX e TOMLAB [38-40]. Vale a pena notar que a mudança de variável mencionada é feita automaticamente pela ferramenta, mas também é importante ter cuidado porque às vezes, de acordo com a ferramenta, a saída é a solução do problema de otimização convexa e o usuário tem que adequá-la para obter a solução do PG.

A programação geométrica tem sido usada no projeto de circuitos analógicos desde 1999 através da tese relacionada [41], que inicialmente propôs a sua aplicação no projeto de amplificadores operacionais. Em seguida, esta aplicação foi expandida para o projeto de outros circuitos, como malhas de captura de fase (PLLs, Phase-Locked Loop), ADCs, VCOs, LNAs e indutores CMOS [42-45]. Na Universidade de São Paulo também há propostas para a sua aplicação no projeto de filtros $\mathrm{G}_{m}-\mathrm{C}$ [46], VCOs [47] e fontes de referência [48]. Embora existam outros trabalhos utilizando a programação geométrica no projeto de LNAs [49], estes 
se centram no projeto de amplificadores de banda estreita, usando uma única tecnologia, e sem considerar alguns dos problemas dos indutores integrados CMOS; temas que serão tratados no desenvolvimento desta dissertação.

\subsection{Formulação de projeto de um $L N A$ de banda estreita}

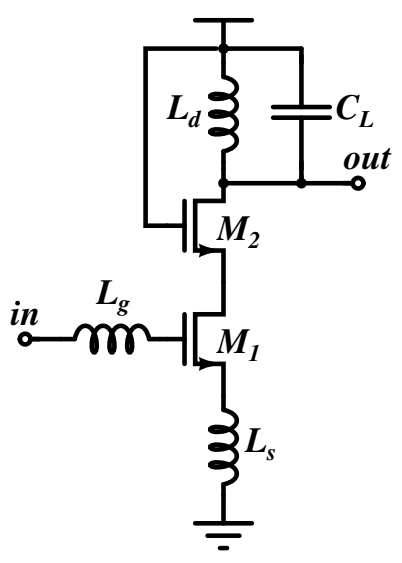

Figura 2.1: $L N A-C S$ com degeneração indutiva.

Para projetar um circuito usando uma determinada topologia, é necessário fazer algumas análises a fim de extrair as diferentes equações que representam o seu comportamento, além de observar alguns dos principais compromissos e como estes são afetados pelas variáveis de projeto. Como consequência, a seguir são desenvolvidas algumas análises de pequenos sinais e a análise de ruído com o propósito de obter alguns dos principais parâmetros de desempenho de um $L N A$ banda estreita. A topologia de amplificador escolhida é o cascode com degeneração indutiva mostrada na figura 2.1, normalmente usada para aplicações de banda estreita devido ao bom desempenho que apresenta com respeito à relação entre o casamento da impedância de entrada e o ruído como mencionado no capítulo anterior. No circuito, $M_{1}$ é o transistor do estágio de transcondutância, $M_{2}$ é usado para melhorar o isolamento entre as portas de entrada e saída, $L_{g}$ e $L_{s}$ são indutores usados para garantir o casamento da impedância de entrada na banda ( $L_{s}$ também permite ajustar a figura de ruído), e finalmente $L_{d}$ e $C_{L}$ constituem um tanque ressonante na saída que permite obter o ganho máximo na frequência de operação.

\subsubsection{Análise de pequenos sinais}

A análise de pequenos sinais é feita utilizando o circuito mostrado na figura 2.2 e que representa o estágio transcondutância do circuito mostrado na figura 2.1. No modelo, $v_{i n R F}$ e $R_{S}$ são a fonte do sinal de entrada e a sua impedância característica. As impedâncias $Z_{L g}$ e $Z_{L s}$ 


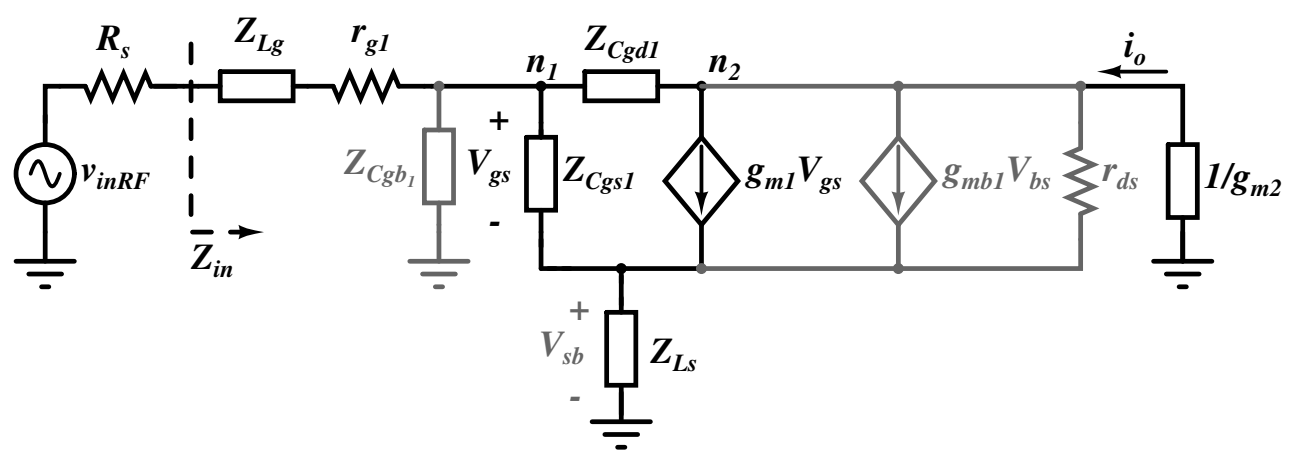

Figura 2.2: Modelo do circuito de banda estreita para análise de pequenos sinais.

representam os indutores na porta e na fonte de $M_{1}$. As variáveis $r_{g 1}, Z_{C g s 1}, Z_{C g d 1}$ e $Z_{C g b 1}$ representam a resistência e as três principais capacitâncias presentes na porta do transistor. As transcondutâncias principal e do corpo de $M_{1}$ são $g_{m 1}$ e $g_{m b 1}$, respectivamente, e $r_{d s}$ é a resistência de dreno-fonte. Se for considerada desprezível a queda de tensão através da impedância $Z_{L s}$, é possível assumir que $V_{s b} \approx 0$ e em seguida ignorar a contribuição da transcondutância do corpo do transistor. Além disso, considerando $Z_{L s}$ uma impedância de baixo valor, pode-se assumir que $Z_{C g s 1}$ está em paralelo com $Z_{C g b 1}$. No entanto, o valor da capacitância $C_{g b}$ é suposto ser zero em saturação e por isso pode ser ignorada. Por outro lado, a resistência $r_{d s}$ é desprezada porque tem um valor elevado que não afeta muito na entrada do circuito.

\section{Impedância de entrada}

O cálculo da impedância de entrada considerando a capacitância da porta-dreno do transistor $C_{g d 1}$ é feito usando o teorema de Miller. Este teorema propõe que uma impedância $(\mathrm{Z})$ localizada entre dois nós de diferentes tensões $n_{1}$ e $n_{2}$ (diferentes da referência), pode ser substituída por duas impedâncias como é mostrado na figura 2.3(a). Os valores das impedâncias $Z_{1}$ e $Z_{2}$ correspondem a:

$$
Z_{1}=\frac{Z}{1-A_{m}} \quad Z_{2}=\frac{Z}{1-\frac{1}{A_{m}}}
$$

e $A_{m}$ é conhecido como o ganho de Miller.

$$
A_{m}=\frac{V_{n 2}}{V_{n 1}}
$$

Aplicando o teorema de Miller para o circuito da figura 2.2 e referindo a impedância $Z_{L s}$, é 
obtido o circuito da figura 2.3(b). A impedância $Z_{L s}$ referida equivale a:

$$
Z_{L s r e f 1}=Z_{L s}\left(1+g_{m 1} Z_{C g s 1}\right)
$$



(a)

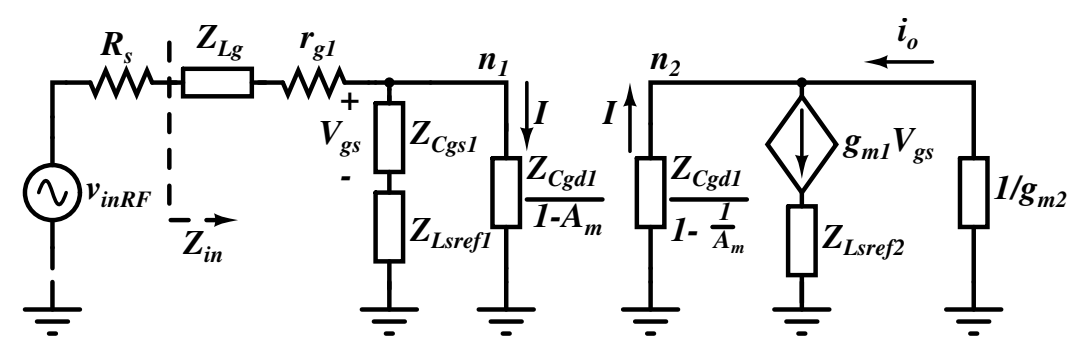

(b)

Figura 2.3: Cálculo de $Z_{\text {in }}$ : (a) Teorema de Miller; (b) Modelo equivalente para o LNA.

$$
Z_{\text {Lsref } 2}=Z_{L s}\left(1+\frac{1}{g_{m 1} Z_{C g s 1}}\right)
$$

e assumindo que a impedância de carga do estágio fonte comum é equivalente ao inverso da transcondutância de $M_{2}$, obtém-se uma expressão para o ganho de Miller do circuito.

$$
A_{m}=\frac{-\frac{g_{m 1}}{g_{m 2}} Z_{C g s 1}}{Z_{C g s 1}+Z_{L s r e f 1}}
$$

A impedância de entrada do circuito da figura 2.3(b) equivale a:

$$
Z_{\text {in }}=Z_{L g}+r_{g 1}+\frac{\frac{Z_{C g d 1}}{1-A_{m}}\left(Z_{C g s 1}+Z_{L s r e f 1}\right)}{Z_{C g s 1}+Z_{L s r e f 1}+\frac{Z_{C g d 1}}{1-A_{m}}}
$$

e substituindo a equação (2.7) em (2.8), após agrupar alguns termos obtém-se a equação (2.9).

$$
Z_{\text {in }}=Z_{L g}+r_{g 1}+\frac{Z_{C g d 1}\left(Z_{C g s 1}+Z_{L s r e f 1}\right)}{Z_{C g s 1}\left(1+\frac{g_{m 1}}{g_{m 2}}\right)+Z_{L s r e f 1}+Z_{C g d 1}}
$$

A partir da equação (2.9) pode-se observar que a impedância de entrada também depende do transistor $M_{2}$ formado pelo transistor $M_{2}$ (figura 2.1). Inclusive, se fosse realizada uma análise mais rigorosa poderia se notar que até a carga do circuito afeta a impedância de entrada. 
Para simplificar um pouco a expressão, pode ser considerado que $\mid Z_{C g s 1}\left(1+\frac{g_{m 1}}{g_{m 2}}\right)+$ $Z_{C g d 1}|>>| Z_{L s r e f 1} \mid$, e o resultado desta aproximação é mostrado na equação seguinte.

$$
Z_{i n}=Z_{L g}+r_{g 1}+\frac{Z_{C g d 1}\left(Z_{C g s 1}+Z_{L s r e f 1}\right)}{Z_{C g s 1}\left(1+\frac{g_{m 1}}{g_{m 2}}\right)+Z_{C g d 1}}
$$

Substituindo as impedâncias na equação (2.10) são obtidas as partes real e imaginária da impedância de entrada do LNA-CS expressas mediante as equações (2.11) e (2.12). Durante o desenvolvimento, as impedâncias dos indutores são tratadas como uma reatância indutiva com uma resistência em série.

$$
\begin{gathered}
\operatorname{Re}\left\{Z_{i n}\right\}=R_{L g}+r_{g 1}+\frac{C_{g s 1}}{C_{g s 1}+\left(1+\frac{g_{m 1}}{g_{m 2}}\right) C_{g d 1}}\left(R_{L s}+\frac{g_{m 1} L_{s}}{C_{g s 1}}\right) \\
\operatorname{Im}\left\{Z_{i n}\right\}=\omega L_{g}+\frac{C_{g s 1}}{C_{g s 1}+\left(1+\frac{g_{m 1}}{g_{m 2}}\right) C_{g d 1}}\left(\omega L_{s}-\frac{g_{m 1} R_{L s}}{\omega C_{g s 1}}-\frac{1}{\omega C_{g s 1}}\right)
\end{gathered}
$$

Nas equações (2.11) e (2.12) pode-se observar que o efeito da capacitância porta-dreno é controlado pela razão $\frac{g_{m 1}}{g_{m 2}}$. Se esta capacitância não é considerada, o resultado são as equações (2.13) e (2.14), normalmente encontradas na literatura. Também uma outra aproximação comum é, além do anterior, considerar o indutor com um fator de qualidade elevado e assim ignorar a contribuição da resistência em série. Este último caso é representado pelas equações (2.15) e (2.16).

$$
\begin{gathered}
\operatorname{Re}\left\{Z_{i n}\right\} \approx R_{L g}+R_{L s}+r_{g 1}+\frac{g_{m 1} L_{s}}{C_{g s 1}} \\
\operatorname{Im}\left\{Z_{i n}\right\} \approx \omega\left(L_{g}+L_{s}\right)-\frac{1}{\omega C_{g s 1}}-\frac{g_{m 1} R_{L s}}{\omega C_{g s 1}} \\
\operatorname{Re}\left\{Z_{i n}\right\} \approx \frac{g_{m 1} L_{s}}{C_{g s 1}} \\
\operatorname{Im}\left\{Z_{i n}\right\} \approx \omega\left(L_{g}+L_{s}\right)-\frac{1}{\omega C_{g s 1}}
\end{gathered}
$$

\section{Ganho de transcondutância}

Para calcular o ganho de transcondutância do LNA é também usado o modelo da figura 2.3(b). De acordo com o segundo estágio gerado após a aplicação do teorema de Miller, a corrente de saída pode ser expressa como:

$$
i_{o}=g_{m 1} V_{g s}-I
$$


e se $I$ corresponde à corrente que flui através da impedância de porta-dreno equivalente neste ramo, pode-se obter uma relação entre a corrente de saída e a tensão de porta-fonte.

$$
\begin{gathered}
I=\frac{V_{g s}+\frac{V_{g s}}{Z_{C g s 1}} Z_{L s r e f 1}}{\frac{Z_{C g d 1}}{1-A_{m}}} \\
\frac{i_{o}}{V_{g s}}=\frac{g_{m 1} Z_{C g s 1} \frac{Z_{C g d 1}}{1-A_{m}}-Z_{C g s 1}-Z_{L s r e f 1}}{Z_{C g s 1} \frac{Z_{C g d 1}}{1-A_{m}}}
\end{gathered}
$$

Por outro lado, tomando o primeiro estágio usado para os cálculos da impedância de entrada, obtém-se uma relação entre a tensão de porta-fonte e a tensão de entrada recorrendo o primeiro ramo deste estágio.

$$
\begin{gathered}
V_{g s}=v_{i n R F}-\left(R s+Z_{L g}+r_{g 1}\right)\left(\frac{V_{g s}}{Z_{C g s 1}}+\frac{Z_{C g d 1}}{1-A_{m}} I\right)-\frac{V_{g s}}{Z_{C g s 1}} Z_{L s r e f 1} \\
\frac{V_{g s}}{v_{\text {inRF }}}=\frac{Z_{C g s 1} \frac{Z_{C g d 1}}{1-A_{m}}}{\frac{Z_{C g d 1}}{1-A_{m}}\left(R_{S}+Z_{L g}+r_{g 1}+Z_{C g s 1}+Z_{L s r e f 1}\right)+\left(R_{s}+Z_{L g}+r_{g 1}\right)\left(Z_{C g s 1}+Z_{L s r e f 1}\right)} \\
\frac{V_{g s}}{v_{\text {inRF }}}=\frac{Z_{C g s 1} \frac{Z_{C g d 1}}{1-A_{m}}}{\left(R_{S}+Z_{\text {in }}\right)\left(\frac{Z_{C g d 1}}{1-A_{m}}+Z_{C g s 1}+Z_{L s r e f 1}\right)}
\end{gathered}
$$

Além disso, fazendo o produto entre as equações (2.19) e (2.22), é calculado o ganho de transcondutância do circuito de acordo com o modelo utilizado que considera a capacitância da porta-dreno do transistor $M O S$.

$$
\begin{gathered}
G_{L N A}=\frac{i_{o}}{V_{g s}} \cdot \frac{V_{g s}}{v_{i n R F}}=\frac{i_{o}}{v_{\text {inRF }}} \\
G_{L N A}=\frac{g_{m 1} Z_{C g s 1} \frac{Z_{C g d 1}}{1-A_{m}}-Z_{C g s 1}-Z_{L s r e f 1}}{\left(R_{S}+Z_{i n}\right)\left(\frac{Z_{C g d 1}}{1-A_{m}}+Z_{C g s 1}+Z_{L s r e f 1}\right)}
\end{gathered}
$$

Se são substituídas as impedâncias na equação (2.24) a expressão resultante é bastante complexa para ser incluída num programa geométrico, portanto é necessário efetuar algumas aproximações de modo a ter uma expressão mais simples. Fatorando alguns termos, assumindo que $Z_{L s r e f 1}$ é desprezível (logo, $A_{m} \approx-\frac{g_{m 1}}{g_{m 2}}$ ) e $\left|g_{m 1} Z_{C g s 1} \frac{Z_{C g d 1}}{1-A_{m}}\right|>>\left|Z_{C g s 1}\right|$, a nova expressão aproximada para o ganho de transcondutância é representada pela equação (2.25), onde $Z_{\text {in }}$ corresponde à impedância de entrada definida pela equação (2.10).

$$
G_{L N A} \approx \frac{g_{m 1} Z_{C g s 1} \frac{Z_{C g d 1}}{1-A_{m}}}{\left(R_{s}+Z_{i n}\right)\left(Z_{C g s 1}+\frac{Z_{C g d 1}}{1-A_{m}}\right)} \Rightarrow\left|G_{L N A}\right| \approx \frac{g_{m 1}}{\omega\left[C_{g s 1}+\left(1+\frac{g_{m 1}}{g_{m 2}}\right) C_{g d 1}\right]\left|R_{s}+Z_{i n}\right|}
$$


Se a capacitância da porta-dreno é ignorada, em seguida o ganho de transcondutância é equivalente à equação (2.26), onde $Z_{\text {in }}$ corresponde à impedância de entrada desprezando esta capacitância.

$$
G_{L N A} \approx \frac{g_{m 1} Z_{C g s 1}}{R_{s}+Z_{i n}} \Rightarrow\left|G_{L N A}\right| \approx \frac{g_{m 1}}{\omega C_{g s 1}\left|R_{s}+Z_{i n}\right|}
$$

Finalmente, o ganho de tensão é definido pela equação seguinte:

$$
A_{v_{L N A}}=G_{L N A} Z_{\text {out }}
$$

onde $Z_{\text {out }}$ corresponde à impedância de saída do circuito.

\subsubsection{Análise de ruído}

Uma vez obtidas as expressões para o ganho e a impedância de entrada na seção anterior, nesta seção é apresentada a análise de ruído do circuito. Embora existam quatro fontes de ruído principais em dispositivos semicondutores (fontes de ruído térmico, balístico, Flicker e emphPopcorn), a seguinte análise focou-se na fonte mais importante de ruído para os circuitos de radiofrequência que é o ruído térmico [8]. Das fontes mencionadas, os ruídos térmico e balístico são fisicamente fundamentais para o funcionamento dos dispositivos MOS e estão sempre presentes. No entanto, o ruído balístico é suposto ser perceptível ou considerável em óxidos de porta muito finos (abaixo do nó de tecnologia de $100 \mathrm{~nm}$ ), ou em presença de correntes de fuga de junção. Por outro lado, o nível de ruído emphPopcorn ou Burst é determinado pelo número de defeitos no silício, no óxido de porta e nas diferentes interfaces, e afeta principalmente os dispositivos bipolares. Finalmente, o ruído Flicker ou $\frac{1}{f}$ é possível ocorrer nos dois casos mencionados anteriormente, mas pode ser desprezado em amplificadores operando na faixa de gigahertz, uma vez que o efeito começa a ser considerável em frequências inferiores a $10 \mathrm{MHz}$. Em vista disso, as análises são desenvolvidas considerando as duas principais fontes de ruído térmico no transistor $M O S$, além do ruído térmico devido às diferentes resistências presentes no circuito. A análise é feita sobre o estágio de transcondutância, já que o amplificador da figura 2.1 é uma cascata de dois estágios (fonte comum e porta comum), e de acordo com a teoria de ruído para sistemas em cascata, o fator de ruído dos estágios subsequentes está dividido pelo produto dos ganhos dos estágios anteriores. Assim, se o primeiro estágio tem um ganho elevado, a contribuição de ruído do segundo é muito pequena e pode ser desprezada.

Uma análise inicial é desenvolvida com base no circuito mostrado na figura 2.4, que considera as duas principais fontes de ruído térmico no transistor $\operatorname{MOS}\left(i_{n 1, g}\right.$ e $\left.i_{n 1, d}\right)$ além do 
efeito da capacitância porta-dreno.

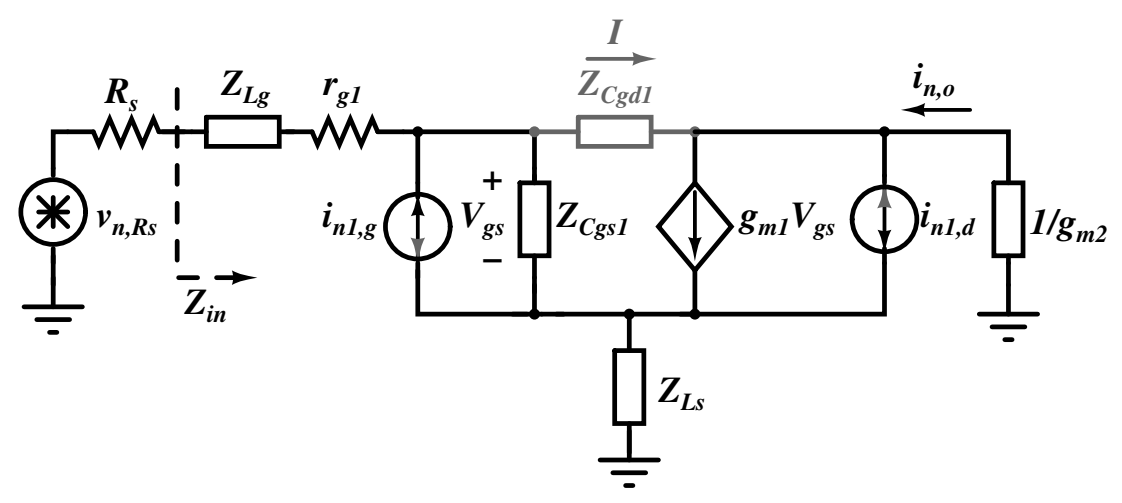

Figura 2.4: Modelo do $L N A$ de banda estreita para a análise de ruído.

O fator de ruído é definido como a razão entre o ruído total na saída e ruído na saída devido apenas à fonte de entrada.

$$
F=1+\frac{\overline{i_{n, o}^{2}}}{\overline{\bar{v}_{n, R s}^{2}} o}
$$

Tendo em conta a correlação entre as fontes de ruído na porta do transistor e do canal, o ruído total na saída pode ser representado por:

$$
\overline{i_{n, o}^{2}}=|x|^{2} \overline{i_{n, d}^{2}}+|y|^{2} \overline{i_{n, g}^{2}}+2 \operatorname{Re}\left\{x^{*} y c\right\} \sqrt{\overline{i_{n, d}^{2} \overline{i_{n, g}^{2}}}}
$$

onde o termo $c$ representa a correlação entre $\overline{i_{n, d}^{2}}$ e $\overline{i_{n, g}^{2}}$, e tem um valor aproximado $c \approx-j 0,395$ [8]. Além disso, os valores quadráticos médios das fontes de ruído associados com o canal e a porta, respectivamente, são geralmente descritos como:

$$
\begin{aligned}
& \overline{i_{n, d}^{2}}=4 K T \Delta f \gamma g_{d s 0} \\
& \overline{i_{n, g}^{2}}=4 K T \Delta f \delta g_{g}
\end{aligned}
$$

com,

$$
g_{g}=\frac{\omega^{2} C_{g s}^{2}}{5 g_{d s}}
$$

e nos quais, $\gamma$ e $\delta$ são parâmetros que dependem da polarização $[8,10]$. $K$ é a de constante de Boltzmann, $T$ é a temperatura em graus Kelvin, e $g_{d s 0}$ é a transcondutância quando $V_{D S}=0$.

$$
g_{d s 0} \approx g_{m}+g_{m b}+g_{d s}
$$


Por outro lado, o ruído na saída devido à fonte de entrada é estimado da seguinte forma:

$$
\begin{gathered}
\overline{i_{\overline{v_{n, R s}^{2}} o}^{2}}=\left|G_{L N A}\right|^{2} \overline{v_{n, R s}^{2}} \\
\overline{v_{n, R s}^{2}}=4 K T \Delta f R_{s}
\end{gathered}
$$

Para representar o ruído total na saída, é necessário usar a teoria de circuitos no modelo da figura 2.4 para calcular o valor de $i_{n, o}$. O primeiro passo é assumir uma corrente $I$ que percorre através da capacitância de porta-dreno e, em seguida, definir a corrente total na saída.

$$
i_{n, o}=g_{m 1} V_{g s}+i_{n 1, d}-I
$$

Além da equação (2.36), considera-se que a capacitância de porta-dreno está dividida usando o teorema de Miller como mostrado nas análises anteriores (figura 2.3(b)). Desta forma, é possível definir uma queda de tensão através desta capacitância,

$$
\frac{Z_{C g d 1}}{1-A_{m}} I=Z_{g}\left(i_{n 1, g}-\frac{V_{g s}}{Z_{C g s 1}}-I\right)
$$

onde $Z_{g}=R_{S}+Z_{L g}+r_{g 1}$ e pode-se colocar em evidência o valor da corrente assumida.

$$
I=\frac{Z_{g}\left(Z_{C g s 1} i_{n 1, g}-V_{g s}\right)}{Z_{C g s 1}\left(\frac{Z_{C g d 1}}{1-A_{m}}+Z_{g}\right)}
$$

Substituindo o valor desta corrente na equação (2.36), a corrente de ruído de saída é obtida em função das correntes de ruído do transistor e da tensão $V_{g s}$.

$$
i_{n, o}=\left[g_{m 1}+\frac{Z_{g}}{Z_{C g s 1}\left(Z_{g}+\frac{Z_{C g d 1}}{1-A_{m}}\right)}\right] V_{g s}+i_{n 1, d}-\frac{Z_{g}}{Z_{g}+\frac{Z_{C g d 1}}{1-A_{m}}} i_{n 1, g}
$$

Para obter uma expressão dependendo apenas nas correntes de ruído do transistor, é necessário formular a tensão de porta-fonte em função das mesmas.

$$
\begin{gathered}
V_{g s}=\frac{Z_{C g d 1}}{1-A_{m}} I-Z_{L s}\left(\frac{V_{g s}}{Z_{C g s 1}}+g_{m 1} V_{g s}+i_{n 1, d}-i_{n 1, g}\right) \\
V_{g s}=\frac{Z_{C g s 1}\left[\frac{Z_{C g d 1}}{1-A_{m}}\left(Z_{L s}+Z_{g}\right)+Z_{L s} Z_{g}\right] i_{n 1, g}-Z_{L s} Z_{C g s 1}\left(\frac{Z_{C g d 1}}{1-A_{m}}+Z_{g}\right) i_{n 1, d}}{\left(R_{s}+Z_{i n}\right)\left(\frac{Z_{C g d 1}}{1-A_{m}}+Z_{C g s 1}+Z_{L s r e f 1}\right)}
\end{gathered}
$$

Posteriormente, ao substituir a equação (2.41) em (2.39), a corrente total de ruído de saída 
é expressa de forma tal que pode-se calcular a sua densidade espectral de potência de acordo com (2.29). No entanto, a expressão resultante é bastante complexa, logo a fim de reduzir alguns cálculos, uma aproximação deve ser feita. Neste caso, o termo $I$ da equação (2.36) é desprezado e, em seguida, substituindo (2.41) sobre esta, é obtida uma nova expressão que continua dependendo da capacitância de porta-dreno.

$$
i_{n, o} \approx G_{L N A}\left(Z_{L s}+Z_{g}\right) i_{n 1, g}+\frac{G_{L N A}}{g_{m 1} Z_{C g s 1} \frac{Z_{C g d 1}}{1-A_{m}}}\left[\frac{Z_{C g d 1}}{1-A_{m}}\left(Z_{g}+Z_{C g s 1}+Z_{L s}\right)+Z_{g}\left(Z_{C g s 1}+Z_{L s}\right)\right] i_{n 1, d}
$$

Finalmente ao escrever a equação (2.42) usando a forma descrita em (2.29) é obtida a densidade espectral de potência da corrente de ruído e, usando as equações (2.28) e (2.34) é obtido o fator de ruído do estágio de transcondutância do LNA.

$$
F_{M 1} \approx 1+\frac{R_{s} \gamma}{g_{m 1}\left|Z_{C g s 1}\right|^{2}}\left[\left(\frac{\left|Z_{X}\right|}{R_{S}}\right)^{2} \frac{1}{\alpha}+\left(\frac{\left|Z_{Y}\right|}{R_{S}}\right)^{2} \frac{\alpha \delta}{5 \gamma}-0,79 \operatorname{Re}\left\{\frac{Z_{X}^{*} Z_{Y}}{R_{s}^{2}}\right\} \sqrt{\frac{\delta}{5 \gamma}}\right]
$$

Na qual:

$$
\begin{gathered}
Z_{X}=Z_{g}+\left(Z_{C g s 1}+Z_{L s}\right)\left[1+\left(1-A_{m}\right) \frac{Z_{g}}{Z_{C g d 1}}\right] \\
Z_{Y}=Z_{g}+Z_{L s} \\
\alpha=\frac{g_{m 1}}{g_{d s 0}}
\end{gathered}
$$

e se uma expressão em função de diferentes parâmetros do circuito é desejada, uma primeira abordagem consiste em substituir os valores das impedâncias e fazer a suposição que a rede de entrada esteja em ressonância e que $A_{m}=-\frac{g_{m 1}}{g_{m 2}}$. Sob essas suposições o fator de ruído corresponde a:

$F_{M 1} \approx 1+\frac{\omega^{2} C_{g s 1}^{2} R_{s} \gamma}{g_{m 1}}\left[\left(\frac{R_{g}^{2} C_{g}^{2}+\omega^{2} \kappa^{2} L_{g}^{2} C_{g d 1}^{2}}{R_{s}^{2} C_{g s 1}^{2}}\right) \frac{1}{\alpha}+\left(\frac{R_{g}^{2}+\omega^{2} L_{g s}^{2}}{R_{s}^{2}}\right) \frac{\alpha \delta}{5 \gamma}-\frac{0,79}{C_{g s 1}}\left(\frac{R_{g}^{2} C_{g}}{R_{s}^{2}}\right) \sqrt{\frac{\delta}{5 \gamma}}\right]$

com,

$$
\begin{gathered}
L_{g s}=L_{g}+L_{s} \\
C_{g}=C_{g s 1}+\kappa C_{g d 1} \\
\kappa=1+\frac{g_{m 1}}{g_{m 2}} \\
R_{g}=R_{S}+R_{L g}+R_{L s}+r_{g 1}
\end{gathered}
$$




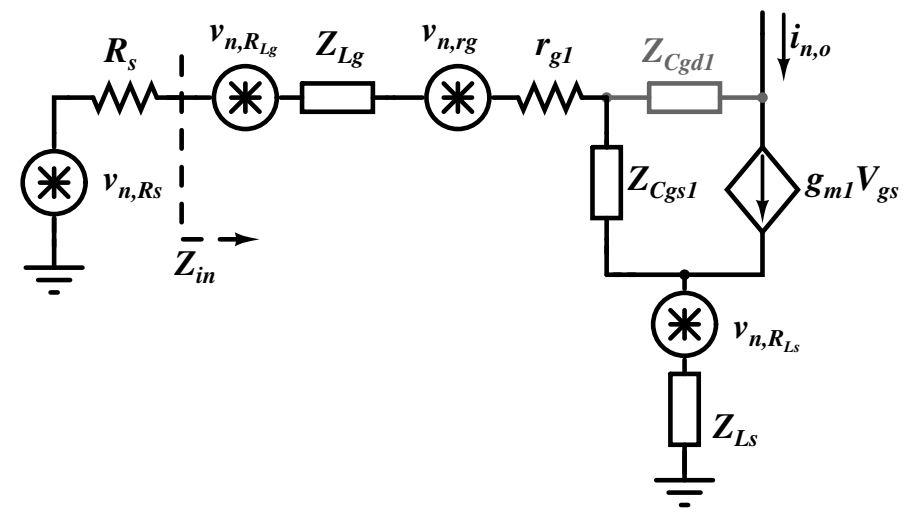

Figura 2.5: Modelo para a análise de ruído das resistências.

Por outro lado, se fosse ignorado o efeito da capacitância de porta-dreno, o fator de ruído seria expresso pela equação seguinte:

$$
F_{M 1} \approx 1+\frac{\omega^{2} C_{g s 1}^{2} R_{s} \gamma}{g_{m 1}}\left[\left(\frac{R_{g}}{R_{s}}\right)^{2} \frac{1}{\alpha}+\left(\frac{R_{g}^{2}+\omega^{2} L_{g s}^{2}}{R_{s}^{2}}\right) \frac{\alpha \delta}{5 \gamma}-0,79\left(\frac{R_{g}}{R_{s}}\right)^{2} \sqrt{\frac{\delta}{5 \gamma}}\right]
$$

e, se as resistências associadas aos indutores e à porta do transistor são desprezadas $\left(R_{g}=R_{S}\right)$, o resultado é a equação normalmente encontrada na literatura $[8,13,50]$.

$$
F_{M 1} \approx 1+\frac{\omega^{2} C_{g s 1}^{2} R_{s} \gamma}{g_{m 1}}\left[\frac{1}{\alpha}+\left(\frac{R_{s}^{2}+\omega^{2} L_{g s}^{2}}{R_{s}^{2}}\right) \frac{\alpha \delta}{5 \gamma}-0,79 \sqrt{\frac{\delta}{5 \gamma}}\right]
$$

Após a obtenção das expressões para o fator de ruído no estágio de transcondutância, considerando apenas o efeito do transistor de entrada, desenvolve-se uma análise para calcular o efeito das diferentes resistências parasitárias presentes. Normalmente, a contribuição das fontes de ruído relacionadas com as resistências dos indutores é desprezada. No entanto, em tecnologias CMOS padrão, os indutores têm um fator de qualidade baixo, o que aumenta o valor destas e se torna necessário considerá-las. Os indutores podem degradar a figura de ruído consideravelmente dependendo da frequência da aplicação, o valor da indutância, e da sua localização no circuito.

O valor quadrático médio que representa o ruído térmico causado por uma resistência é:

$$
\overline{v_{n, R}^{2}}=4 K T \Delta f R
$$

o que torna possível estimar a contribuição de ruído na saída das resistências principais na topologia. Neste caso, em concordância com a figura 2.5, são consideradas as resistências associadas aos indutores na porta e fonte do transistor de entrada $M_{1}\left(R_{L g}\right.$ e $R_{L s}$ 
respectivamente), além da sua resistência de porta $r_{g 1}$.

$$
F_{R}=1+\frac{R_{L g}+R_{L s}+r_{g 1}}{R_{S}}
$$

Como uma consequência das análises feitas neste capítulo, o fator de ruído do $L N A$ equivale a:

$$
F_{L N A}=F_{M 1}+\left(F_{M 2}-1\right)+\left(F_{R}-1\right)
$$

onde o efeito do transistor $M_{2}$ pode ser desprezado porque é dividido pelo ganho do estágio de transcondutância.

Finalmente, a figura de ruído é expressa através da equação (2.57).

$$
N F_{L N A}=10 \log \left(F_{L N A}\right)
$$

\subsection{Considerações para aplicar a programação geométrica no projeto do $L N A$ de banda estreita}

Algumas das expressões mais importantes que representam o comportamento de um LNACS foram extraídas para aplicar a programação geométrica no fluxo de projeto. No entanto, como mencionado anteriormente, um PG pode ser formulado usando somente algumas funções particulares, de modo que é necessário garantir a compatibilidade entre as expressões extraídas e este tipo de funções. A seguir são apresentadas as diferentes considerações usadas para formular o projeto de um LNA-CS como um programa geométrico padrão.

\subsubsection{Linearidade}

Frequentemente a análise de linearidade é feita utilizando a série de Volterra, o que leva a expressões complexas e não compatíveis com a programação geométrica. No entanto, existe uma relação entre a linearidade e a tensão de polarização do transistor de entrada [51, 52], que neste caso particular é estimada através de simulações do circuito. As simulações são feitas utilizando o processo de 0,35 $\mu \mathrm{m}$ da Austria MicroSystems (AMS), considerando que a entrada está casada e os indutores como uma indutância e resistência em série com fator de qualidade $Q=5$. O transistor de entrada $M_{1}$ tem uma largura $W_{1}=450 \mu \mathrm{m}$ e comprimento de canal mínimo. Também é importante notar que a simulação do ponto de interceptação de terceira ordem e sua medição torna-se tediosa, se para cada ponto de polarização deve-se garantir o casamento de impedâncias na entrada. Portanto, para melhorar o processo iterativo 
desses testes, foi escrito um script para automatizar a obtenção dos resultados como mostrado no apêndice A.

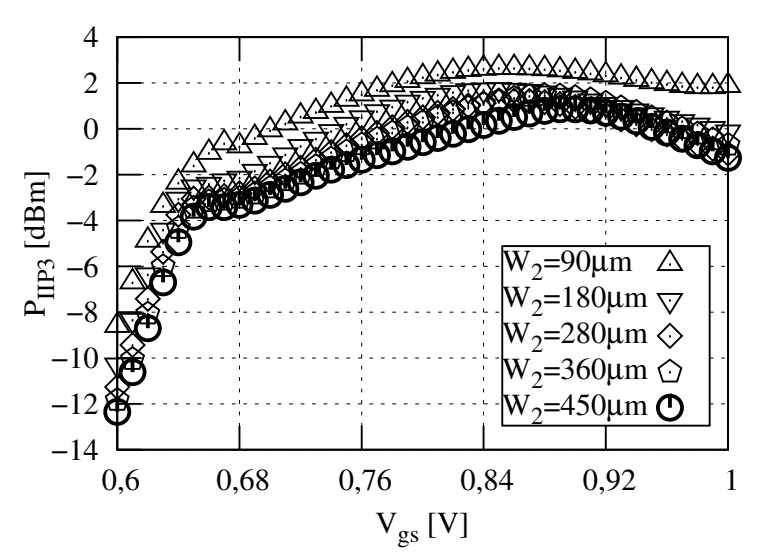

(a)

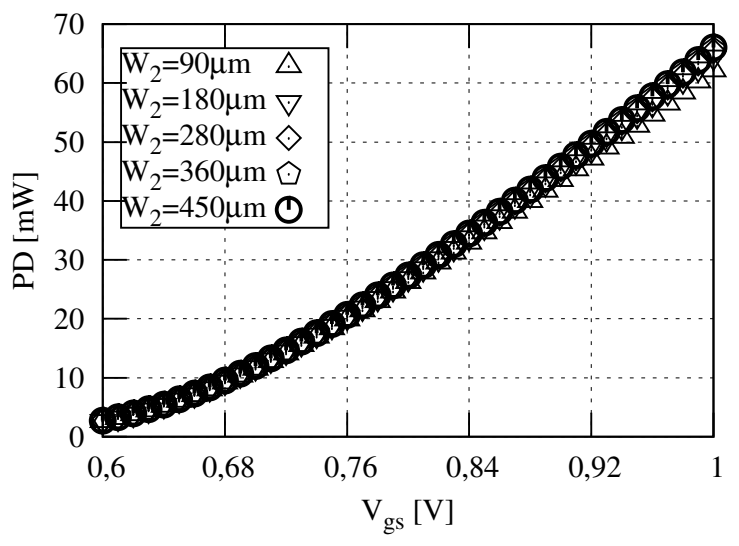

(b)

Figura 2.6: Resultados de simulação variando-se a tensão $V_{g s}$ de $M_{1}$ : (a) Ponto de interceptação de terceira ordem; (b) potência dissipada.

Os resultados destes testes são mostrados na figura 2.6, onde para cada ponto, um acoplamento adequado na entrada é garantido $\left(S_{11}<-16 \mathrm{~dB}\right)$. Também pode ser observado que cada traço é feito para uma largura de canal diferente de $M_{2}$. Das figuras 2.6(a) e 2.6(b) pode-se concluir que uma boa linearidade pode ser conseguida através do aumento da tensão de polarização ou pelo menos usando o transistor $M_{1}$ na região de inversão forte. No entanto, o aumento desta tensão afeta diretamente o consumo de potência até rapidamente alcançar valores inadmissíveis, de modo que a linearidade pode ser considerada durante o projeto do circuito dando um limite mínimo na tensão de polarização, além de uma restrição na dissipação de potência máxima.

\subsubsection{Modelagem do transistor}

Para obter uma boa concordância entre a solução do programa geométrico e as simulações feitas usando esses resultados, é importante ter expressões adequadas para representar o comportamento do transistor MOS. Além disso, adicionar esse comportamento num PG precisa de equações posinomiais precisas. No entanto, para descrever o comportamento do transistor, expressões bastante complexas com diversos parâmetros de ajuste são usadas nos modelos mais sofisticados, e por outro lado as expressões normalmente relatadas nos livros são mais simples e adequadas para ser usadas em um PG, mas não possuem precisão adequada na medida em que o comprimento do canal diminui. Portanto, é necessário fazer uma caracterização do transistor 
através de simulações usando o modelo fornecido pela foundry, a fim de fazer ajuste de dados e gerar modelos posinomiais precisos para os diferentes parâmetros.

Neste caso em particular são considerados modelos monomiais devido a sua simplicidade, baixo erro de modelagem e a vantagem que podem ser usados como restrições igualdade e desigualdade em um PG. Estes modelos precisam ser desenvolvidos para as transcondutâncias e tensões porta-fonte de $M_{1}$ e $M_{2}\left(g_{m_{1,2}}\right.$ e $\left.V_{g s_{1,2}}\right)$, além das capacitâncias de porta-fonte e portadreno de $M_{1}\left(C_{g s 1}\right.$ e $C_{g d 1}$ respectivamente). Os modelos gerados são descritos como se segue:

$$
g_{m_{1,2}}, V_{g s_{1,2}}, C_{g s 1, g d 1}=K_{g, V, C} n_{f_{1,2}}^{\alpha 1} W_{f_{1,2}}^{\alpha 2} I_{D_{1,2}}^{\alpha 3} V_{D S_{1,2}}^{\alpha 4} L_{1,2}^{\alpha 5}
$$

onde $K_{g, V, C}, \alpha 1, \alpha 2, \alpha 3, \alpha 4$ e $\alpha 5$ são constantes resultado do ajuste de dados; $n_{f}$ é o número de dedos do layout do transistor; $W_{f}$ é a largura desses dedos; $I_{D}$ é a corrente de dreno; $V_{D S}$ é a tensão dreno-fonte e $L$ é o comprimento do canal do transistor. Embora a dependência das capacitâncias no consumo de corrente e a tensão de dreno-fonte é quase insignificante, por simplicidade na escrita dos scripts para o processo de modelagem é assumida desta forma.

Normalmente estes modelos dependem do comprimento de canal, mas em radiofrequência é comum assumir comprimento de canal mínimo e desta forma, os modelos podem ser gerados sob essa hipótese. É também importante destacar que a precisão do modelo depende do tamanho do espaço de projeto e também deve ter um comportamento convexo. Se a função modelada não é convexa em relação as variáveis, o erro máximo é bastante elevado [37,41].

\subsubsection{Outras considerações}

- A função objetivo pode ser uma expressão que representa um só parâmetro de desempenho, ou pode ser a soma de várias expressões que representam parâmetros de desempenho diferentes ou uma determinada figura de mérito que involve esses parâmetros (em caso tal, poderia considerar se como um PG multiobjetivo). Neste trabalho, em primeiro lugar é considerado o fator de ruído do $L N A$ como parte desta função objetivo a ser minimizada. No entanto, a equação (2.47) não é uma função posinômial devido ao seu último termo entre colchetes, de modo que esse termo é desprezado porque não tem uma contribuição importante no ruído total ao ser resultado da correlação entre os ruídos da porta e do canal do transistor, e assim garantir a compatibilidade com a programação geométrica sem alterar consideravelmente o resultado final.

Por outro lado, a manipulação das leis de Kirchhoff em um PG é difícil porque estas são descritas mediante igualdades posinomiais, portanto, são introduzidas duas expressões 
somadas ao fator de ruído na função objetivo com essa finalidade $\left(\frac{V_{D D}}{V_{D S 1}}\right.$ e $\left.\frac{V_{D D}}{V_{D S 2}}\right)$.

Também, poderia se adicionar na função objetivo alguma expressão que permita garantir o casamento de impedância, diminuir o número de dispositivos, diminuir o consumo de potência ou diminuir a área. No entanto, se varias expressões são adicionadas, é recomendavel definir uma figura de mérito atribuindo pesos para elas.

- A capacitancia $C_{g}$ (eq. (2.49)) é considerada através da criação de um novo modelo monomial utilizando os modelos de $C_{g s 1}$ e $C_{g d 1}$ para diferentes valores da razão $\frac{g m 1}{g m 2}$ assumidos. Este modelo novo depende dos mesmos parâmetros que os modelos utilizados para criá-lo.

- Os indutores não são dispositivos ideais, eles têm alguns parasitas associados, especialmente os indutores implementados em tecnologia CMOS padrão sem melhorias para RF. Estes indutores podem afetar consideravelmente o comportamento do circuito dependendo do seu fator de qualidade. Um fator de qualidade inferior a dez é considerado baixo. Neste caso, durante a formulação do PG o indutor é tratado como uma indutância com uma resistência em série porque incluir as outras parasitas aumenta a complexidade matemática e faz expressões não compatíveis com a programação geométrica. No entanto, antes de gerar o layout é importante realizar as simulações usando um modelo mais complexo de indutor, que se não estiver incluído no Design Kit devem ser usadas ferramentas como ASITIC [53] e VPCD (ferramenta da Cadence) para criá-los.

- Se é assumida uma impedância característica da antena $R_{S}=50 \Omega$, e se quer considerar o coeficente de reflexão na entrada $S_{11}$ (equações (2.59) e (2.60)), as expressões para a impedância de entrada do circuito devem ser incluídas com a melhor precisão possível para garantir o mínimo valor de $S_{11}$ e correpondência entre o PG e as simulações. No entanto, como as equações (2.11) e (2.12) que representam com precisão as partes real e imaginária da impedância de entrada são posinômios e apenas expressões monomiais podem ser usadas como igualdades em um PG. Assim, é fácil supor que usando as equações (2.15) e (2.16) irão resolver o problema, mas usá-las irá representar uma penalidade na precisão dos resultados.

$$
\begin{aligned}
S_{11} & =\frac{Z_{\text {in }}-50}{Z_{\text {in }}+50} \\
\left|S_{11}\right|_{d B} & =20 \log \left|S_{11}\right|
\end{aligned}
$$

Neste caso, de acordo com as equações (2.9) e (2.43), uma proporção $\frac{g_{m 1}}{C_{g s 1}}$ elevada representa um ruído menor e uma impedância de entrada maior. Assim, se a figura de 
ruído é usada como a função objetivo a ser minimizada, esta proporção tende a ser elevada e saturar o valor da impedância de entrada em $R_{S}$. Isto significa que as equações (2.11) e (2.12) podem ser usadas como restrições de desigualdade que tenderão à igualdade enquanto a figura de ruído é minimizada.

- O ganho de tensão é considerado usando as equações (2.27) e (2.25) calculando a impedância de saída do tanque ressonante e medir o ganho. Para isso é necessário ter uma boa estimativa da impedância de saída, que pode ser representada por uma resistência de saída $\left(R_{o}\right)$ estimada da seguinte forma,

$$
\begin{aligned}
R_{L d} & =\frac{\omega_{o} L_{d}}{Q} \\
K_{Q L d} & =\frac{Q^{2}}{1+Q^{2}} \\
R_{o L d} & =\frac{Q^{2} R_{L d}}{K_{Q L d}} \\
C_{L} & =\frac{K_{Q L d}}{\omega_{o}^{2} L d}
\end{aligned}
$$

onde $Q$ é o fator de qualidade do indutor; $K_{Q L d}$ é uma constante que depende dos fatores de qualidade; $R_{o L d}$ é a resistência em paralelo equivalente do indutor e $C_{L}$ é a capacitância total necessária para garantir ressonância na frequência $\omega_{o}$.

- O resistor associado à porta do transistor $r_{g 1}$ é considerado utilizando a seguinte equação,

$$
r_{g 1}=\frac{R_{s q} W}{3 n_{f}^{2} L}
$$

onde $R_{s q}$ é o valor da resistência por quadrado do material poly de porta; $n_{f}$ é o número de dedos do transistor; $W$ e $L$ são a largura e comprimento do canal respectivamente.

\subsection{Resumo da formulação de projeto do $L N A$ de banda estreita}

Nas figuras 2.7(a) até 2.7(d) são apresentados os gráficos comparativos entre as diferentes equações obtidas na formulação matemática do circuito, e os resultados de um $L N A$ de teste projetado para 2,45 GHz usando um processo de $0,18 \mu \mathrm{m}$ da $I B M$. Nos gráficos o subscrito PG representa as equações usadas no programa geométrico.

As figuras 2.7(a) e 2.7(b) mostram a parte real e imaginária da impedância de entrada do circuito, demonstrando que a inclusão da capacitancia porta-dreno $\left(C_{g d}\right)$ na formulação é 


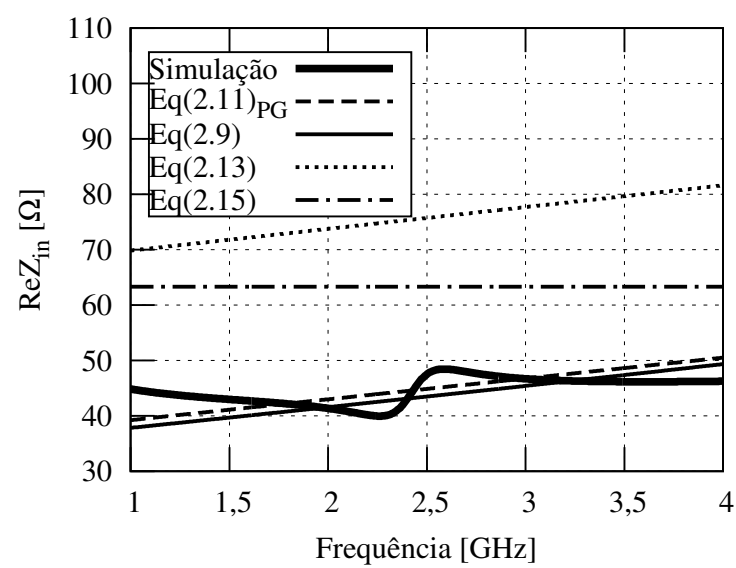

(a)

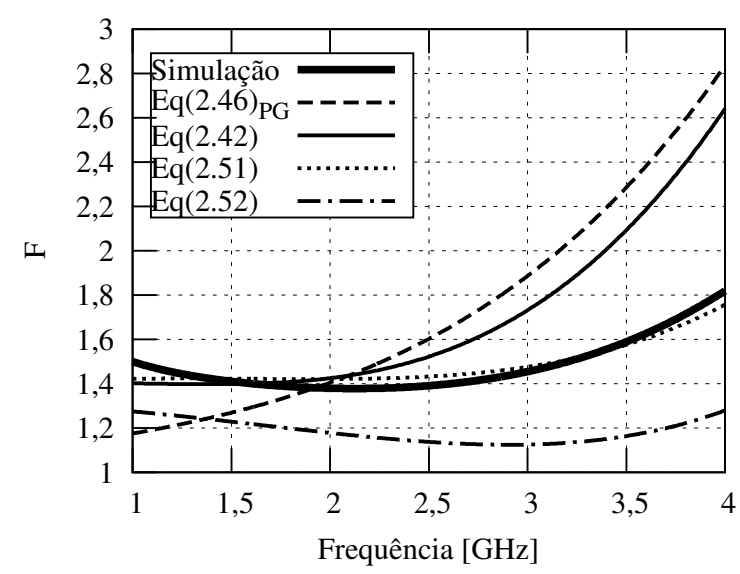

(c)

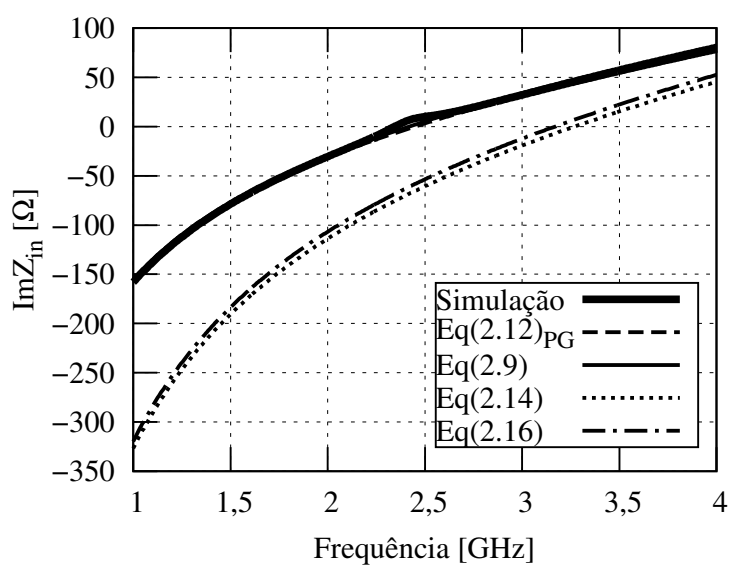

(b)

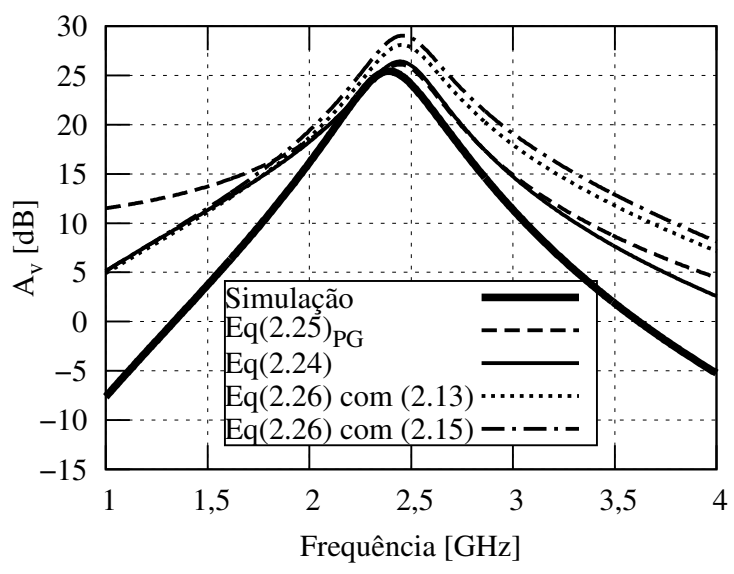

(d)

Figura 2.7: Comparação das equações formuladas: (a) Parte real da impedância de entrada; (b) Parte imaginária da impedância de entrada; (c) Fator de ruído; (d) Ganho de tensão.

relevante para garantir o casamento de impedancias com maior precisão uma vez que os erros introduzidos ao negligenciar esta capacitancia são consideraveis (na figura 2.7(b) a 2,45 GHz o descasamento é de aproximadamente $50 \Omega$ ).

Na figura 2.7(c) é mostrado o fator de ruído do circuito onde os valores entre as diferentes aproximações divergem um pouco, isto pode ser produto do modelo de ruído do transistor (que podería até desprezar o ruído do canal). Por outro lado, traçar estas curvas permite observar que algumas das incompatibilidades entre a formulação matemática e as simulações ou medições, comumente atribuídas à constante $\gamma$ (É comum achar na literatura que o $\gamma$ em dispositivos de canal curto tem um valor de perto de $2[8,10])$, podem ser resultado de ignorar a capacitância porta-dreno ou os resistores dos indutores. Nos cálculos dos gráficos é usado $\gamma=\frac{2}{3}$ e ainda assim a figura de ruído e igual o maior do que no caso simulado.

A figura 2.7(d) é gerada usando a equação (2.27) e considerando como impedância de 
saída uma rede RLC em ressônancia. Tanto para o ganho como para a impedância de entrada, observa-se uma boa compatibilidade entre o resultado da simulação e as equações obtidas considerando a capacitância porta-dreno.

Por último, a partir dos gráficos pode-se observar que as expressões consideradas no programa geométrico são precisas o que irá permitir boa correspondência entre os resultados do PG e as simulações, reduzindo os ajustes posteriores necessários.

\subsection{Forma padrão do PG para o LNA de banda estreita}

Uma vez que as diferentes considerações necessárias para aplicar a programação geométrica são feitas, um exemplo de um programa geométrico padrão incluindo as principais restrições pode ser formulado de acordo com a expressão (2.2).

$$
\begin{aligned}
& \text { minimizar } 1+\frac{\omega^{2} C_{g s 1}^{2} R_{s} \gamma}{g_{m 1}}\left[\left(\frac{R_{g}^{2} \chi^{2}+\omega \kappa^{2}}{g_{m 2}^{2} R_{s}^{2} C_{g s 1}^{2}}\right) \frac{1}{\alpha}+\left(\frac{R_{g}^{2}+\omega^{2} L_{g s}^{2}}{R_{s}^{2}}\right) \frac{\alpha \delta}{5 \gamma}\right]+\frac{R_{L g}+R_{L s}+r_{g 1}}{R_{s}}+\frac{V_{D D}}{V_{D S 1}}+\frac{V_{D D}}{V_{D S 2}} \\
& \text { sujeito a }\left[r_{g 1}+R_{L g}+\frac{C_{g s 1}}{C_{g}}\left(R_{L s}+\frac{g_{m 1} L_{s}}{C_{g s}}\right)\right] \frac{1}{R s} \leq 1 \\
& \frac{1}{\omega^{2} C_{g 1} L_{g}}\left(1+g_{m 1} R_{L s}\right) \leq 1 \\
& \frac{\omega C_{g}}{g_{m 1} R_{o}}\left[R_{s}+r_{g 1}+R_{L g}+\frac{C_{g s 1}}{C_{g}}\left(R_{L s}+\frac{g_{m 1} L_{s}}{C_{g s 1}}\right)\right] A_{v \min } \leq 1 \\
& \left(\frac{m_{1}}{C_{g s 1, g d 1, g}}\right) K_{C_{g s 1, g d 1, g}} n f_{1}^{\beta 1_{g s 1, g d 1, g}} W_{f 1}^{\beta 2_{g s 1, g d 1, g}} L_{1}^{\beta 3_{g s 1, g d 1, g}} I_{D 1}^{\beta 4_{g s 1, g d 1, g}} V_{D S 1}^{\beta 5_{g s 1, g d 1, g}}=1 \\
& \left(\frac{m_{1,2}}{g_{m_{1,2}}}\right) K_{g_{m_{1,2}}} n f_{1,2}^{\Phi 1_{M_{1}, M_{2}}} W_{f 1,2}^{\Phi 2_{M_{1}, M_{2}}} L_{1,2}^{\Phi 3_{M_{1}, M_{2}}} I_{D 1,2}^{\Phi 4_{M_{1}, M_{2}}} V_{D S 1,2}^{\Phi 5_{M_{1}, M_{2}}}=1 \\
& \left(\frac{1}{V_{g s_{1,2}}}\right) K_{V g s_{1,2}} n_{f_{1,2}}^{\alpha 1_{M_{1}, M_{2}}} W_{f 1,2}^{\alpha 2_{M_{1}, M_{2}}} L_{1,2}^{\alpha 3_{M_{1}, M_{2}}} I_{D 1,2}^{\alpha 4_{M_{1}, M_{2}}} V_{D S 1,2}^{\alpha 5_{M_{1}, M_{2}}}=1 \\
& \frac{1}{V_{D D}}\left(V_{D S 1}+V_{D S 2}+m_{2} I_{D 2} R_{L d}+m_{1} I_{D 1} R_{L s}\right) \leq 1 \\
& \frac{R_{s q} W_{1}}{3 n_{1}^{2} L}\left(\frac{1}{r_{g 1}}\right)=1 \\
& \frac{Q^{2} R_{L d}}{K_{Q_{L d}} R_{o}}=1 \text {; } \\
& \frac{K_{Q_{L d}}}{\omega^{2} L_{d} C_{L}} \text {; } \\
& \frac{n_{f 1,2} W_{f 1,2}}{W_{1,2}}=1 \\
& \frac{m_{1,2} W_{1,2}}{W_{M 1, M 2}}=1 \\
& \frac{m_{1} I_{D 1}}{m_{2} I_{D 2}}=1 \\
& \frac{V_{g s \min }}{V_{g s 1}} \leq 1 \\
& \frac{g_{m 1}}{\chi g_{m 2}}=1 \\
& \frac{W_{1,2}}{W_{\max }} \leq 1
\end{aligned}
$$




\section{Formulação de projeto de um $L N A$ de banda larga usando programação geométrica}

No capítulo anterior são esclarecidos os principais conceitos sobre a programação geométrica e sua forma padrão, são listadas algumas das variáveis do transistor que podem ser modeladas mediante monômios, e é explicado porque a análise de ruído está focada apenas no ruído térmico, entre outros tópicos tratados. Além disso, a formulação rigorosa do problema de projeto de um $L N A$ de banda estreita utilizando programação geométrica, é apresentada como objetivo principal deste trabalho. No entanto, também pode ser explorada a possibilidade de aplicar esses conceitos para o projeto de circuitos de banda larga. Por tanto, neste capítulo é apresentada a formulação do problema projeto de um $L N A$ de banda larga, usando uma topologia para cancelamento do ruído térmico, e é estudada a possibilidade de assistir o projeto descrevendo alguns dos parâmetros de desempenho do circuito como um programa geométrico. Para isso, inicialmente são feitas análises de circuito para extrair as equações que representam o comportamento deste. Depois, semelhante ao capítulo anterior, algumas considerações são descritas para incluir a programação geométrica no fluxo de projeto, e finalmente é apresentada a forma padrão do problema de otimização usando esta metodologia.

\subsection{Formulação de projeto de um $L N A$ de banda larga}

O circuito a ser analisado nesta seção é mostrado na figura 3.1, e corresponde a um amplificador de baixo ruído de banda larga com cancelamento de ruído. A principal vantagem desta topologia é que o casamento da impedância entrada pode ser obtido através do primeiro estágio, enquanto que a sua contribuição de ruído é cancelada pelos estágios seguintes, como descrito no primeiro capítulo. No circuito, $M_{1}$ forma um estágio de porta comum, responsável pelo acoplamento da impedância de entrada. Devido à maior contribuição de ruído dos estágios porta comum em comparação com os estagios de fonte comum, essa deve ser reduzida. Para isso, dois estágios 


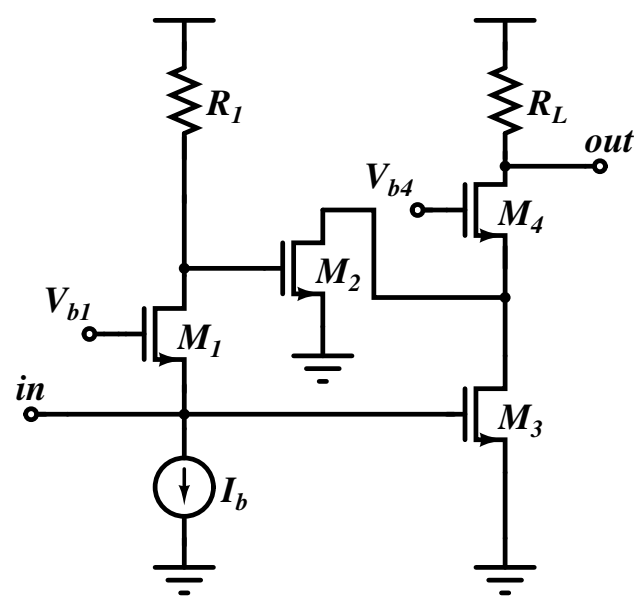

Figura 3.1: $L N A$ com cancelamento de ruído.

de fonte comum formados pelos transistores $M_{2}$ e $M_{3}$ são adicionados, com as portas ligadas a dois nós nos quais o sinal de ruído está defasado $180^{\circ}$, mas o sinal de radiofrequência continua em fase. Os sinais são amplificados por esses estágios, e posteriormente somados de modo que os sinais de ruído são subtraídos, enquanto os sinais de radiofrequência somados. Como consequência, o sinal de ruído através de $M_{4}$ e a resistência de carga $R_{L}$, tem uma contribuição mínima ou nula de ruído devido ao transistor $M_{1}$.

\subsubsection{Análise de pequenos sinais}

Tal como estabelecido no capítulo anterior, existem alguns parâmetros de desempenho do LNA que devem ser formulados de modo a prever o seu comportamento, especialmente com respeito à frequência. Para o LNA de banda larga, mesmo que para o $L N A$ de banda estreita, a primeira análise feita é a análise de pequenos sinais, a fim de extrair as equações para a impedância de entrada e o ganho transcondutância. Para este bloco, a análise é feita com base no modelo para pequenos sinais da figura 3.2. No modelo, a parte superior (caracterizada pelo subscrito 1 nos dispositivos) representa o estágio porta comum. Os dois estágios fonte comum são analisados utilizando o modelo no interior do rectângulo com traços cinza (subscritos 2 e 3). Durante a análise do estágio de entrada, os estágios fonte comum são considerados como duas impedâncias equivalentes $Z_{i n M 2}$ e $Z_{i n M 3}$. Além disso, a resistência de porta $r_{g 1}$, a capacitância de porta-substrato $Z_{C g b 1}$, e a capacitância de porta-dreno $Z_{C g d 1}$, não são consideradas durante a análise. $r_{g 1}$ e $Z_{C g b 1}$ consideram-se desprezíveis, e $Z_{C g d s}$ elevada em comparação com $R_{1}$ que está praticamente em paralelo. Por outro lado, o efeito do transistor $M_{4}$ (figura 3.1) é considerado no modelo mediante a resistência equivalente vista desde a saída dos estágios fonte comum. Essa resistência equivale ao inverso da transcondutância de $M_{4}$, em paralelo com a resistência de sáida do estágio que não está sendo analisado. 


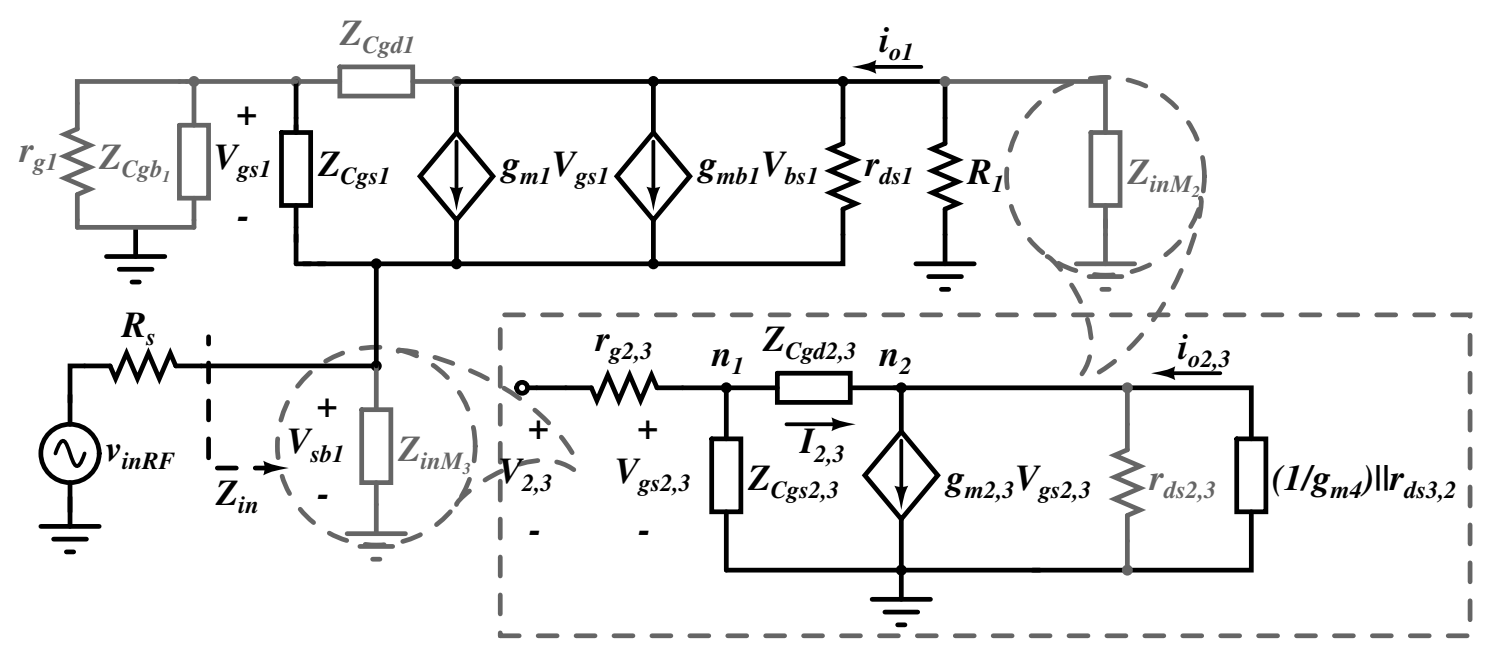

Figura 3.2: Modelo do circuito de banda larga para análise de pequenos sinais.

\section{Impedância de entrada}

Como acima mecionado, o cálculo da impedância de entrada é feito com base no circuito mostrado na figura 3.2. Neste caso, o teorema de Miller é usado na estimativa da impedância de entrada dos estágios de fonte comum.

Assumindo uma corrente através da resistência da fonte de entrada do sinal $\left(i_{R s}\right)$, e verificando o nó da fonte de $M_{1}$ obtém-se que:

$$
i_{R_{s}}=\frac{Z_{C g s 1}+Z_{i n M 3}}{Z_{C g s 1} Z_{\text {inM } 3}} V_{g s 1}+i_{o 1}
$$

onde $Z_{C g s 1}$ corresponde à impedância devido à capacitância porta-fonte do transistor $M_{1} ; Z_{i n M 3}$ é a impedância de entrada de $M_{3}$, e $i_{o 1}$ é a corrente de saída do estágio porta comum. Isolando o valor dessa corrente analisando o nó da saída de $M_{1}$,

$$
\begin{gathered}
i_{o 1}=\left(g_{m 1}+g_{m b 1}\right) V_{g s 1}+\frac{V_{g s 1}-\frac{R_{1} Z_{i n M 2}}{R_{1}+Z_{i n M 2}}}{r_{d s 1}} i_{o 1} \\
i_{o 1}=\frac{g_{m 1}+g_{m b 1}+\frac{1}{r_{d s 1}}}{1+\frac{R_{1} Z_{i n M 2}}{\left(R_{1}+Z_{i n M 2}\right) r_{d s 1}}} V_{g s 1}
\end{gathered}
$$

nas equações, $g_{m 1}$ e $g_{m b 1}$ são as transcondutâncias de $M_{1} ; Z_{i n M 2}$ é a impedância de entrada de $M_{2} ; V_{g s 1}$ e $r_{d s 1}$ são a tensão porta-fonte e a resistência dreno-fonte de $M_{1}$, e $R_{1}$ é a resistência de carga do estágio porta comum.

Finalmente, substituindo a equação (3.3) em (3.1), é obtida uma expressão completa para a 
impedância de entrada do LNA com cancelamento de ruído (equação (3.4)).

$Z_{i n}=\frac{Z_{C g s 1} Z_{i n M 3}\left[Z_{i n M 2}\left(R_{1}+r_{d s 1}\right)+R_{1} r_{d s 1}\right]}{\left(Z_{C g s 1}+Z_{i n M 3}\right)\left[Z_{i n M 2}\left(R_{1}+r_{d s 1}\right)+R_{1} r_{d s 1}\right]+Z_{C g s 1} Z_{i n M 3}\left(R_{1}+Z_{i n M 2}\right)\left[1+\left(g_{m 1}+g_{m b 1}\right) r_{d s 1}\right]}$

Tomando o modelo da parte inferior da figura 3.2, é desenvolvida uma análise para estimar a impedância de entrada dos estágios de fonte comum. Nessa análise, o teorema de Miller é utilizado para estimar o efeito da capacitância de porta-dreno de $M_{2}$ e $M_{3}$. Como mencionado no capítulo anterior, a relação entre as tensões dos nós $n_{2}$ e $n_{1}$ é conhecida como o ganho de Miller,

$$
A_{m 2,3}=-\left(\frac{1}{g_{m 4}} \| r_{d s 3,2}\right) g_{m 2,3}=-\frac{g_{m 2,3} r_{d s 3,2}}{1+g_{m 4} r_{d s 3,2}}
$$

o $\frac{1}{g_{m 4}}$ representa a resistência equivalente do transistor $M_{4}$, vista desde os drenos de $M_{2}$ e $M_{3}$; $r_{d s 3,2}$ e $g_{m 2,3}$ são as resistências de dreno-fonte e as transcondutâncias desses transistores.

Aplicando o teorema de Miller são estimadas as impedâncias de entrada para os estágios mencionados.

$$
Z_{i n M 2,3}=r_{g 2,3}+\frac{Z_{C g s 2,3} Z_{C g d 2,3}}{Z_{C g d 2,3}+\left(1-A_{m 2,3}\right) Z_{C g s 2,3}}
$$

No entanto, existe uma outra forma de escrever as considerações anteriores baseada nos princípios da topologia. A partir da equação (3.4), pode-se observar que o comportamento em frequência da impedância de entrada é definido pela impedância de porta-fonte de $M_{1}$, e a impedância de entrada dos estágios de fonte comum. De modo que, para manter o casamento de impedâncias na banda de operação, o efeito destas impedâncias deve ser considerável apenas nas frequências fora da banda. De acordo isto, uma primeira aproximação sobre o equacionamento anterior, consiste em assumir que a impedância de entrada de $M_{3}$ é suficientemente alta na banda de operação para não afetar consideravelmente o acoplamento na entrada $\left(R_{S}|| Z_{\text {inM3 }} \approx R_{S}\right)$. Analogamente, a impedância de $M_{2}$ não deve afetar o valor da impedância de saída do primeiro estágio $\left(R_{1}|| Z_{i n M 2} \approx R_{1}\right)$. Em vista do anterior, o efeito das resistências da porta de $M_{2}$ e $M_{3}$ pode ser desprezado em comparação com as impedâncias capacitivas que dominam a magnitude da impedância desses transistores. Outra simplificação seria desprezar a capacitância porta-dreno e simplificar a equação (3.6) para obter que:

$$
Z_{\text {inM2,3 }} \approx Z_{C g s 2,3}
$$


$\operatorname{com} Z_{C g s 2,3}>>R_{s}$

Assim, de acordo com a análise anterior, as equações (3.1) e (3.3) podem ser escritas como se mostra nas equações (3.8) e (3.9).

$$
\begin{gathered}
i_{R_{s}}=\frac{V_{g s 1}}{Z_{C g s 1}}+i_{o 1} \\
i_{o 1}=\frac{g_{m 1}+g_{m b 1}+\frac{1}{r_{d s 1}}}{1+\frac{R_{1}}{r_{d s 1}}} V_{g s 1}
\end{gathered}
$$

Em seguida, a nova estimativa para a impedância de entrada é:

$$
Z_{\text {in }}=\frac{Z_{C g s 1}\left(R_{1}+r_{d s 1}\right)}{R_{1}+r_{d s 1}+Z_{C g s 1}+\left(g_{m 1}+g_{m b 1}\right) Z_{C g s 1} r_{d s 1}}
$$

onde, se a impedância da capacitância de porta-fonte de $M_{1}$ é consideravelmente maior do que a $R_{S}$

$$
Z_{i n} \approx \frac{R_{1}+r_{d s 1}}{1+\left(g_{m 1}+g_{m b 1}\right) r_{d s 1}}
$$

além disso, se a transcondutância do corpo e a resistência de dreno-fonte de $M_{1}$ são desprezadas, obtêm-se as equações (3.12) e (3.12) respectivamente. Se ambas as transcondutâncias são desprezadas, o resultado é a equação (3.14).

$$
\begin{gathered}
Z_{i n} \approx \frac{R_{1}+r_{d s 1}}{1+g_{m 1} r_{d s 1}} \\
Z_{i n} \approx \frac{1}{g_{m 1}+g_{m b 1}} \\
Z_{i n} \approx \frac{1}{g_{m 1}}
\end{gathered}
$$

\section{Ganho de transcondutância}

Assumindo que uma corrente de saída $i_{o}$ percorrendo através do transistor $M_{4}$ e o resistor $R_{L}$, então o ganho de transcondutância do $L N A$ pode ser definido como a razão entre esta corrente, e a fonte de tensão de entrada do sinal de radiofrequência. Além disso, esta corrente assumida é resultado da soma das correntes dos transistores $M_{2}$ e $M_{3}\left(i_{o 2}\right.$ e $\left.i_{o 3}\right)$, e ao mesmo tempo, a 
corrente através de $M_{2}$ depende da corrente de $M_{1}\left(i_{o 1}\right)$.

$$
G_{L N A}=\frac{i_{o}}{v_{\text {inRF }}}=\frac{i_{o 2}+i_{o 3}}{v_{\text {inRF }}}=\left(\frac{-R_{1} i_{o 1}}{v_{\text {inRF }}}\right) \frac{i_{o 2}}{-R_{1} i_{o 1}}+\frac{i_{o 3}}{v_{\text {inRF }}}
$$

A equação (3.15) resume o mencionado anteriormente. Uma outra maneira de representar essa equação em função das transcondutâncias dos diferentes estágios é a seguinte:

$$
G_{L N A}=\left(-G_{M 1} R_{1}\right) G_{M 2}+G_{M 3}
$$

onde $G_{M 1}$ é o ganho de transcondutância do estágio porta comum; $G_{M 2}$ é o ganho do estágio fonte comum com respeito à tensão de saída do estágio anterior. Por outro lado, $G_{M 3}$ é o ganho do estágio fonte comum formado pelo transistor $M_{3}$, com respeito à fonte de tensão de entrada do sinal de radiofrequência.

A transcondutância do estágio de entrada é definida como se segue:

$$
G_{M 1}=\frac{i_{o 1}}{v_{i n R F}}
$$

em seguida, analisando a rede de entrada e fatorando obtém-se que:

$$
\begin{gathered}
v_{i n R F}=-V_{g s 1}-\left(i_{o 1}+\frac{V_{g s 1}}{Z_{C g s}}\right) R_{S} \\
v_{i n R F}=-R_{s} i_{o 1}-\left(1+\frac{R_{S}}{Z_{C g s 1}}\right) V_{g s 1}
\end{gathered}
$$

onde a tensão de porta-fonte de $M_{1}$ é isolada a partir da equação (3.9),

$$
V_{g s 1}=\frac{R_{1}+r_{d s 1}}{1+\left(g_{m 1}+g_{m b 1}\right) r_{d s 1}} i_{o 1}
$$

e substituindo (3.20) em (3.19) e colocando em evidência $i_{o 1}$ é obtida a equação (3.21).

$$
v_{i n R F}=-\left\{\frac{R_{s}\left[R_{1}+r_{d s 1}+Z_{C g s 1}+\left(g_{m 1}+g_{m b 1}\right) Z_{C g s 1} r_{d s 1}\right]+Z_{C g s 1}\left(R_{1}+r_{d s 1}\right)}{Z_{C g s 1}\left[1+\left(g_{m 1}+g_{m b 1}\right) r_{d s 1}\right]}\right\} i_{o 1}
$$

Da equação (3.21) é possível evidenciar a impedância de entrada usando (3.10),

$$
v_{\text {inRF }}=-\left[\frac{R_{S}\left(\frac{R_{1}+r_{d s 1}}{Z_{\text {in }}}\right)+R_{1}+r_{d s 1}}{1+\left(g_{m 1}+g_{m b 1}\right) r_{d s 1}}\right] i_{o 1}
$$

para posteriormente obter a expressão completa do ganho de transcondutância do estágio de 
entrada (equação (3.23)).

$$
G_{M 1}=-\frac{Z_{i n}\left[1+\left(g_{m 1}+g_{m b 1}\right) r_{d s 1}\right]}{\left(R_{1}+r_{d s 1}\right)\left(R_{s}+Z_{i n}\right)}
$$

A partir de (3.23), pode-se observar que o ganho de transcondutância de $M_{1}$ varia com a frequência de acordo com a impedância de entrada. E similar à análise da impedância de entrada, a transcondutância do corpo e o resistor dreno-fonte podem ser desprezados para simplificar os cálculos.

$$
\begin{gathered}
G_{M 1} \approx-\frac{Z_{i n}\left(1+g_{m 1} r_{d s 1}\right)}{\left(R_{1}+r_{d s 1}\right)\left(R_{S}+Z_{i n}\right)} \\
G_{M 1} \approx-\frac{Z_{i n}\left(g_{m 1}+g_{m b 1}\right)}{R_{S}+Z_{i n}} \approx-\frac{1}{R_{S}+\frac{1}{g_{m 1}+g_{m b 1}}} \\
G_{M 1} \approx-\frac{Z_{\text {in }}}{R_{S}+Z_{i n}} \approx-\frac{1}{R_{S}+\frac{1}{g_{m 1}}}
\end{gathered}
$$

Nas equações (3.24) até (3.25), são apresentados os resultados de fazer as simplificações descritas. Para cada caso a impedância de entrada também muda como visto em (3.25) e (3.26).

Por outro lado, a análise do ganho de transcondutância dos estágios de fonte comum é feita usando o modelo da parte inferior da figura 3.2 como mencionado anteriormente. De acordo com o modelo, são calculados os ganhos de transcondutância $G_{2}$ e $G_{3}$.

$$
G_{2,3}=\frac{i_{o 2,3}}{V_{2,3}}
$$

Ao analisar o nó $n_{2}$ é possível isolar as correntes de saída como uma função das tensões de porta-fonte,

$$
\begin{gathered}
i_{o 2,3}+I_{2,3}=g_{m 2,3} V_{g s 2,3} \\
i_{o 2,3}=\left[g_{m 3}-\frac{\left(1-A_{m 2,3}\right)}{Z_{C g d 2,3}}\right] V_{g s 2,3}
\end{gathered}
$$

e percorrendo a rede de entrada, as tensões porta-fonte pódem-se isolar como uma função das tensões de entrada $\left(V_{2,3}\right)$. Pelo fato de $Z_{i n M 2,3}$ ser bastante maior do que a $R_{s}$, e ao mesmo tempo $R_{S}$ é maior do que $r_{g 2,3}$, então esta última é desprezível (equação (3.31)).

$$
V_{2,3}=\left(\frac{1}{Z_{C g s 2,3}}+\frac{1-A_{m 2,3}}{Z_{C g d 2,3}}\right) r_{g 2,3} V_{g s 2,3}+V_{g s 2,3}
$$




$$
V_{g s 2,3}=\left(\frac{Z_{\text {inM } 2,3}-r_{g 2,3}}{Z_{\text {inM2,3 }}}\right) V_{2,3} \approx V_{2,3}
$$

Finalmente, substituindo (3.31) em (3.29), os ganhos de transcondutância para $M_{2}$ e $M_{3}$ são cálculados.

$$
\begin{aligned}
G_{2} & =\frac{i_{o 2}}{V_{2}}=g_{m 2}-\frac{1-A_{m 2}}{Z_{C g d 2}} \\
G_{3} & =\frac{i_{o 3}}{V_{3}}=g_{m 3}-\frac{1-A_{m 3}}{Z_{C g d 3}}
\end{aligned}
$$

Retomando as equações (3.15) e (3.16), o ganho calculado para o estágio do transistor $M_{2}$ coincide com a definição do ganho total $G_{M 2}$ (equação (3.34)). Por outro lado, o ganho de $M_{3}$ não coincide com a definição do $G_{M 3}$, e por tanto aplicando um divisor de tensão é possível obtê-lo (equação (3.35)).

$$
\begin{gathered}
V_{2}=-R_{1} i_{o 1} \quad \Longrightarrow \quad G_{M 2}=G_{2} \\
V_{3}=\left(\frac{Z_{\text {in }}}{R_{S}+Z_{\text {in }}}\right) v_{\text {inRF }} \Longrightarrow G_{M 3}=\frac{i_{o 3}}{v_{\text {inRF }}}=\left(\frac{Z_{\text {in }}}{R_{S}+Z_{\text {in }}}\right) G_{3}
\end{gathered}
$$

Desprezando o efeito das capacitâncias porta-dreno obtêm-se que:

$$
\begin{gathered}
G_{M 2} \approx g_{m 2} \\
G_{M 3} \approx g_{m 3}\left(\frac{Z_{i n}}{R_{s}+Z_{i n}}\right)
\end{gathered}
$$

e substituindo (3.23), (3.34) e (3.35) em (3.16), pode-se expressar o ganho de transcondutância total.

$$
G_{L N A}=\frac{Z_{i n}}{R_{s}+Z_{i n}}\left[\frac{1+\left(g_{m 1}+g_{m b 1}\right) r_{d s 1}}{\left(R_{1}+r_{d s 1}\right)}\left(g_{m 2}-\frac{1-A_{m 2}}{Z_{C g d 2}}\right) R_{1}+g_{m 3}-\frac{1-A_{m 3}}{Z_{C g d 3}}\right]
$$

Também, substituindo (3.23), (3.36) e (3.37) em (3.16) é obtida a aproximação (3.39).

$$
G_{L N A} \approx \frac{Z_{i n}}{R_{s}+Z_{i n}}\left[\frac{1+\left(g_{m 1}+g_{m b 1}\right) r_{d s 1}}{R_{1}+r_{d s 1}} g_{m 2} R_{1}+g_{m 3}\right]
$$

Da mesma forma que para a impedância de entrada, os resultados de desprezar a transcondutância do corpo e o resistor de dreno-fonte de $M_{1}$ são mostrados nas equações (3.40) a (3.42), e em (3.42) está a equação mais simplificada para representar o ganho de 
transcondutância do $L N A$ com cancelamento de ruído analisado.

$$
\begin{gathered}
G_{L N A} \approx \frac{Z_{\text {in }}}{R_{s}+Z_{i n}}\left[\frac{1+g_{m 1} r_{d s 1}}{R_{1}+r_{d s}} g_{m 2} R_{1}+g_{m 3}\right] \\
G_{L N A} \approx \frac{Z_{i n}}{R_{s}+Z_{i n}}\left[\left(g_{m 1}+g_{m b 1}\right) g_{m 2} R_{1}+g_{m 3}\right] \\
G_{L N A} \approx \frac{\frac{1}{g_{m 1}}}{R_{s}+\frac{1}{g_{m 1}}}\left(g_{m 1} g_{m 2} R_{1}+g_{m 3}\right)
\end{gathered}
$$

Para terminar a análise de pequenos sinais, o ganho de tensão total do LNA é calculado como o produto entre o ganho transcondutância e a resistência de saída, que neste caso é assumida equivalente à resistência de carga $\left(R_{L}\right)$.

$$
A_{v L N A}=G_{L N A} R_{L}
$$

\subsubsection{Análise de ruído}

Uma vez que a impedância de entrada e o ganho do circuito são formulados, em seguida, a análise de ruído é desenvolvida com o objetivo de explicar o efeito de cancelamento de ruído presente e formular a contribuição de ruído total do circuito. Primeiro, é analisada a contribuição de ruído total de acordo com os estágios e a propriedade ou princípio de cancelamento de ruído da topologia. Em seguida, cada um dos estágios é formulado, começando com a contribução do estágio porta comum e a sua resistência de carga, e terminando com a contribuição de ruído dos estágios fonte comum. A análise é feita utilizando o modelo da figura 3.3 e aplicando o método de sobreposição. Como se pode ver no esquemático, existem seis fontes de ruído no circuito que devem ser analisadas através de quatro análises diferentes, já que dois pares delas estão correlacionadas $\left(i_{n 1, g} \operatorname{com} i_{n 1, d}\right.$ e $\left.i_{n 2-3, g} \operatorname{com} i_{n 2-3, d}\right)$.

O fator de ruído total do amplificador pode ser expresso pela soma dos diferentes fatores de ruído produto dos dispositivos ruídosos existêntes no circuito. Neste caso, os transistores $M_{1}$ a $M_{3}$ e a resistência $R_{1}$ de acordo com a figuras 3.1 e 3.3.

$$
F_{L N A}=F_{M 1}+\left(F_{R_{1}}-1\right)+\left(F_{M 2}-1\right)+\left(F_{M 3}-1\right)
$$

Ao mesmo tempo, se estes fatores são expressos segundo a equação (2.28), então o fator de 


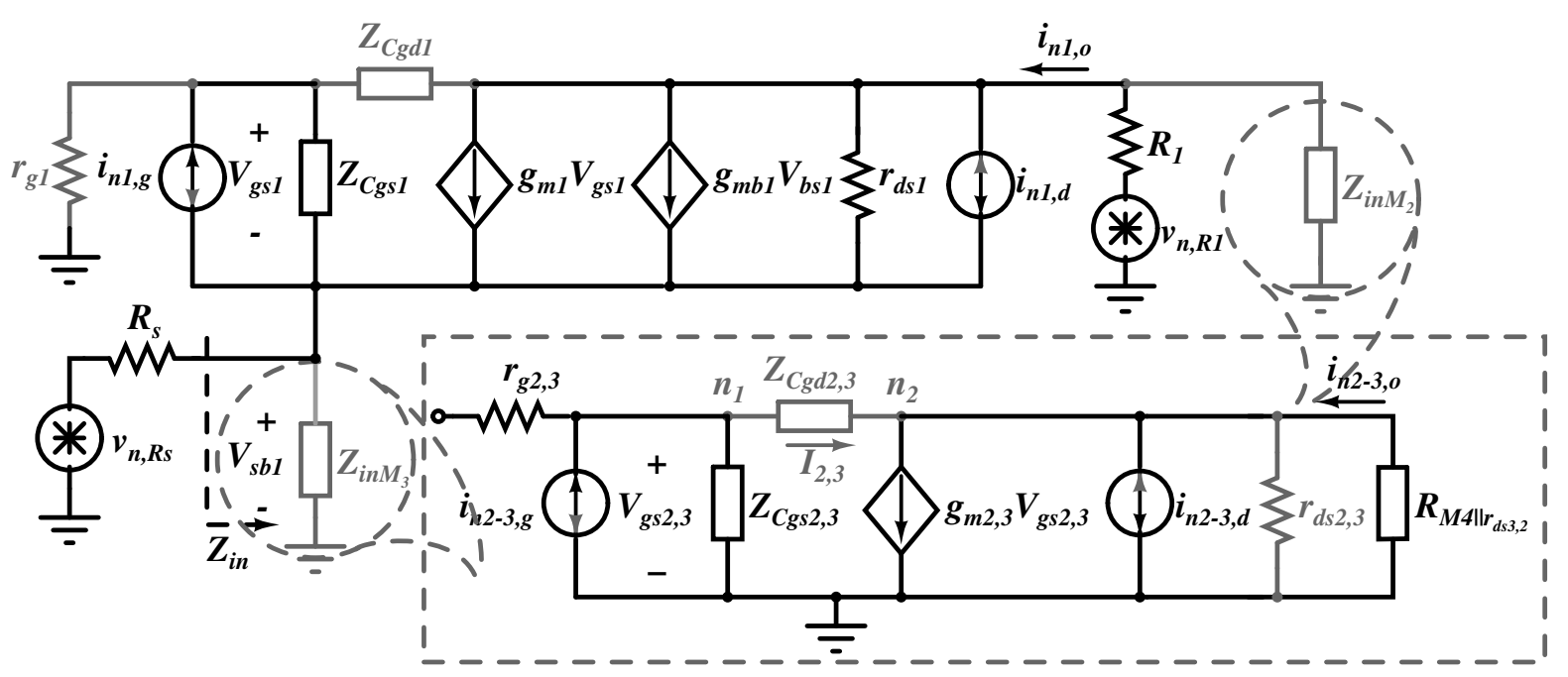

Figura 3.3: Modelo do $L N A$ de banda larga para a análise de ruído.

ruído total pode ser escrito como se segue:

$$
F_{L N A}=1+\frac{\overline{i_{n M 1, o}^{2}}}{\overline{i_{\overline{v_{n, R s}^{2}} o}^{2}}}+\frac{\overline{i_{\overline{v_{n, R 1}^{2}}}^{2}}}{\overline{i_{\overline{v_{n, R s}^{2}}}^{2}}}+\frac{\overline{i_{n 2, o}^{2}}}{\overline{i_{\overline{v_{n, R s}^{2}}}^{2}}}+\frac{\overline{i_{n 3, o}^{2}}}{\overline{i_{v_{n, R s}^{2}}^{2}}}
$$

onde $\overline{i_{n M 1, o}^{2}}$ e $\overline{i_{v_{n, R s}^{2}}^{2}}$ correspondem aos valores quadrático médio das correntes de ruído referidas à sáida, produto dos dispositivos ruídosos presentes no estágio de entrada $\left(M_{1}\right.$ e $R_{1}$ respectivamente). Por outra parte, $\overline{i_{n 2, o}^{2}}$ e $\overline{i_{n 3, o}^{2}}$ são os valores quadrático médio das correntes de ruído referidas à saída devido aos transistores $M_{2}$ e $M_{3}$. Finalmente, $\overline{i_{\bar{v}, R s}^{2}}$ é o valor quadrático médio da corrente de ruído referida à saída, produto da tensão de ruído do resistor da fonte de sinal de entrada (equação (2.34)).

Os valores quadrático médio das correntes de ruído referidas à saída produto do estágio de porta comum são calculados da seguinte forma:

$$
\begin{gathered}
\overline{i_{n M 1, o}^{2}}=\overline{\left|-i_{n 1, o} R_{1} G_{M 2}+i_{n 1, o} R_{s} G_{3}\right|^{2}}=\overline{\left|i_{n 1, o}\left(R_{S} G_{3}-R_{1} G_{M 2}\right)\right|^{2}} \\
\overline{i_{\overline{v_{n, R 1}^{2}} o}^{2}}=\overline{v_{n R 1, o}^{2}}\left|G_{M 2}\right|^{2}
\end{gathered}
$$

onde $G_{M 2}$ e $G_{3}$ são os ganhos de transcondutância dos estágios fonte comum anteriormente calculados. $R_{1}$ e $R_{S}$ são as resistências de carga do estágio porta comum e da fonte de sinal respectivamente. $i_{n 1, o}$ é a corrente de ruído através de $M_{1}$ (figura 3.3), e $\overline{v_{n R 1, o}^{2}}$ corresponde ao valor quadrático médio da tensão de ruído do resistor $R_{1}$.

Substituindo as equações (3.46) e (3.47) em (3.45), e evidenciando a corrente de ruído de 
$M_{1}$, a equação (3.45) pode ser escrita como:

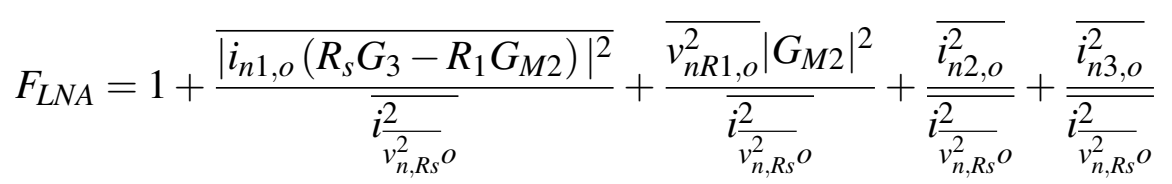

e se,

$$
R_{s} G_{3}=R_{1} G_{M 2}
$$

entao contribuição de ruído do transistor $M_{1}$ é anulada ou cancelada, e o fator de ruído pode-se expressar por meio da equação (3.50).

$$
F_{L N A}=1+\frac{\overline{v_{n R 1, o}^{2}}\left|G_{M 2}\right|^{2}}{\overline{i_{v_{n, R s}^{2}}^{2}}}+\frac{\overline{i_{n 2, o}^{2}}}{\overline{\bar{v}_{n, R s}^{2}} o}+\frac{\overline{i_{n 3, o}^{2}}}{\overline{i \overline{v_{n, R s}^{2}} o}}
$$

Ainda depois de conhecer que a contribuição de ruído do transistor do estágio de entrada pode ser cancelada, é importante conhecer essa contribuição porque podem existir alguns casos em que o cancelamento não possa ser totalmente executado.

Usando o modelo da figura 3.3, e fazendo a soma das correntes no nó de saída do transistor $M_{1}$, a corrente de ruído $\left(i_{n 1, o}\right)$ pode ser representada como se segue:

$$
i_{n 1, o}=i_{n 1, d}+\left(g_{m 1}+g_{m b 1}\right) V_{g s 1}+\frac{V_{g s 1}-R_{1} i_{n 1, o}}{r_{d s 1}}
$$

e evidenciando essa corrente e a tensão porta-fonte e obtida a equação (3.52).

$$
\left(R_{1}+r_{d s 1}\right) i_{n 1, o}=r_{d s 1} i_{n 1, d}+\left[1+\left(g_{m 1}+g_{m b 1}\right) r_{d s 1}\right] V_{g s 1}
$$

Por outro lado, recorrendo a malha de entrada é isolada a tensão porta fonte como mostrado na equação (3.53) e posteriormente substituída em (3.52) para obter a expressão (3.54).

$$
\begin{gathered}
V_{g s 1}=\frac{R_{s} Z_{C g s 1}}{R_{s}+Z_{C g s 1}}\left(i_{n 1, g}-i_{n 1, o}\right) \\
\left(R_{1}+r_{d s 1}\right) i_{n 1, o}=r_{d s 1} i_{n 1, d}+\left[1+\left(g_{m 1}+g_{m b 1}\right) r_{d s 1}\right] \frac{R_{s} Z_{C g s 1}}{R_{s}+Z_{C g s 1}}\left(i_{n 1, g}-i_{n 1, o}\right)
\end{gathered}
$$

A expressão anterior é tratada a modo de evidenciar a corrente de ruído total do transistor, 
e as correntes de ruído da porta e do canal do mesmo.

$$
\left\{R_{1}+r_{d s 1}+\frac{R_{s} Z_{C g s 1}\left[1+\left(g_{m 1}+g_{m b 1}\right) r_{d s 1}\right]}{R_{s}+Z_{C g s 1}}\right\} i_{n 1, o}=r_{d s 1} i_{n 1, d}+\frac{R_{s} Z_{C g s 1}\left[1+\left(g_{m 1}+g_{m b 1}\right) r_{d s 1}\right]}{R_{s}+Z_{C g s 1}} i_{n 1, g}
$$

Usando a equação (3.55), a corrente de ruído do transistor $M_{1}$ é isolada, e a impedância de entrada usando a equação (3.10) é posta em evidência.

$$
i_{n 1, o}=\frac{Z_{i n}}{\left(R_{1}+r_{d s 1}\right)\left(R_{s}+Z_{i n}\right)}\left\{\frac{r_{d s 1}\left(R_{s}+Z_{C g s 1}\right)}{Z_{C g s 1}} i_{n 1, d}+R_{s}\left[1+\left(g_{m 1}+g_{m b 1}\right) r_{d s 1}\right] i_{n 1, g}\right\}
$$

Por último, usando a equação (3.23) em (3.56), é possível evidenciar o ganho de transcondutância do estágio $\left(G_{M 1}\right)$, e expressar a corrente de ruído por meio da equação seguinte

$$
i_{n 1, o}=\frac{r_{d s 1}\left|G_{M 1}\right|\left(R_{s}+Z_{C g s 1}\right)}{Z_{C g s 1}\left[1+\left(g_{m 1}+g_{m b 1}\right) r_{d s 1}\right]} i_{n 1, d}+R_{S}\left|G_{M 1}\right| i_{n 1, g}
$$

Conhecendo a corrente de ruído de $M_{1}$, o seu valor quadrático médio pode ser calculado com (2.29), e posteriormente a sua contribução ao fator de ruído total pode ser calculada usando (3.48).

Uma vez que a contribuição de ruído do transistor de entrada é estimada, em seguida, para terminar a formulação do estágio de porta comum, a contribuição do resistor $R_{1}$ é calculada e descrita pelas equações (3.58) e (3.59).

$$
\begin{gathered}
F_{R_{1}}=1+\frac{\overline{v_{n R 1, o}^{2}}\left|G_{M 2}\right|^{2}}{\overline{\bar{v}_{n, R s}^{2}}} \\
F_{R_{1}}=1+\frac{\left|G_{2}\right|^{2} R_{1}}{\left|G_{L N A}\right|^{2} R_{s}}
\end{gathered}
$$

De forma análoga que para a análise de pequenos sinais, os transistores $M_{2}$ e $M_{3}$ são analisados usando o mesmo modelo, mostrado na parte inferior da figura 3.3. A análise começa com o cálculo da soma das correntes no nó $n_{2}$,

$$
i_{n 2-3, o}=i_{n 2-3, d}+g_{m 2,3} V_{g s 2,3}-I_{2,3}
$$

depois, a corrente $I_{2,3}$ é substituída usando o teorema de Miller para colocar em evidência a 
tensão porta fonte,

$$
i_{n 2-3, o}=i_{n 2-3, d}+\left(g_{m 2,3}-\frac{1-A_{m 2,3}}{Z_{C g d 2,3}}\right) V_{g s 2,3}
$$

e posteriomente evidenciar o ganho de transcondutância usando (3.32) e (3.33), obtendo uma expressão para a corrente de ruído total em função da tensão de porta-fonte dos transistores.

$$
i_{n 2-3, o}=i_{n 2-3, d}+G_{2,3} V_{g s 2,3}
$$

Analisando o nó de entrada pode-se isolar a tensão porta-fonte dos transistores. Igual do que na formulação do ganho, é assumido que $Z_{i n M 2,3}>>r_{g 2,3}$ pelas razões já expostas.

$$
V_{g s 2,3}=\frac{Z_{i n M 2,3}-r_{g 2,3}}{Z_{i n M 2,3}} r_{g 2,3} i_{n 2-3, g} \approx r_{g 2,3} i_{n 2-3, g}
$$

Consequência do anterior, e substituindo (3.63) em (3.62) as correntes de ruído para os transistores dos estágios fonte-comum podem ser calculadas da seguinte forma:

$$
\begin{aligned}
& i_{n 2, o}=i_{n 2, d}+G_{2} r_{g 2} i_{n 2, g} \\
& i_{n 3, o}=i_{n 3, d}+G_{3} r_{g 3} i_{n 3, g}
\end{aligned}
$$

é considerando que $G_{2,3} r_{g 2,3} i_{n 2-3, g}<<i_{n 2-3, d}$ são obtidas as aproximações (3.66) e (3.67).

$$
\begin{aligned}
& i_{n 2, o} \approx i_{n 2, d} \\
& i_{n 3, o} \approx i_{n 3, d}
\end{aligned}
$$

Tomando as expressões (3.64) e (3.65) e representá-las na forma definida pela equação (2.29) obtém-se:

$$
\overline{i_{n 2-3, o}^{2}}=\overline{i_{n 2-3, d}^{2}}+\left|G_{2,3}\right|^{2} r_{g 2,3}^{2} \overline{i_{n 2-3, g}^{2}}+2 \operatorname{Re}\left\{G_{2,3} r_{g 2,3}(-j 0,395)\right\} \sqrt{\overline{i_{n 2-3, d}^{2}} \overline{i_{n 2-3, g}^{2}}}
$$

e substituindo esses valores quadrático médio usando (2.28), (2.30), (2.31), (2.34) e (3.48) é possível estimar o fator de ruído dos estágios fonte comum.

$$
F_{M 2,3}=1+\frac{\omega^{2} C_{g s 2,3}^{2} \gamma}{g_{m 2,3} R_{S}\left|G_{L N A}\right|^{2}}\left[\left(\frac{g_{m 2,3}^{2}}{\omega^{2} C_{g s 2,3}^{2}}\right) \frac{1}{\alpha}+r_{g 2,3}\left|G_{2,3}\right|^{2} \frac{\gamma \delta}{5 \alpha}-0,79\left(\frac{g_{m 2,3}^{2} r_{g 2,3}}{\omega C_{g s 2,3}}\right) \sqrt{\frac{\delta}{5 \gamma}}\right]
$$


Assumindo que o ruído do canal do transistor é dominante (equações (3.66) e (3.67)), uma outra estimativa para o fator de ruído pode ser obtida.

$$
F_{M 2,3}=1+\left(\frac{g_{m 2,3}}{R_{S}\left|G_{L N A}\right|^{2}}\right) \frac{\gamma}{\alpha}
$$

De acordo com a equação (3.70), o comportamento em frequência do fator de ruído é definido pelo ganho de transcondutância, que por sua vez varía devido à impedância de entrada.

Utilizando a aproximação descrita em (3.70), e assumindo que o ruído do transistor de entrada é cancelado, então o fator de ruído total do $L N A$ pode ser calculado substituindo essas aproximações em (3.50).

$$
F_{L N A}=1+\frac{1}{\left|G_{L N A}\right|^{2} R_{S}}\left[\left|G_{2}\right|^{2} R_{1}+\left(g_{m 2}+g_{m 3}\right) \frac{\gamma}{\alpha}\right]
$$

Por último, assumindo que a entrada está casada, e substituindo os ganhos de transcondutância total e de $M_{2}$ pelas equações (3.42) e (3.36), o fator de ruído total é expresso da seguinte forma:

$$
F_{L N A}=1+\frac{R_{s}}{R_{1}}+\left[\left(\frac{1}{g_{m 2} R_{1}}\right) \frac{R_{s}}{R_{1}}+\frac{1}{g_{m 3} R_{s}}\right] \frac{\gamma}{\alpha}
$$

e pode ser simplicado para obter (3.73) usando de novo a condição para o cancelamento do ruído do estágio de entrada.

$$
F_{L N A}=\left(1+\frac{R_{s}}{R_{1}}\right)\left(1+\frac{1}{g_{m 2} R_{1}} \frac{\gamma}{\alpha}\right)
$$

\subsection{Considerações para aplicar programação geométrica no projeto do $L N A$ de banda larga}

Nas seções anteriores é apresentada a formulação dos principais parâmetros de desempenho de um LNA de banda larga com cancelamento de ruído. Este processo de formulação matemática é feito de modo a obter as equações que representam o comportamento do circuito, que posteriormente são adaptadas para representar o problema de projeto do circuito como um programa geométrico (GP). Para fazer isso, várias considerações são necessárias a fim de formular um PG padrão útil com sucesso.

Neste projeto, a linearidade ea modelagem do transistor são tratados como no capítulo 
anterior. Para a linearidade é definida uma restrição na tensão de polarização dos transistores $M_{2}$ e $M_{3}$, de modo a ter voltagens de saturação altos. Por outro lado, a modelagem do transistor é feita em função das variáveis definidas na equação (2.58). Para este projeto específico, são gerados modelos para a transcondutância de todos os transistores e as tensões porta-fonte. Também é modelada a capacitância porta-fonte dos transistores fonte comum.

Para o projeto do LNA de banda larga, a função objectivo é también uma função multiobjetivo. Esta função é formada pelo fator de ruído e as relações entre a tensão de alimentação e as tensões dreno-fonte, além da relação entre a corrente de saída e as correntes dos estágios de fonte comum. O fator de ruído é tomado a partir da equação (3.71), assumindo que: o ganho transcondutância do estágio fonte comum formado pelo transistor $M_{2}$ corresponde à transcondutância do dispositivo (3.36), e que a capacitância porta-fonte e a resistência drenofonte de $M_{1}$ são despresíveis. Além disso, considera-se a condição de cancelamento de ruído (equação (3.49)) e se desprezan os efeitos da transcondutância do corpo de $M_{1}$ e a resistência de sáido do mesmo. Consequência do anterior, a impedância de entrada é escrita como (3.14) e, em seguida, o ganho de transcondutância pode-se simplificar a:

$$
\left|G_{L N A}\right| \approx \frac{g_{m 2} R_{1}}{R_{s}}
$$

e substituíndo (3.74) em (3.71) o fator de ruído adaptado para o PG correponde à equação (3.75).

$$
F_{L N A} \approx 1+\frac{R_{s}}{g_{m 2}^{2} R_{1}^{2}}\left[g_{m 2}^{2} R_{1}+\left(g_{m 2}+g_{m 3}\right) \frac{\gamma}{\alpha}\right]
$$

Por outro lado, as relações entre a tensão de alimentação e as diferentes tensões drenofonte, e a relações entre a corrente de saída e as corrente dos estágios de fonte comum, são implementadas para garantir que o circuito satisfaz as leis de Kirchhoff.

Outra consideração é limitar a razão entre as transcondutâncias dos transistores dos estágios fonte comum e o transistor de saída, através da definição de uma constante $K_{\text {adgm }}$.

A última consideração consiste em assumir que as impedâncias de entrada dos transistores $M_{2}$ e $M_{3}$ correspondem à impedância de sua capacitância porta-fonte. Assim, se uma frequência máxima para garantir o acoplamento da entrada é definida $\left(\omega_{\max }\right)$, então uma constante $K_{R}$ também pode ser definida a fim de manter o efeito destas capacitâncias baixo até o valor dessa frequência $\left(Z_{C g s 2,3} \geq K_{R} R_{1, s}\right.$ na banda). A constante definida tem uma restrição arbitraria de $K_{R}>5$, e a frequência máxima é introduzida como uma especificação. 


\subsection{Resumo da formulação de projeto do $L N A$ de banda larga}

Nas figuras 3.4(a) até 3.4(d) são apresentados os gráficos comparativos entre as diferentes equações obtidas na formulação matemática do circuito, e os resultados de um LNA de teste projetado para atingir aproximadamente $1,5 \mathrm{GHz}$ de largura de banda, usando um processo de $0,18 \mu \mathrm{m}$ da $I B M$. Nos gráficos o subscrito PG representa às equações usadas no programa geométrico formulado.

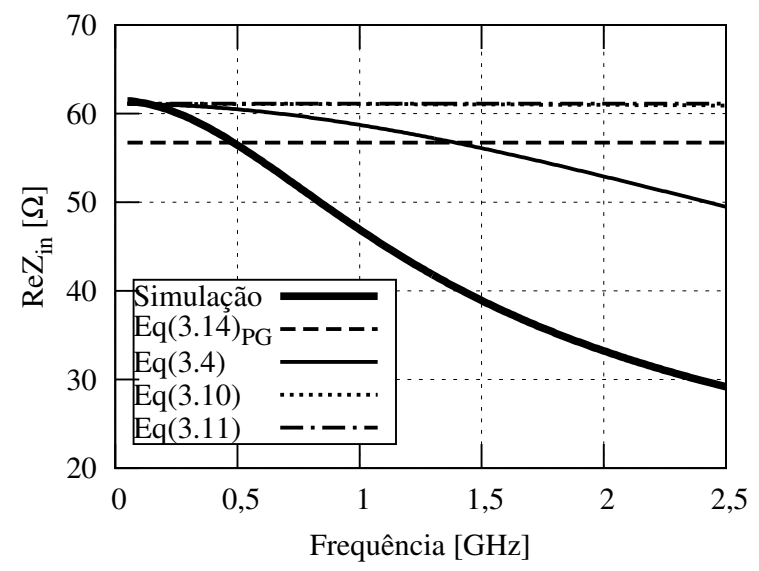

(a)

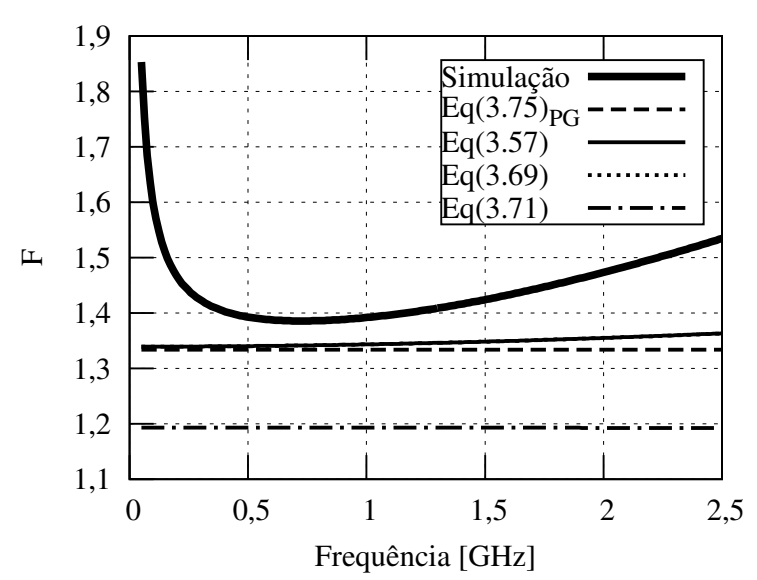

(c)

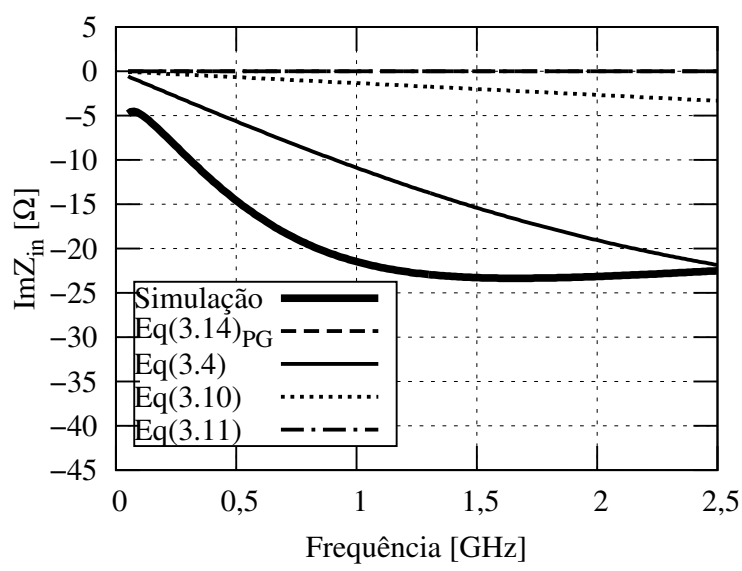

(b)

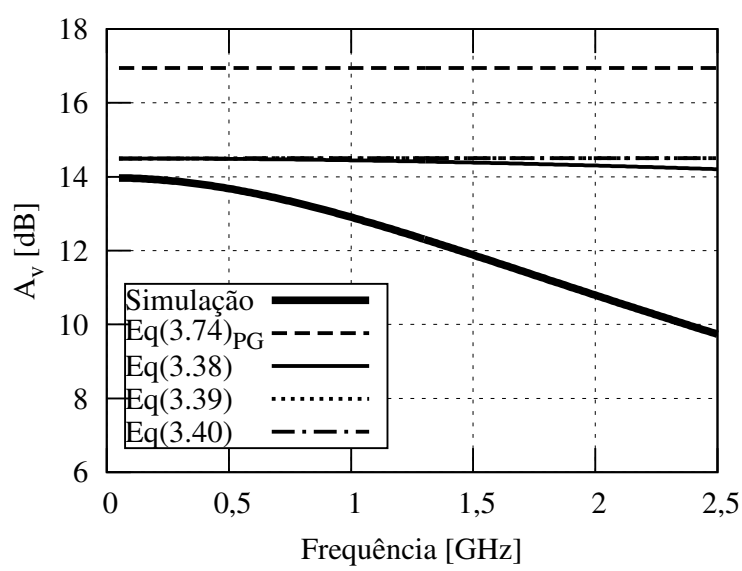

(d)

Figura 3.4: Comparação das equações formuladas: (a) Parte real da impedância de entrada; (b) Parte imaginária da impedância de entrada; (c) Fator de ruído; (d) Ganho de tensão.

As figuras 3.4(a) e 3.4(b) mostram a parte real e imaginária da impedância de entrada do circuito. A partir dos gráficos pode-se concluir que as impedâncias de entrada dos estágios fonte comum (especialmente o transistor $M_{3}$ ), estão afetando consideravelmente o valor da impedância de entrada total do $L N A$. Esse efeito é resultado do compromisso entre obter um ganho alto, garantir o cancelamento do ruído e manter uma capacitancia porta-fonte baixa na banda de operação. 
Na figura 3.4(c) é apresentado o fator de ruído do circuito. Para este caso particular, o LNA é projetado para garantir o cancelamento do ruído de acordo com a equação (3.49). Assim, no gráfico pode ser observado que todas as estimativas do fator de ruído estão perto do valor da simulação se o princípio de cancelamento de ruído é aplicado. O aumento do fator de ruído nas frequências mais baixas é produto do ruído flicker que começa a afetar. Por outro lado, o aumento do ruído nas frequências maiores é producto da diferença no comportamento da impedância de entrada entre as equações é a simulação. Além disso, é importante notar que a figura de ruído obtida está abaixo $3 \mathrm{~dB}$ em toda a faixa plotada, e que de acordo com o capítulo 1 , é uma das desvantangens de usar estágios porta comum que é resolvido com a técnica de cancelamento de ruído. Por último, ao igual do que no circuito de banda estreita, nos cálculos feitos para plotar as equações é usado $\gamma=\frac{2}{3}$.

A figura 3.4(d) é gerada usando a equação (3.43), considerando como impedância de saída equivalente à resistência de carga $\left(R_{L}\right)$ em paralelo com a soma das resistências dreno-fonte de $M_{4}\left(r_{d s 4}\right)$ e o paralelo de $r_{d s 2}$ e $r_{d s 3}$. No caso do programa geométrico a resistência de saída assumida é $R_{L}$. Consequência disso o ganho usado no PG está superestimado em comparação à simulação e as equações mais precisas. $\mathrm{O}$ ganho simulado tem uma largura de banda menor devido à diferença da impedância de entrada e as capacitâncias que estão criando pólos em diferentes nós do circuito, e que não foram consideradas nas análises desenvolvidos no presente capítulo. As análises apresentadas estão focadas em garantir o casamento da impedância de entrada e o cancelamento de ruído em uma determinada faixa de frequência, e como pode ser visto, os ganhos são calculados assumindo uma saída puramente resistiva.

Para resumir, as diferentes equações formuladas no capítulo permitem estimar um ponto de partida para projetar um LNA de banda larga usando a técnica de cancelamento de ruído. As análises desenvolvidas estão focadas em obter uma boa estimativa da impedância de entrada com baixo nível de ruído. Além disso, em contraste com o circuito de banda estreita, erros maiores são admitidos porque é analisada uma banda de operação maior. No caso do banda estreita é importante garantir uma boa estimativa dos parâmetros de desempenho na frequência central de operação. No entanto, demonstra-se que as equações extraídas permitem formular o problema de projeto do LNA de banda larga analisado como um programa geométrico. 


\subsection{Forma padrão do PG para o $L N A$ de banda larga}

Igual ao capítulo anterior, após as diferentes considerações necessárias para aplicar a programação geométrica são feitas, um exemplo de programa geométrico padrão incluindo as principais restrições pode ser formulado de acordo com a expressão (2.2).

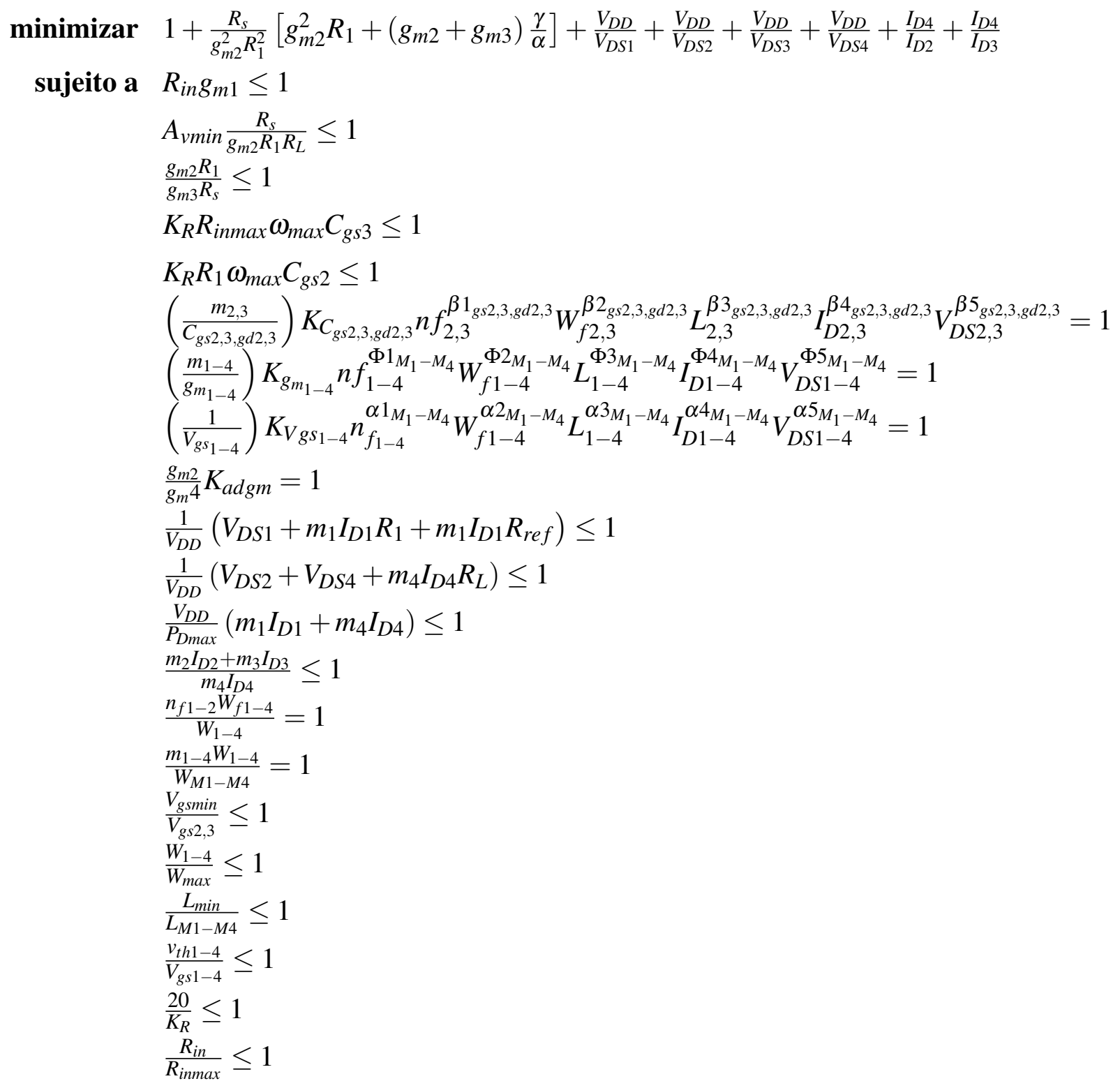




\section{Projeto, simulação e fabricação dos LNAs}

Durante os capítulos anteriores é formulado o problema de projeto de dois tipos de amplificadores de baixo ruído ( $L N A)$ como um problema de otimização. Diferentes análises são utilizadas para extrair expressões que representam o comportamento do circuito com uma precisão adequada, e essas expressões são implementadas em um programa geométrico para posteriormente obter o dimensionamento dos circuitos. Neste capítulo são apresentados os resultados de resolver esses programas geométricos, e alguns testes feitos para validar os resultados usando cinco processos CMOS diferentes. Para o circuito de banda estreita é apresentado um script escrito para automatizar o projeto e realizar alguns testes. Por outro lado, para o circuito de banda larga são apresentados os resultados dos diferentes $L N A$ s, e os resultados de um misturador de baixo ruído utilizando o estágio de cancelamento de ruído como estágio de transcondutância (este último usando um processo de 0,18 $\mu \mathrm{m} C M O S$ ). Em seguida, os layouts e resultados pós-layout de quatro circuitos diferentes fabricados são mostrados e alguns resultados das medições são discutidos.

Como tem sido mencionado, os testes feitos neste trabalho envolvem cinco processos CMOS diferentes, e cada um deles tem algumas restrições importantes relatadas na tabela 4.1. Os números entre colchetes representam um intervalo de valores e, em alguns casos, o passo obrigatorio (por exemplo, $n_{f}=$ [2:02:16] representa que o número de dedos no transistor permitido pela $X F A B$ é entre dois e dezesseis, em incrementos de dois). A barra é usada para mostrar duas possibilidades (por exemplo, $W_{f}=5 / 10$ indica que no transistor da $A M S$ é possível usar somente uma largura de dedo igual a cinco ou dez micrômetros). Além disso, algumas suposições a respeito dos indutores são feitas com o fim de diminuir os erros quando os circuitos sejam simulados utilizando modelos de indutor complexos, como aqueles incluídos nos kits de projeto, ou aqueles gerados com ferramentas como ASITIC e VPCD. 
Tabela 4.1: Restrições dos dispositivos segundo o processo usado.

\begin{tabular}{||c||ccccccc||}
\hline Foundry & Proc. $[\mu \mathrm{m}]$ & $V_{D D}[\mathrm{~V}]$ & $n_{f}$ & $W_{f}[\mu \mathrm{m}]$ & $L[\mu \mathrm{m}]$ & Ind.[nH] & $\mathrm{Q}$ \\
\hline \hline AMS & 0,35 & 3,3 & {$[1: 20]$} & {$[5 / 10]$} & 0,35 & {$[0,5: 7]$} & 4,5 \\
TowerJazz & 0,18 & 1,8 & {$[4: 2: 128]$} & {$[1,5: 8]$} & {$[0,18: 0,5]$} & {$[0,5: 9]$} & 8 \\
XFAB & 0,18 & 1,8 & {$[2: 2: 16]$} & {$[1,8: 10]$} & {$[0,18: 0,3]$} & {$[0,5: 10]$} & 10 \\
$I B M$ & 0,18 & 1,8 & {$[1: 24]$} & {$[0,22: 10]$} & {$[0,18: 10]$} & {$[0,5: 10]$} & 9 \\
$I B M$ & 0,13 & {$[1,2 / 1,5]$} & {$[1: 20]$} & {$[0,16: 5]$} & {$[0,12: 5]$} & {$[0,5: 12]$} & 11 \\
\hline
\end{tabular}

\subsection{Resultados do LNA de banda estreita}

No capítulo 2, o projeto de um amplificador de baixo ruído de banda estreita é formulado como um problema de otimização na forma padrão de um programa geométrico. Nesta seção, algumas especificações de projeto são definidas, os modelos do transistor gerados e, em seguida, o problema de optimização é resolvido usando um software adequado disponível. Posteriormente, simulações ao nível de circuito são executadas a fim de verificar a precisão das equações extraídas e os modelos dos transistores. Neste caso, o problema de otimização é resolvido usando o $C V X$ e as simulações são feitas usando o Hspice da Synopsys ou o Eldorf da Mentor Graphics.

\subsubsection{Automação de projeto}

De acordo com o mencionado no inicio da seção, um conjunto de especificações são definidas com a finalidade de realizar diferentes testes, como projetar amplificadores com diferentes frequências de operação. No entanto, mesmo se o projeto é assistido por computador, a realização de testes requer com frequência de intervenção do projetista, já que algumas partes do fluxo de projeto não estão relacionadas. Isto acontece porque as mesmas ferramentas não são usadas em etapas consecutivas do fluxo, e porque pelo geral diferentes ferramentas são necessárias. Como consequência, Propõe-se uma metodologia de projeto ea criação de um script que automatiza o fluxo de através do compartilhamento de dados entre as diferentes ferramentas usadas.

O diagrama de fluxo da metodologia proposta é mostrado na figura 4.1. O script principal desenvolvido é responsável pela ligação e compartilhamento de dados entre os scripts das diferentes etapas do diagrama. Quase todos os blocos ou estágios no diagrama são representados ou executados por um script diferente. Inicialmente, o fluxo tem duas entradas, uma representada por um arquivo de tecnologia que contém informações do processo de fabricação (dados da tabela 4.1), e outra inserida pelo projetista com as especificações de projeto, o 




Figura 4.1: Diagrama de fluxo da metodologia de projeto usando programação geométrica.

espaço de projeto a ser analisado e o setup das simulações. No caso o projetista introduza uma restrição para um dispositivo que exceda o valor permitido pela tecnologia, esta restrição será limitada segundo o arquivo de tecnologia. Na seguinte etapa do fluxo, os modelos dos 
diferentes parâmetros do transistor relatados no capítulo 2 são gerados. Posteriomente, esses modelos são usados na solução de diferentes programas geométricos dependendo das ralações $\left(g_{m 1} / g_{m 2}\right)$ introduzidas pelo projetista. Depois de cada solução, as restrições são redefinidas para forçar a obtenção de um número inteiro de dedos do transistor e de dispositivos em paralelo. Uma vez que todas as soluções são armazenadas, a melhor solução é escolhida de modo que a relação $g_{m 1} / g_{m 2}$ ótima é conhecida. Se o espaço de projeto definido é grande, o modelamento do transistor vai introduzir erros consideráveis, por tanto, o espaço é reduzido em torno do ponto ótimo obtido e as etapas anteriores são repetidas para reduzir esses erros. Após concluir as etapas de otimização, as dimensões dos dispositivos obtidas são exportadas para um netlist e a verificação através de simulações de circuito começa. Finalmente, os resultados das simulações devem atingir as especificações introduzidas.

É importante notar que durante no fluxo proposto, o projetista intervém só na primeira etapa introduzindo as especificações de projeto, e nos ajustes finais se são necessários.

\subsubsection{Resultados dos diferentes $L N A$ s projetados}

Aproveitando a metodologia de automação de projeto proposta, são realizados diferentes testes definindo uma série considerações e especificações de projeto. As especificações são as mesmas para todas as tecnologias usadas nos testes, mas a frequência central de operação muda de um teste para o outro. A execução de cada teste demora em média cerca de 16 minutos seguindo o fluxo de projeto previamente definido, e as simulações são realizadas utilizando o circuito da figura 4.2, onde $C_{\text {in }}$ e $C_{\text {out }}$ têm valor de $20 \mathrm{pF}$ e $R_{\text {bias }}$ de $12 \mathrm{~K} \Omega$. A tensão de polarização e as dimensões dos demais dispositivos são calculadas utilizando o programa geométrico. Por outro lado, o $P_{I I P 3}$ é simulado considerando dois tons separados $1 \mathrm{MHz}$.

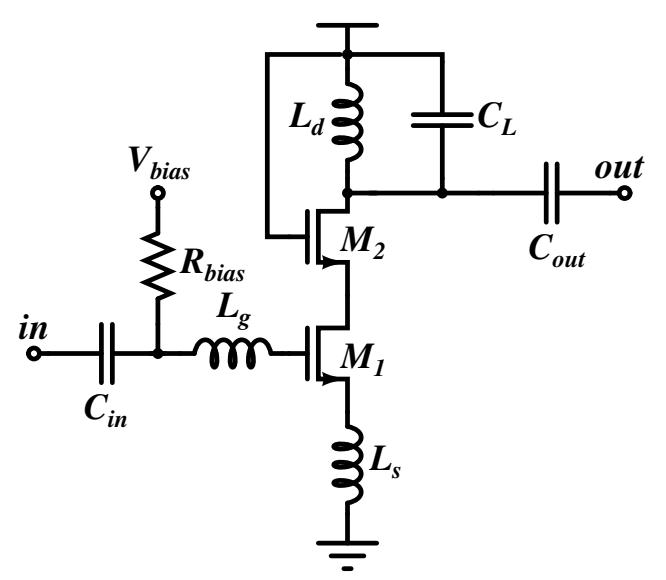

Figura 4.2: Esquemático do $L N A$ de banda estreita usando nas simulações. 
Tabela 4.2: Resultados dos PGs resolvidos para diferentes tecnologias e frequências de operação.

\begin{tabular}{|c|c|c|c|c|c|c|c|c|}
\hline Tipo & $\mathrm{F}$ & $\mathrm{NF}[\mathrm{dB}]$ & $\operatorname{Re} Z_{\text {in }}[\Omega]$ & $\operatorname{Im} Z_{\text {in }}[\Omega]$ & $S_{11}[\mathrm{~dB}]$ & $A_{v}[\mathrm{~dB}]$ & $P_{D}[\mathrm{~mW}]$ & $P_{I I P 3}[\mathrm{dBm}]$ \\
\hline Spec. & $\overline{\mathrm{min}}$ & $\overline{\min }$ & [41:61] & $\overline{\approx 0}$ & $\overline{s-20}$ & $\geq 20$ & $\overline{s 15}$ & $\overline{\mathrm{NA}}$ \\
\hline \multicolumn{9}{|c|}{ TowerJazz para $f_{o}=1,5 \mathrm{GHz}$} \\
\hline PG & 1,49 & 1,73 & 41 & $-0,3$ & $-20,12$ & 23,9 & 9,89 & NA \\
\hline Sim. & 1,31 & 1,17 & 42,4 & $-2,37$ & $-21,29$ & 24 & 10,27 & $-4,5$ \\
\hline \multicolumn{9}{|c|}{$X F A B$ para $f_{o}=1,8 \mathrm{GHz}$} \\
\hline PG & 1,52 & 1,84 & 45,59 & $-0,65$ & $-26,54$ & 27,31 & 10,5 & NA \\
\hline Sim. & 1,38 & 1,41 & 44,84 & $-0,67$ & $-25,11$ & 26,5 & 10,1 & $-2,5$ \\
\hline \multicolumn{9}{|c|}{$A M S$ para $f_{o}=2,45 \mathrm{GHz}$} \\
\hline $\mathrm{PG}$ & 1,92 & 2,84 & 61 & 0,01 & -20 & 22,4 & 12,2 & NA \\
\hline Sim. & 1,91 & 2,8 & 62,5 & 2,5 & $-18,8$ & 21,6 & 12,9 & $-0,1$ \\
\hline \multicolumn{9}{|c|}{$I B M 018$ para $f_{o}=3,5 \mathrm{GHz}$} \\
\hline PG & 1,63 & 2,12 & 51,73 & $-0,3$ & $-35,22$ & 20,96 & 12,3 & NA \\
\hline Sim. & 1,42 & 1,53 & 44,16 & $-1,92$ & $-24,62$ & 20,99 & 11,5 & 2,2 \\
\hline \multicolumn{9}{|c|}{$I B M 013$ para $f_{o}=5 \mathrm{GHz}$} \\
\hline PG & 1,95 & 2,9 & 57,3 & $-1,5$ & $-23,2$ & 20,94 & 6,92 & NA \\
\hline Sim. & 1,56 & 1,9 & 57 & 2,24 & $-23,2$ & 22 & 7,91 & $-4,5$ \\
\hline
\end{tabular}

Na tabela 4.2 se apresentam o conjunto de especificações de projeto inseridas, além dos resultados obtidos para os diferentes parâmetros de desempenho considerados no LNA de banda estreita. Também, são comparados os resultados dos programas geométricos com os resultados das simulações para cinco $L N A$ s projetados em diferentes tecnologias operando em frequências entre $1,5 \mathrm{GHz}$ e $5 \mathrm{GHz}$. Na tabela observa-se que os erros entre os resultados dos programas geométricos e das simulações são baixos, demonstrando que as equações extraídas e as considerações descritas no capítulo 2 são precisas e levam a bons resultados, mesmo sem ajustes. A equação de impedância de entrada considerando a capacitância de porta-dreno do transistor MOS é bastante precisa. No caso da expressão para a figura de ruído, na medida em que o comprimento do canal diminui, o erro entre a equação e o resultado da simulação aumenta. Além disso, o ganho de tensão e os consumo de potência são estimados com boa precisão. A linearidade, medida em termos do ponto de interceptação de terceira ordem $\left(P_{I I P 3}\right)$, não tem uma expressão no PG, mas como descrito no capítulo 2 é considerada colocando uma restrição no ponto de polarização.

Na tabela 4.3 estão indicados os resultados para o dimensionamento dos dispositivos. Pode-se observar que não foram feitos ajustes e que o número de dedos do transistor está de acordo com intervalos definidos na tabela 4.1. Assim, os projetos finais estão prontos para ser implementados usando os kits de projeto e gerar a vista de layout se for necessário. A partir destes resultados, é importante notar que o transistor $M_{2}$ não precisa de ser igual ao transistor 
Tabela 4.3: Dimensões dos dispositivos obtidas nos PGs resolvidos.

\begin{tabular}{|c|c|c|c|c|c|c|c|c|c|}
\hline Transistor & $W_{t}[\mu \mathrm{m}]$ & $n_{f}$ & $W_{f}[\mu \mathrm{m}]$ & $\mathrm{m}$ & $\mathrm{L}[\mu \mathrm{m}]$ & $L_{g}[\mathrm{nH}]$ & $L_{S}[\mathrm{nH}]$ & $L_{d}[\mathrm{nH}]$ & $C_{L}[\mathrm{pF}]$ \\
\hline Spec. & [100:650] & Tech. & Tech. & NA & Tech. & Tech. & Tech. & Tech. & $\leq 5$ \\
\hline \multicolumn{10}{|c|}{ TowerJazz para $f_{o}=1,5 \mathrm{GHz}$} \\
\hline$M_{1}$ & 512,2 & 66 & 7,76 & 1 & 0,18 & \multirow{2}{*}{7,86} & \multirow{2}{*}{0,5} & \multirow{2}{*}{3,25} & \multirow{2}{*}{3,31} \\
\hline$M_{2}$ & 100 & 14 & 7,14 & 1 & 0,35 & & & & \\
\hline \multicolumn{10}{|c|}{$X F A B$ para $f_{o}=1,8 \mathrm{GHz}$} \\
\hline$M_{1}$ & 460,3 & 16 & 9,59 & 3 & 0,18 & \multirow{2}{*}{7,57} & \multirow{2}{*}{0,5} & \multirow{2}{*}{3,7} & \multirow{2}{*}{2} \\
\hline$M_{2}$ & 100 & 10 & 10 & 1 & 0,3 & & & & \\
\hline \multicolumn{10}{|c|}{$A M S$ para $f_{o}=2,45 \mathrm{GHz}$} \\
\hline $\bar{M}$ & 420 & 14 & 10 & 3 & 0,35 & \multirow{2}{*}{6,33} & \multirow{2}{*}{0,5} & \multirow{2}{*}{6,75} & \multirow{2}{*}{0,49} \\
\hline$M_{2}$ & 130 & 13 & 10 & 1 & 0,35 & & & & \\
\hline \multicolumn{10}{|c|}{$I B M 018$ para $f_{o}=3,5 \mathrm{GHz}$} \\
\hline$M_{1}$ & 458 & 24 & 9,54 & 2 & 0,18 & \multirow{2}{*}{2,12} & \multirow{2}{*}{0,5} & \multirow{2}{*}{2} & \multirow{2}{*}{0,92} \\
\hline$M_{2}$ & 100 & 10 & 10 & 1 & 0,35 & & & & \\
\hline \multicolumn{10}{|c|}{$I B M 013$ para $f_{o}=5 \mathrm{GHz}$} \\
\hline$M_{1}$ & 220 & 15 & 4,87 & 3 & 0,23 & \multirow{2}{*}{1,74} & \multirow{2}{*}{0,5} & \multirow{2}{*}{2} & \multirow{2}{*}{0,4} \\
\hline$M_{2}$ & 100 & 20 & 5 & 1 & 0,35 & & & & \\
\hline
\end{tabular}

do estágio de transcondutância, nem ter comprimento mínimo de canal (como é geralmente assumido). O fato de deixar o script analisar e decidir a melhor relação $g_{m 1} / g_{m 2}$, ajuda a encontrar as melhores dimensões para este dispositivo. Essa relação pode ser extraída da tabela 4.4 onde são apresentados os resultados para alguns dos parâmetros do transistor modelados mediante monômios como descrito no capítulo 2. Os erros obtidos entre os resultados da otimização e da extração de parâmetros do transistor durante as simulações são bastante baixos.

Tabela 4.4: Resultados das variáveis do transistor modeladas.

\begin{tabular}{||c||ccccc||}
\hline Tipo & $C_{g s 1}[\mathrm{fF}]$ & $C_{g d 1}[\mathrm{fF}]$ & $g_{m 1}[\mathrm{mS}]$ & $g_{m 2}[\mathrm{mS}]$ & $V_{g s 1}[\mathrm{~V}]$ \\
\hline \hline \multicolumn{5}{|c||}{ TowerJazz para $f_{o}=1,5 \mathrm{GHz}$} \\
\hline PG & 279 & 112,7 & 82,2 & 24,8 & 0,612 \\
Sim. & 279 & 112,7 & 84,2 & 25,1 & 0,61 \\
\hline \multicolumn{5}{|c||}{ XFAB para $f_{o}=1,8 \mathrm{GHz}$} \\
\hline PG & 458 & 170,1 & 67 & 26 & 0,791 \\
Sim. & 480,3 & 179,1 & 67 & 24 & 0,788 \\
\hline \multicolumn{5}{|c||}{ AMS para $f_{o}=2,45 \mathrm{GHz}$} \\
\hline PG & 397,4 & 97,7 & 42 & 18,7 & 0,687 \\
Sim. & 390 & 92,3 & 44,2 & 19,4 & 0,707 \\
\hline \multicolumn{5}{|c||}{ IBM018 para $f_{o}=3,5 \mathrm{GHz}$} \\
\hline PG & 538,2 & 129 & 92,7 & 29,1 & 0,563 \\
Sim. & 541,5 & 134,5 & 89,4 & 26,5 & 0,562 \\
\hline \multicolumn{5}{|c||}{$I B M 013$ para $f_{o}=5 \mathrm{GHz}$} \\
\hline PG & 415 & 68,1 & 60 & 31 & 0,465 \\
Sim. & 430 & 70,5 & 66 & 33 & 0,464 \\
\hline
\end{tabular}


Isto último produto do processo de remodelamento, descrito no fluxo de projeto como uma redução do espaço de projeto em torno do primeiro resultado obtido.

Finalmente, nas figuras 4.3 até 4.7 são mostrados os resultados gráficos para os principais parâmetros de desempenho dos diferentes LNAs projetados e resumidos nas tabelas anteriores. Cada subfigura está composta de três curvas, uma que representa o resultado de simulação, outra o resultado usando a equação aplicada no PG, e a última representa o resultado usando a equação mais completa extraída no capítulo 2. Os diferentes parâmetros apresentados nas figuras seguintes são: no quadrante superior esquerdo é representado o fator de ruído; no quadrante superior direito o ganho de tensão; no quadrante inferior esquerdo está o coeficiente de reflexão de entrada; e no quadrante inferior direito está o gráfico da potência de saída e da intermodulação de terceira ordem, a fim de calcular o ponto de interceptação de terceira ordem referido à entrada. Na maioria dos casos, o coeficiente de reflexão de entrada e o ganho de tensão se comportam de forma muito precisa na frequência de acordo com as expressões estimadas. No entanto, o fator de ruído não é estimado com igual precisão por causa das diferentes aproximações e considerações feitas. Além disso, à medida que aumenta frequência é comum que o comportamento em frequência mude um pouco entre as simulações é as equações.
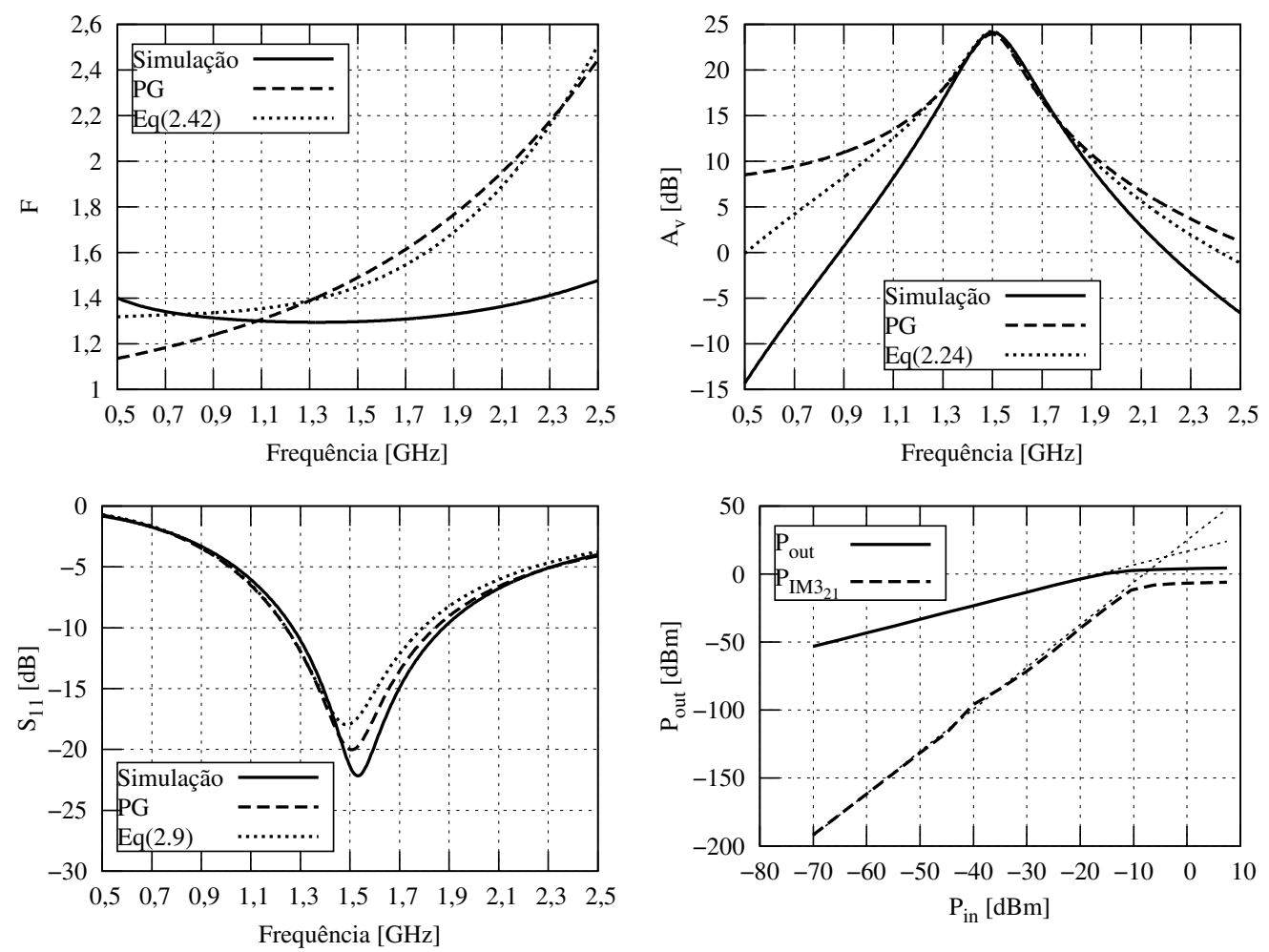

Figura 4.3: Resultados principais para um $L N A$ de banda estreita projetado para $1,5 \mathrm{GHz}$ usando o processo da TowerJazz. 



Figura 4.4: Resultados principais para um $L N A$ de banda estreita projetado para $1,8 \mathrm{GHz}$ usando o processo da $X F A B$.
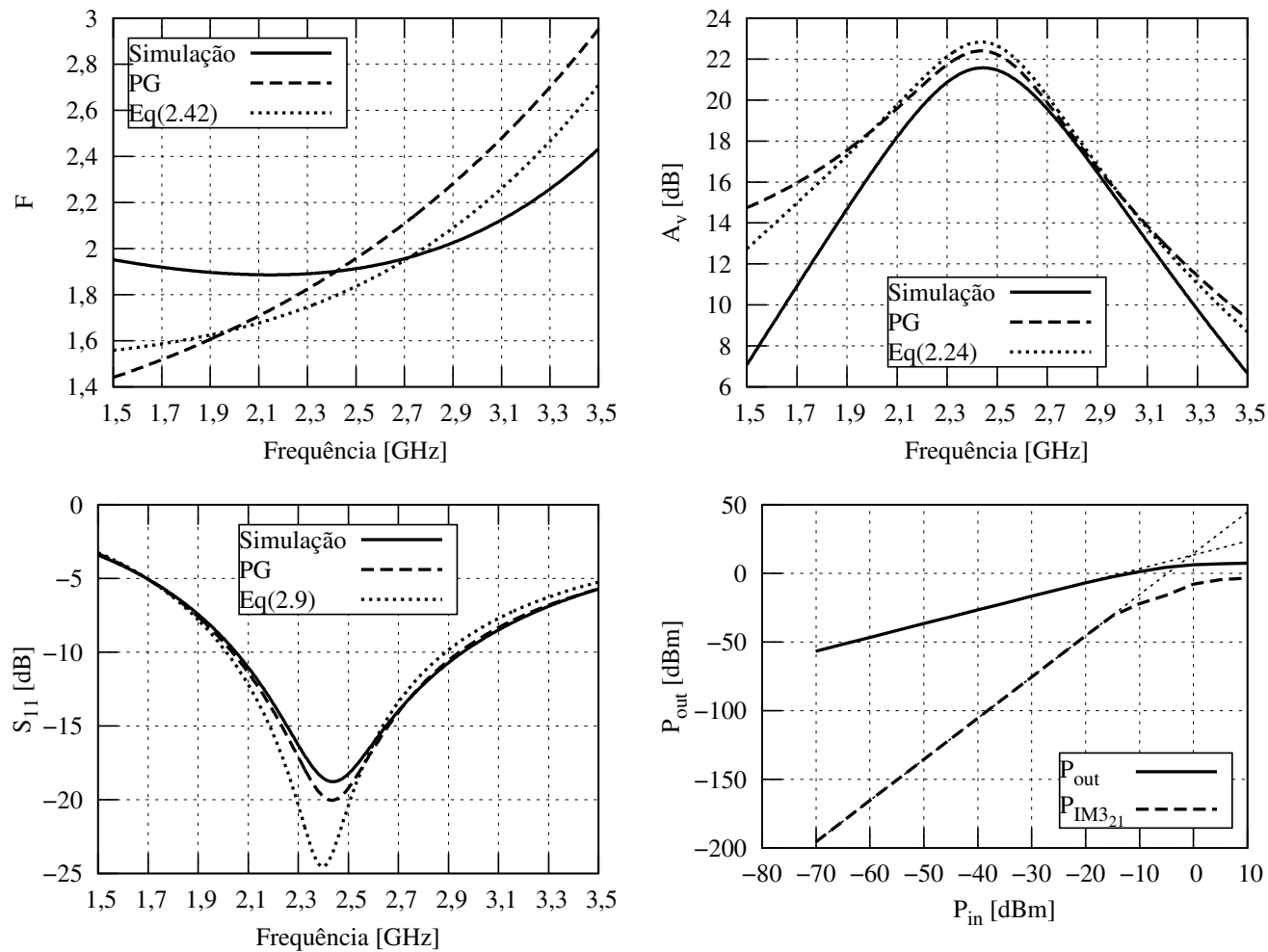

Figura 4.5: Resultados principais para um $L N A$ de banda estreita projetado para $2,45 \mathrm{GHz}$ usando o processo da $A M S$. 

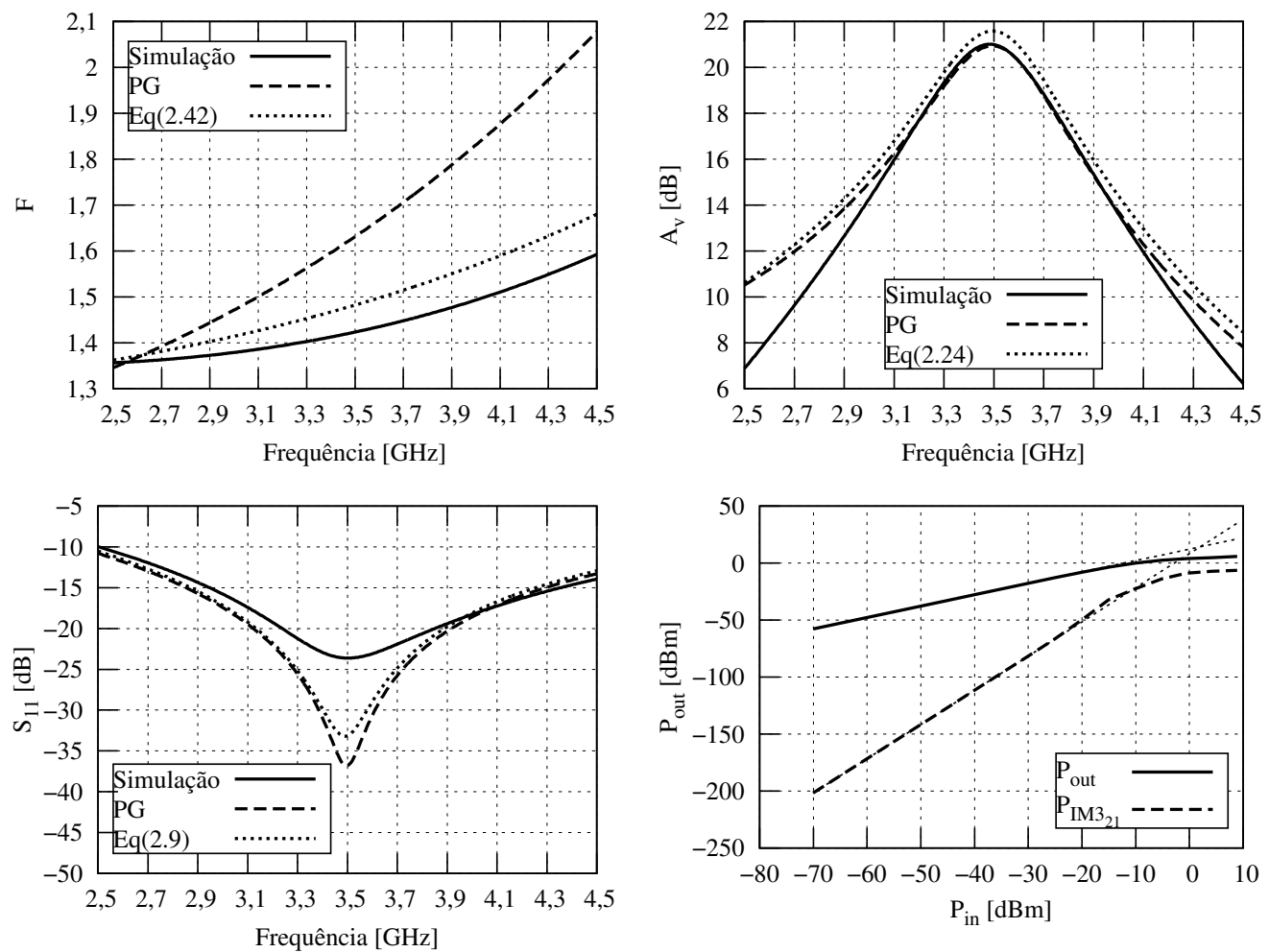

Figura 4.6: Resultados principais para um $L N A$ de banda estreita projetado para 3,5 GHz usando o processo de $0,18 \mu \mathrm{m}$ da $I B M$.
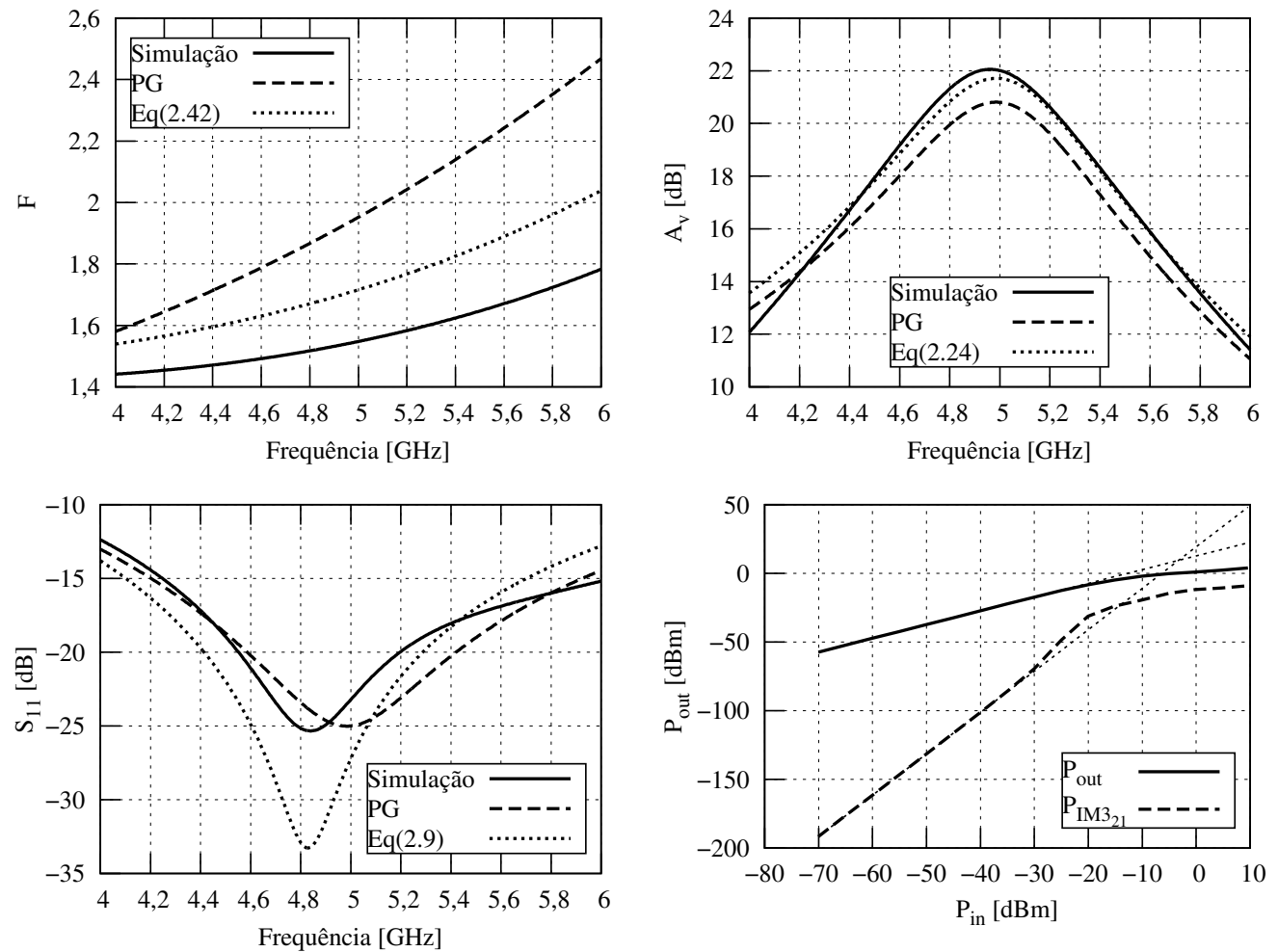

Figura 4.7: Resultados principais para um $L N A$ de banda estreita projetado para $5 \mathrm{GHz}$ usando o processo de $0,13 \mu \mathrm{m}$ da $I B M$. 


\subsubsection{Resumo dos resultados}

Em adição aos testes mostrados antes, são efetuados um outro conjunto de simulações. Para cada tecnologia, são projetados $L N A$ s para diferentes frequências de operação e os resultados estão resumidos nas figuras 4.8(a) a 4.8(f). Os testes são efetuados considerando as restrições das tabelas 4.2 e 4.3 .

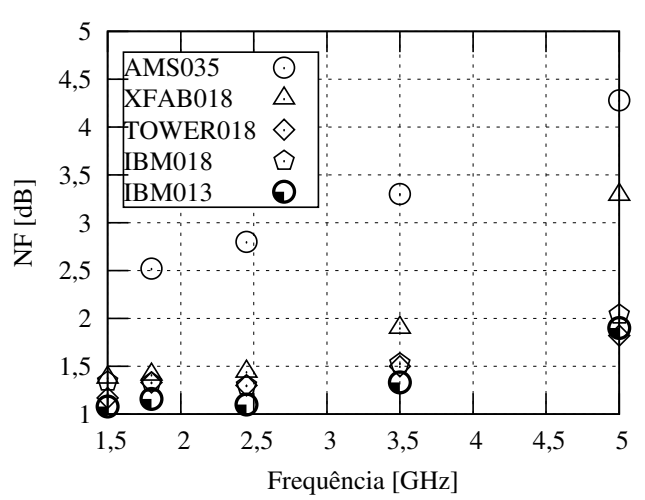

(a)

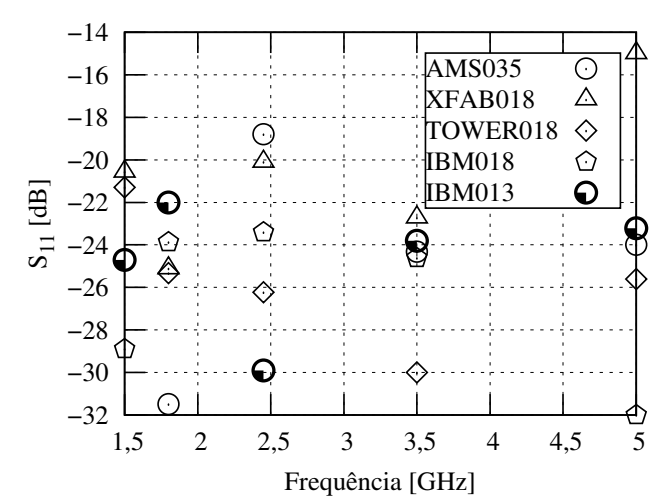

(c)

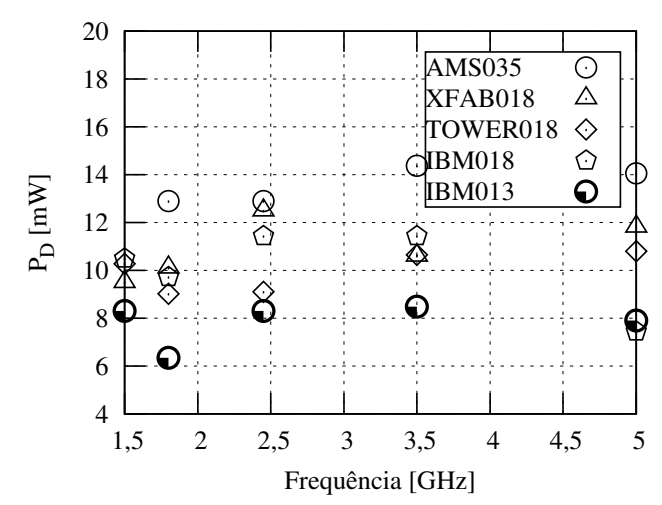

(e)

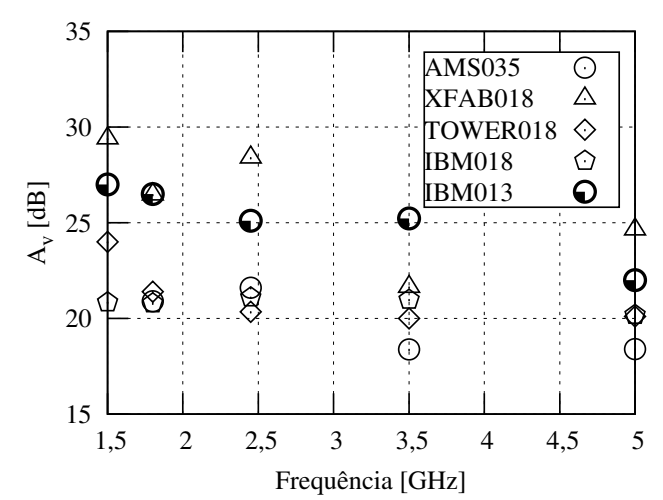

(b)

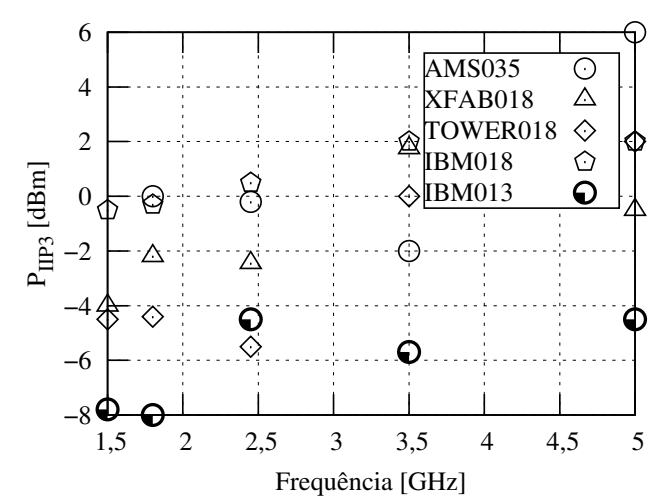

(d)



(f)

Figura 4.8: Resultados de simulação de $L N A$ s projetados para diferentes frequências de operação:(a) Figura de ruído; (b) Ganho de tensão; (c) Coeficiente de reflexão de entrada; (d) Interceptação de terceira ordem; (e) Consumo de potência; (f) Isolamento reverso. 
Usando as restrições e especificações relacionadas nas tabelas, todos os programas geométricos têm solução, com exceção do teste para a tecnologia da $A M S$ para $1,5 \mathrm{GHz}$ de frequência central de operação. Este teste não tem solução devido aos valores de indutância que são limitados nesta tecnologia. Também, nesta tecnologia pode ser visto que para os testes em frequências acima de $3 \mathrm{GHz}$, o ganho começa a diminuir (figura 4.8(b)) devido à restrição do consumo de potência (figura 4.8(e)) e a restrição no tamanho do transistor. Além disso, a partir da figura 4.8(a) pode-se observar que quanto menor seja o comprimento do canal do transistor, menor é o valor da figura de ruído que pode ser obtida. Por outro lado, na figura 4.8(d) a linearidade de todos os circuitos é boa, considerando que uma intercepção de terceira ordem normal tem de ser superior a $-10 \mathrm{dBm}$. Finalmente, o isolamento reverso (figura 4.8(f)) de todos os blocos é inferior do que $-30 \mathrm{~dB}$ que é um valor adequado.

Existem outros testes que podem ser executados utilizando esta metodologia de projeto. A especificação de potência pode ser reduzida até que o PG parar de convergir (ter solução), em seguida, o último ponto de convergência pode ser considerado o caso de consumo mínimo de potência para o conjunto de especificações e restrições dadas. De forma análoga, a especificação do ganho de tensão pode ser aumentada, e assim sucessivamente.

\subsection{Resultados do LNA de banda larga}

Durante o capítulo 3 foi formulado como um programa geométrico o problema de projeto de um LNA de banda larga com cancelamento de ruído. As principais especificações foram consideradas e um conjunto de modelos monomiais para representar alguns dos parâmetros do transistor foram criados de acordo com a forma descrita no capítulo 2. A seguir, nas tabelas 4.5 a 4.7, são apresentados os resultados para cinco $L N A$ s de banda larga projetados usando o programa geométrico descrito. Os circuitos foram simulados usando o esquemático da figura 4.9 , onde a resistência de carga usada é de $R_{L}=65 \Omega$, a resistência de polarização $R_{\text {bias }}=12 \mathrm{~K} \Omega$, e foram usados capacitores de desacoplamento de $20 \mathrm{pF}$ na entrada e saída, e nas portas dos transístores e $M_{2}$ e $M_{3}$ para isolar o ponto de polarização dos mesmos.

Igual aos resultados do circuito de banda estreita, não existem ajustes nos resultados apresentados nesta seção. No entanto, neste caso para obter um projeto finalizado serão necessários alguns ajustes para melhorar a largura de banda e aumentar o ganho, mantendo o casamento de impedâncias. Apesar disso, os resultados relacionados nas tabelas e os gráficos apresentados demonstram que o programa geométrico dá como resultado um ponto inicial de projeto bom. A modelagem dos parâmetros do transistor permite obter circuitos bem 


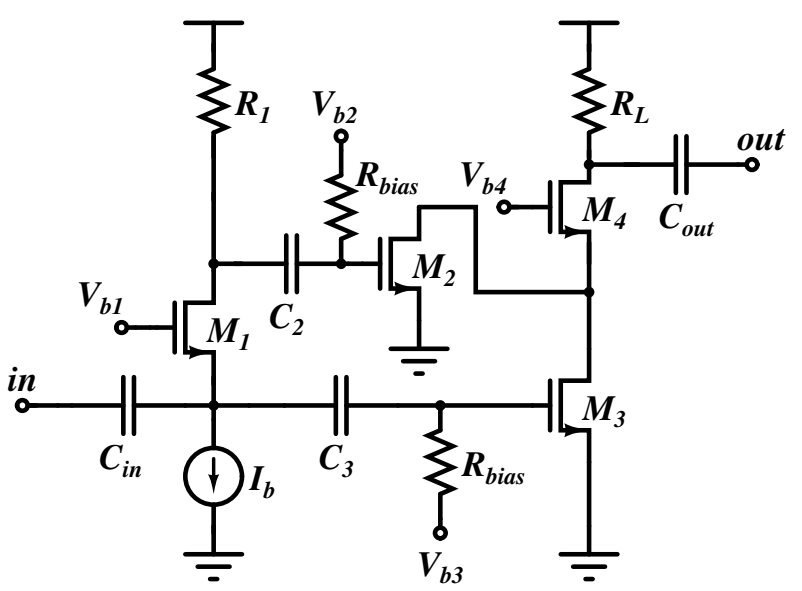

Figura 4.9: Esquemático do $L N A$ de banda larga usado nas simulações.

dimensionados e polarizados, o que ajuda a garantir o cancelamento de ruído nas simulações. Além disso, os testes efetuados consistem em obter o maior ganho de potência possível, mantendo ao mesmo tempo uma certa proporção entre a resistência da fonte de sinal de entrada e o capacitor de porta-fonte do transistor $M_{3}$.

Tabela 4.5: Resultados de PGs resolvidos para LNAs de banda larga em diferentes tecnologias.

\begin{tabular}{|c|c|c|c|c|c|c|c|}
\hline Tipo & $\mathrm{F}$ & $\mathrm{NF}[\mathrm{dB}]$ & $S_{11}[\mathrm{~dB}]$ & $S_{21}[\mathrm{~dB}]$ & $S_{22}[\mathrm{~dB}]$ & $P_{D}[\mathrm{~mW}]$ & $P_{I I P 3}[\mathrm{dBm}]$ \\
\hline Spec. & $\min$ & $\min$ & -20 & $\max$ & $-17,7$ & $\leq 25$ & NA \\
\hline \multicolumn{8}{|c|}{ TowerJazz para $0,2 \mathrm{GHz} \leq f_{o} \leq 1,6 \mathrm{GHz}$} \\
\hline PG & 1,46 & 1,64 & -20 & 11,4 & $-17,7$ & 15,2 & NA \\
\hline Sim. & {$[1,4: 1,5]$} & {$[1,5: 1,8]$} & $\leq-7$ & 12,16 & $\leq-9$ & 14,3 & {$[-2: 1,6]$} \\
\hline \multicolumn{8}{|c|}{$X F A B$ para $0,2 \mathrm{GHz} \leq f_{o} \leq 0,9 \mathrm{GHz}$} \\
\hline PG & 1,31 & 1,2 & -20 & 11,32 & $-17,7$ & 20 & NA \\
\hline Sim. & {$[1,54: 1,96]$} & {$[1,87: 2,9]$} & $\leq-7,4$ & 10,27 & $\leq-9$ & 19,3 & {$[-8,4:-0,6]$} \\
\hline \multicolumn{8}{|c|}{$A M S$ para $0,2 \mathrm{GHz} \leq f_{o} \leq 1,7 \mathrm{GHz}$} \\
\hline PG & 1,54 & 1,9 & -20 & 6,23 & $-17,7$ & 25 & NA \\
\hline Sim. & {$[2,12: 2,84]$} & {$[3,28: 4,5]$} & $\leq-7,4$ & 6,75 & $\leq-14$ & 24,28 & {$[-4,9:-3,4]$} \\
\hline \multicolumn{8}{|c|}{$I B M 018$ para $0,2 \mathrm{GHz} \leq f_{o} \leq 1,8 \mathrm{GHz}$} \\
\hline PG & 1,28 & 1,08 & -20 & 12,2 & $-17,7$ & 20 & NA \\
\hline Sim. & {$[1,34: 1,53]$} & {$[1,27: 1,84]$} & $\leq-6,8$ & 12,6 & $\leq-9$ & 20,83 & {$[-7,1:-2,9]$} \\
\hline \multicolumn{8}{|c|}{$I B M 013$ para $0,4 \mathrm{GHz} \leq f_{o} \leq 2 \mathrm{GHz}$} \\
\hline PG & 1,3 & 1,14 & -20 & 13,83 & $-17,7$ & 10,14 & $\mathrm{NA}$ \\
\hline Sim. & {$[1,46: 1,63]$} & {$[1,55: 2,1]$} & $\leq-7$ & 13,65 & $\leq-9$ & 9,82 & [-10:-6] \\
\hline
\end{tabular}

$\mathrm{Na}$ tabela 4.5 observa-se que o ganho máximo na banda é bem estimado, igual do que o consumo de potência. Por outro lado, quease todas as figuras de ruído são inferiores a $3 \mathrm{~dB}$, o que é um resultado bom para aplicações de banda larga, mesmo com um erro alto entre os resultados das expressões e das simulações devido a todas as aproximações feitas no capítulo 3. As larguras de banda foram estimadas utilizando dois critérios: o primeiro é o mais comum, que 
é o valor de frequência onde o ganho cai $3 \mathrm{~dB}$ respeito ao máximo valor; o segundo consiste em garantir um coeficiente de reflexão de entrada inferior a $-7 \mathrm{~dB}$. Além disso, para obter o intervalo de valores de linearidade relatados, foram avaliados três pontos na banda de frequência. A frequência de corte inferior, a frequência de corte superior, e o valor de frequência onde o ganho é máximo. Por último, o isolamento reverso $\left(S_{12}\right)$ não foi relatado na tabela nem os gráficos, mas para todos os casos o valor é inferior do que $-50 \mathrm{~dB}$ em toda a banda.

Na tabela 4.6 são apresentados os resultados da modelagem dos parâmetros do transistor, e são comparados com os valores extraídos do simulador, observando-se que os erros são bastante baixos. Por último, na tabela 4.7 estão relacionadas as dimensões dispositivos. A partir desta tabela, pode-se observar como os dispositivos devem ser seleccionados para garantir o cancelamento de ruído. Para satisfazer a equação (3.49), o transistor $M_{3}$ deve ser maior do que $M_{2}$ porque $R_{1}$ é sempre maior do que $R_{s}$.

Tabela 4.6: Resultados de algumas das variáveis dos transistores modeladas para os $L N A$ s de banda larga.

\begin{tabular}{|c|c|c|c|c|c|}
\hline Tipo & $g_{m 1}[\mathrm{mS}]$ & $g_{m 2}[\mathrm{mS}]$ & $g_{m 3}[\mathrm{mS}$ & $C_{g s 2}[\mathrm{fF}]$ & $C_{g_{s} 3}[\mathrm{fF}]$ \\
\hline \multicolumn{6}{|c|}{ TowerJazz para $0,2 \mathrm{GHz} \leq f_{o} \leq 1,6 \mathrm{GHz}$} \\
\hline$\overline{\mathrm{PG}}$ & 16,6 & 17,2 & 90 & 53 & 280 \\
\hline Sim. & 15,34 & 18,3 & 83,2 & 50,3 & 275,8 \\
\hline \multicolumn{6}{|c|}{$X F A B$ para $0,2 \mathrm{GHz} \leq f_{o} \leq 0,9 \mathrm{GHz}$} \\
\hline PG & 16,4 & 7,93 & 90 & 56,13 & 520,88 \\
\hline Sim. & 13,4 & 7,58 & 93,1 & 58,7 & 557,2 \\
\hline \multicolumn{6}{|c|}{$A M S$ para $0,2 \mathrm{GHz} \leq f_{o} \leq 1,7 \mathrm{GHz}$} \\
\hline PG & 16,4 & 8,19 & 50 & 38,7 & 454,72 \\
\hline Sim. & 13,8 & 6,6 & 53,5 & 37,76 & 447,76 \\
\hline \multicolumn{6}{|c|}{$I B M 018$ para $0,2 \mathrm{GHz} \leq f_{o} \leq 1,8 \mathrm{GHz}$} \\
\hline PG & 16,4 & 8,15 & 100 & 42,9 & 294,3 \\
\hline Sim. & 15,4 & 8,51 & 112 & 39 & 289,5 \\
\hline \multicolumn{6}{|c|}{$I B M 013$ para $0,2 \mathrm{GHz} \leq f_{o} \leq 2 \mathrm{GHz}$} \\
\hline $\mathrm{PG}$ & 16,4 & 14 & 120 & 53 & 425,6 \\
\hline Sim. & 14,9 & 14 & 118 & 52,8 & 423,5 \\
\hline
\end{tabular}

Além do anterior, após a análise dos resultados para todos os cinco desenhos, apesar de não ter sido relatado nas tabelas pelo tamanho das mesmas, é importante notar que as tensões de polarização de $M_{2}$ e $M_{3}$ podem ser iguais, e a tensão de polarização do transistor $M_{4}$ pode ser a fonte de alimentação. Desta forma, o número de pinos e tensões de polarização necessários são reduzidos, e o número de variáveis envolvidas no projeto diminui. Por outro lado, a corrente referência foi assumida ideal durante as simulações, mas pode ser implementada usando um resistor, indutores tipo choke ou um espelho de corrente convencional. Em qualquer caso este dispositivo deve adicionar o menor ruído possível. 
Tabela 4.7: Dimensões dos dispositivos obtidas nos PGs resolvidos para os LNAs de banda larga.

\begin{tabular}{|c|c|c|c|c|c|c|c|}
\hline Transistor & $W_{t}[\mu \mathrm{m}]$ & $n_{f}$ & $W_{f}[\mu \mathrm{m}]$ & $\mathrm{m}$ & $\mathrm{L}[\mu \mathrm{m}]$ & $R_{1}[\Omega]$ & $I_{b}[\mathrm{~mA}]$ \\
\hline Spec. & [40:500] & Tech. & Tech. & NA & Tech. & NA. & NA. \\
\hline \multicolumn{8}{|c|}{ TowerJazz para $0,2 \mathrm{GHz} \leq f_{o} \leq 1,6 \mathrm{GHz}$} \\
\hline$M_{1}$ & 197 & 26 & 7,56 & 1 & 0,18 & \multirow{4}{*}{262} & \multirow{4}{*}{0,754} \\
\hline$M_{2}$ & 87,3 & 12 & 7,57 & 1 & 0,18 & & \\
\hline$M_{3}$ & 500 & 64 & 7,81 & 1 & 0,18 & & \\
\hline$M_{4}$ & 80,5 & 12 & 6,7 & 1 & 0,26 & & \\
\hline \multicolumn{8}{|c|}{$X F A B$ para $0,2 \mathrm{GHz} \leq f_{o} \leq 0,9 \mathrm{GHz}$} \\
\hline$M_{1}$ & 500 & 18 & 9,23 & 3 & 0,3 & \multirow{4}{*}{567} & \multirow{4}{*}{0,845} \\
\hline$M_{2}$ & 56,7 & 6 & 9,45 & 1 & 0,18 & & \\
\hline$M_{3}$ & 500 & 18 & 9,26 & 3 & 0,18 & & \\
\hline$M_{4}$ & 79 & 8 & 9,88 & 1 & 0,24 & & \\
\hline \multicolumn{8}{|c|}{$A M S$ para $0,2 \mathrm{GHz} \leq f_{o} \leq 1,7 \mathrm{GHz}$} \\
\hline$M_{1}$ & 450 & 15 & 10 & 3 & 0,35 & \multirow{4}{*}{305} & \multirow{4}{*}{0,643} \\
\hline$M_{2}$ & 40 & 4 & 10 & 1 & 0,35 & & \\
\hline$M_{3}$ & 480 & 16 & 10 & 3 & 0,35 & & \\
\hline$M_{4}$ & 110 & 11 & 10 & 1 & 0,35 & & \\
\hline \multicolumn{8}{|c|}{$I B M 018$ para $0,2 \mathrm{GHz} \leq f_{o} \leq 1,8 \mathrm{GHz}$} \\
\hline$M_{1}$ & 113,6 & 12 & 9,46 & 1 & 0,18 & \multirow{4}{*}{613} & \multirow{4}{*}{0,94} \\
\hline$M_{2}$ & 43,6 & 5 & 8,73 & 1 & 0,18 & & \\
\hline$M_{3}$ & 431,5 & 15 & 9,59 & 3 & 0,18 & & \\
\hline$M_{4}$ & 75,5 & 10 & 7,55 & 1 & 0,26 & & \\
\hline \multicolumn{8}{|c|}{$I B M 013$ para $0,2 \mathrm{GHz} \leq f_{o} \leq 2 \mathrm{GHz}$} \\
\hline$M_{1}$ & 86,5 & 18 & 4,81 & 1 & 0,12 & \multirow{4}{*}{429} & \multirow{4}{*}{0,758} \\
\hline$M_{2}$ & 62,7 & 13 & 4,83 & 1 & 0,12 & & \\
\hline$M_{3}$ & 500 & 20 & 5 & 5 & 0,12 & & \\
\hline$M_{4}$ & 72,2 & 15 & 4,82 & 1 & 0,21 & & \\
\hline
\end{tabular}

Por último, nas figuras 4.10(a) até 4.10(f), são apresentados os gráficos dos principais parâmetros analisados no $L N A$ de banda larga com cancelamento de ruído. Nestes gráficos são comparados os cinco circuitos projetados usando diferentes tecnologias, em vez de comparar cada um deles contra as expressões utilizadas. Isso devido a que as expressões utilizadas para o circuito de banda larga não são precisas na frequência como mostrado nas figuras 3.4(a) até $3.4(\mathrm{~d})$.

Na figura 4.10(a) observa-se que o valor mais baixo de ruído obtido foi com um processo de $0,18 \mu \mathrm{m}$. No entanto olhando para a tabela 4.5, a relação entre a figura de ruído e consumo de potência mostra que o processo de $0,13 \mu \mathrm{m}$ atinge uma figura de ruído similar com quase metade do consumo. Em ambos os casos a figura de ruído permanece menor do que $3 \mathrm{~dB}$ em toda a janela examinada após $100 \mathrm{MHz}$. Além do anterior, na figura 4.10(b) observa-se que o processo de $0,13 \mu \mathrm{m}$ possui o maior ganho e largura de banda dos circuitos projetados. Assim, 
à medida que o comprimento do canal diminui, a frequência de ganho unitário do transistor aumenta e então o produto ganho-largura-de-banda aumenta.

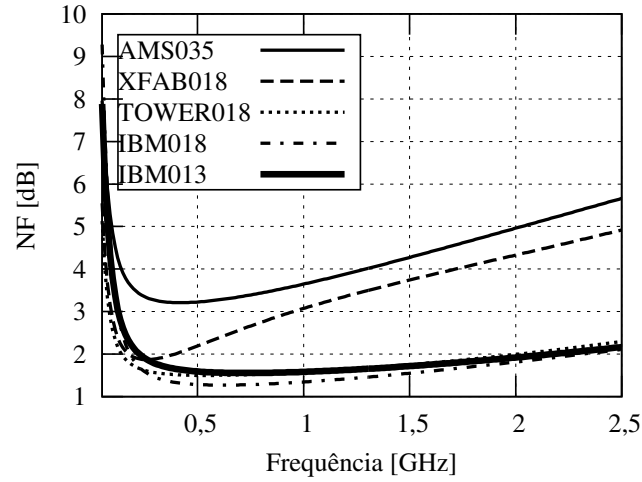

(a)



(c)

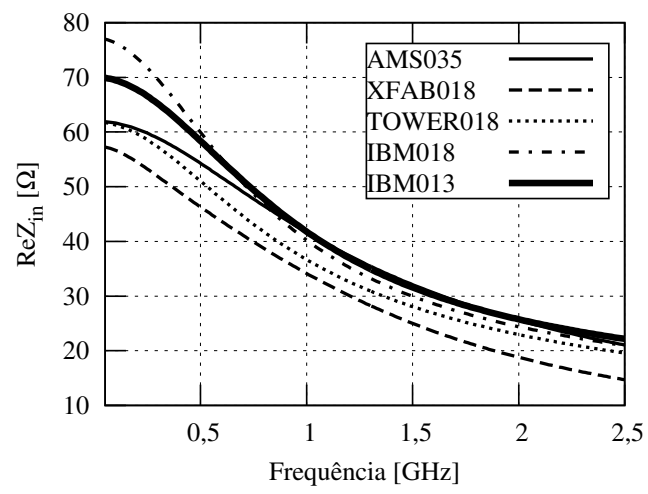

(e)

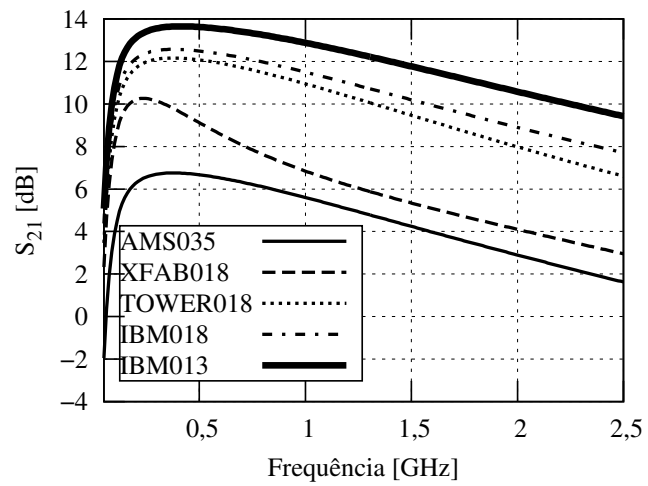

(b)

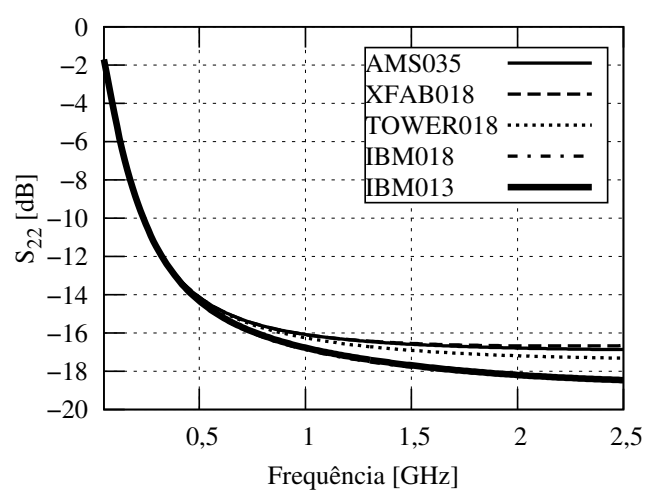

(d)

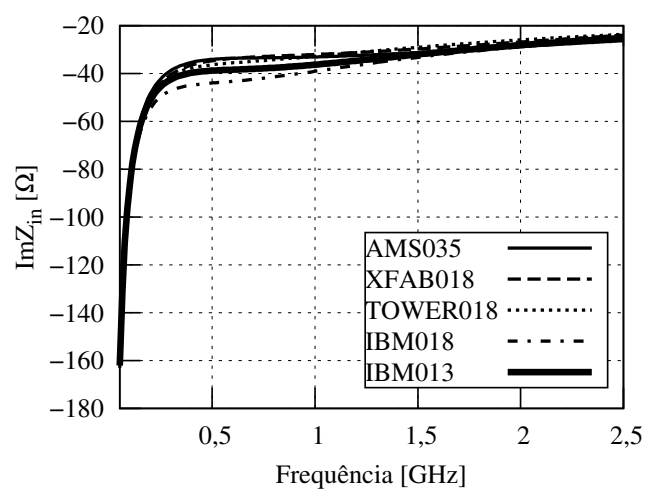

(f)

Figura 4.10: Resultados de simulação dos $L N A$ s de banda larga projetados:(a) Figura de ruído; (b) Ganho; (c) Coeficiente de reflexão de entrada; (d) Coeficiente de reflexão de saída; (e) Parte real da impedância de entrada; (f) Parte imaginária da impedância de entrada.

Nas figuras 4.10(b) e 4.10(f), pode-se observar uma diferença no comportamento nas frequências baixas em comparação às figuras 3.4(d) e 3.4(b). Essa diferença é causada pelos 
capacitores de desacoplamento (especialmente $C_{\text {in }}$ e $C_{\text {out }}$ ), que durante as simulações feitas no capítulo 3 foram considerados na faixa de micro farads, mas nas simulações do presente capítulo foram assumidos de $20 \mathrm{pF}$, que é um valor que pode ser implementado em um chip CMOS. Estas capacitâncias afetam diretamente o casamento da impedância de entrada e de saída (figuras 4.10(c) e 4.10(d)) e como não foram consideradas durante a formulação, é normal obter incompatibilidade entre os resultados dos programas geométricos e das simulações. Por outro lado, devido a que o valor da resistência de carga é igual em todos os circuitos, na figura 4.10(d) observa-se que os casamentos da impedância de saída para os cinco LNAs são bastante semelhantes. Além disso, a parte imaginária das impedâncias de entrada dos circuitos são também semelhantes (figura 4.10(f)), isto principalmente pelo efeito dos capacitores de desacoplamento na entrada do bloco e nas portas de $M_{2}$ e $M_{3}$.

Na figura 4.10(e) mostra-se como a parte real da impedância de entrada começa a diminuir enquanto as capacitâncias de entrada dos estágios seguintes, e as capacitâncias parasitárias do estágio de entrada começam a afetar pelo aumento da frequência. Esse efeito também afeta diretamente a largura de banda, e foi considerado no programa geométrico definindo um limite para as impedâncias de entrada dos estágios de fonte comum $\left(Z_{\text {inM2 }}\right.$ e $\left.Z_{i n M 3}\right)$ respeito à resistência da fonte do sinal $\left(R_{S}\right)$, como mencionado no capítulo 3 . Nessa forma, pode-se estimar a frequência na qual este valor começa a ser considerável mudando a parte real da impedância de entrada e reduzindo consideravelmente o ganho.

Com os resultados obtidos, verifica-se que a programação geométrica pode ser útil durante a primeira etapa do projeto de um LNA de banda larga com cancelamento de ruído. Após essa primeira solução, é bom melhorar o casamento da impedância de entrada e a largura de banda mediante alguns ajustes. Também durante o teste apresentado nesta seção, o objetivo era alcançar o maior ganho possível com a menor figura ruído. Um outro teste poderia ser feito diminuindo a especificação do ganho e então obter larguras de banda maiores. Além desse teste, um teste mínimo consumo de potência pode ser feito como explicado para o circuito de banda estreita.

\subsection{Layouts e resultados pós-layout}

Nesta dissertação, o objetivo principal da criação de ferramentas para a automação de projeto, consiste em reduzir o tempo que o projetista demora na concepção de um projeto inicial bom. Depois disso, esse projeto inicial pode ser ajustado e preparado para ser desenhado o layout, realizar as verificações pós-layout e enviar o circuito para fabricação. Nesta seção 
são apresentados os layouts e os resultados das simulações pós-layout de dois LNAs de banda estreita e dois blocos LNA-misturador de banda larga. Os blocos foram projetados usando uma versão preliminar do script de automação. Após esses layouts foram enviados para fabricação, o script de automação e as considerações para incluir a programação geométrica no fluxo de projeto mudaram consideravelmente, de modo a reduzir os erros entre os resultados de otimização e das simulações, como mostrado nos resultados já apresentados neste capítulo. Os circuitos são projetados usando três processos de $0,18 \mu \mathrm{m}$, o $x c 018$ da XFAB, o ts018sl da TowerJazz e o cmrf7sf da IBM. Os layouts foram desenhados usando ASSURA e as simulações pós-layout feitas usando o SPECTRERF, ambas as ferramentas da Cadence. Por outro lado, para os dois primeiros processos mencionados foi necessário criar os indutores usando a ferramenta VPCD também da Cadence.

\subsubsection{Resultados pós-layout dos LNAs de banda estreita}

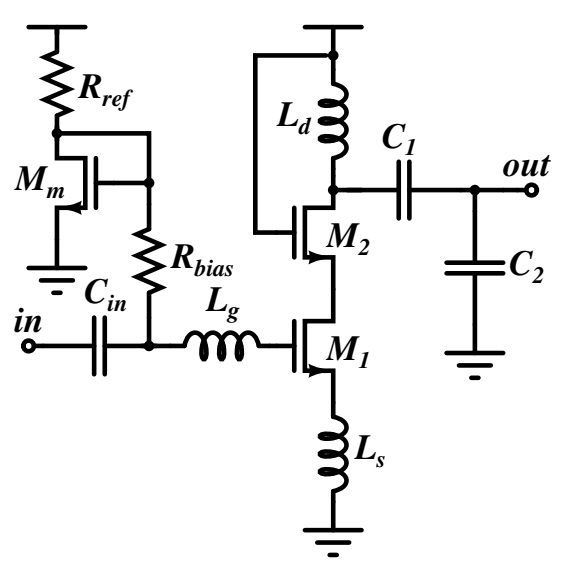

Figura 4.11: Vista esquemática completa do LNA de banda estreita implementado.

Os amplificadores usam a topologia mostrada no esquemático da figura 4.11, onde $C_{\text {in }}$ é um capacitor de desacoplamento $\left(C_{i n}=20 \mathrm{pF}\right), R_{\text {bias }}, M_{m}$ e $R_{\text {ref }}$ constituem o espelho de corrente para polarização com uma corrente de referência $I_{r e f}=200 \mu \mathrm{A}$, e $C_{1}$ e $C_{2}$ são um divisor capacitivo utilizado para reduzir a impedância de saída para $50 \Omega$ e facilitar os testes. Para cada circuito são apresentados os resultados das simulações pré e pós layout, além de algumas análises de corners realizadas. Entre os parâmetros de desempenho apresentados estão a figura de ruído, o casamento de impedância de entrada, os parâmetros de espalhamento e a linearidade. Além disso, alguns testes de estabilidade são feitos considerando o fator e a medida 
de estabilidade $K_{f}$ e $B_{f}$ respectivamente, definidos da seguinte forma:

$$
\begin{gathered}
K_{f}=\frac{1+\left|B_{f}\right|^{2}-\left|S_{11}\right|^{2}-\left|S_{22}\right|^{2}}{2\left|S_{12} S_{21}\right|} \\
\left|B_{f}\right|=\left|S_{11} S_{22}-S_{12} S_{21}\right|
\end{gathered}
$$

onde o LNA é incondicionalmente estável se $K_{f}>1$ e $B_{f}<1$, o que significa que o circuito é estável para quaisquer combinação das impedâncias de entrada e saída. Quando o fator $K_{f}$ é menor que a unidade, o circuito é potencialmente instável e pode ocorrer oscilação com uma determinada combinação das impedâncias de fonte y carga do amplificador. Se $K_{f}>1$ e $B_{f}>1$ se deve ter cuidado na escolha das impedâncias. Nenhuma dessas condições assegura que o circuito seja instável.

\section{Resultados pós-layout do LNA banda estreita usando o processo de $0,18 \mu \mathrm{m}$ da $X F A B$}

O primero $L N A$ é projetado e implementado utilizando o processo $x c 018$ da $X F A B$ com a opção de baixa potência. O dimensionamento do circuito obtido é mostrado na tabela 4.8. Na tabela 4.9 são apresentados os parâmetros de desempenho do $L N A$, e a comparação entre os resultados do PG e das simulações pré e pós layout. A discrepância entre os valores dos indutores é devido a que alguns ajustes são necessários porque a indutância do bondwire e a capacitância do pad não são consideradas no programa geométrico. Por outro lado, a diferença na figura de ruído pode ser produzida pelas componentes parasitas do indutores de entrada. Finalmente, o ganho formulado usando programação geométrica é menor porque neste caso a impedância de saída ou de carga é considerara como $50 \Omega$, mas pode ser um pouco mais elevada. Este amplificador em especial destina-se para atingir um consumo de potência reduzido, mantendo um ruído baixo e ganho adequado. Na tabela 4.9, os NA significam que o valor de aquele parâmetro em particular não pode ser calculado a partir do PG.

\begin{tabular}{|c|c|c|c|c|c|c|c|c|}
\hline Transistor & $W_{t}[\mu \mathrm{m}]$ & $n_{f}$ & $W_{f}[\mu \mathrm{m}]$ & $\mathrm{m}$ & $\mathrm{L}[\mu \mathrm{m}]$ & $L_{g}[\mathrm{nH}]$ & $L_{S}[\mathrm{nH}]$ & $L_{d}[\mathrm{nH}]$ \\
\hline$\overline{M_{1}}$ & 304 & 10 & 7,6 & 4 & 0,18 & $81^{\mathrm{a}} 754^{\mathrm{b}}$ & $1^{\mathrm{a}} \quad 087^{\mathrm{b}}$ & 5 \\
\hline$M_{2}$ & 273 & 10 & 9,1 & 3 & 0,18 & $0,1 \quad 1,34$ & $1 \quad 0,01$ & $J$ \\
\hline
\end{tabular}

Tabela 4.8: Dimensionamento do $L N A$ de banda estreita em $X F A B$.

a PG.

b Ajustado nas simulações.

Vale a pena notar que neste exemplo inicial durante a formulação do PG não são incluídos os efeitos do pad nem do bondwire. Também, as simulações pré-layout relatadas são feitas sem o anel de pads criado, e as simulações pós-layout incluem todos os dispositivos e as suas 
Tabela 4.9: Resultados de projeto do $L N A$ de banda estreita em $0,18 \mu \mathrm{m}$ da $X F A B$.

\begin{tabular}{||c||ccccccc||}
\hline Resultado & NF[dB] & $S_{11}[\mathrm{~dB}]$ & $S_{21}[\mathrm{~dB}]$ & $S_{12}[\mathrm{~dB}]$ & $S_{22}[\mathrm{~dB}]$ & $P_{D}[\mathrm{~mW}]$ & $P_{I I P 3}[\mathrm{dBm}]$ \\
\hline \hline PG & 1,1 & -27 & 13,4 & NA & NA & 3,8 & NA \\
Sim. Pré & 1,34 & $-14,3$ & 14,6 & -43 & $-29,5$ & 3,8 & $-7,2$ \\
Sim. Pós & 1,64 & -11 & 13,4 & $-40,2$ & $-17,8$ & 3,84 & $-6,8$ \\
Corner $^{\mathrm{a}}$ & 1,45 & $-10,9$ & 14,5 & $-40,6$ & $-8,9$ & 4,57 & -8 \\
Corner $^{\mathrm{b}}$ & 1,78 & -11 & 12,03 & $-40,1$ & $-17,48$ & 3,28 & $-5,8$ \\
Corner $^{\mathrm{c}}$ & 1,46 & $-10,9$ & 14,4 & $-40,1$ & $-13,9$ & 4,11 & $-7,7$ \\
Corner $^{\mathrm{d}}$ & 1,72 & $-10,8$ & 13 & $-39,8$ & $-18,8$ & 3,63 & $-6,9$ \\
\hline
\end{tabular}

a Pior caso de potência.

b Pior caso de velocidade.

c Pior indutor com transistor rápido.

${ }^{\mathrm{d}}$ Melhor indutor com transistor lento.

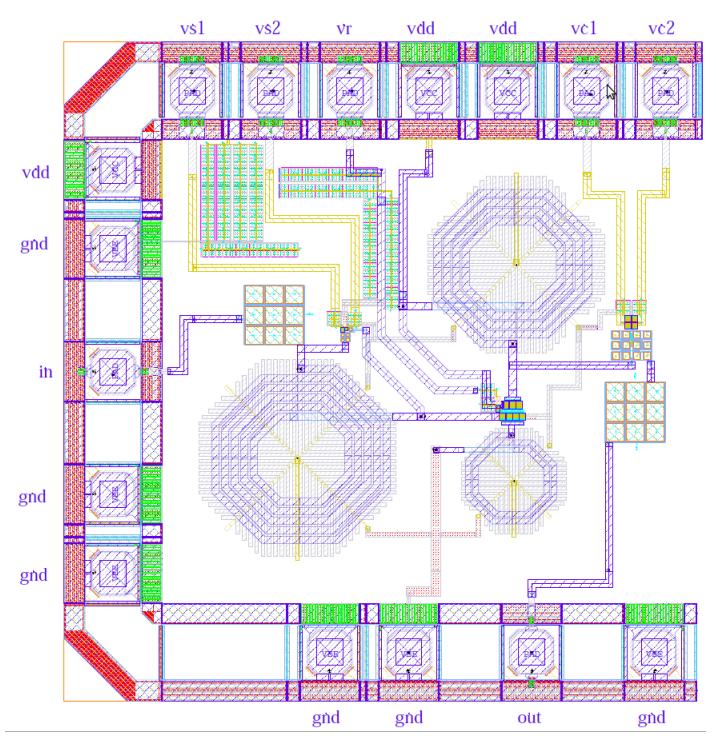

Figura 4.12: Layout do $L N A$ de banda estreita usando o processo XCO18LP da XFAB.

parasitas extraídas a partir do layout mostrado na figura 4.12. O layout é desenhado cumprindo as regras do processo, verificado através da análise de layout versus esquemático ( $L V S)$, e ocupa uma área de $1 \mathrm{~mm}^{2}$ incluindo os pads. Como a opção de metalização usada inclue um metal espesso na última camada, os indutores gerados alcançam fatores de qualidade em torno de dez. Não obstante, para superar um erro durante o projeto dos indutores ou neutralizar o efeito das variações do processo, alguns capacitores controlados digitalmente são adicionados a fim de assegurar testabilidade. Estes capacitores são colocados nos terminais do indutor da porta e no divisor capacitivo na saída. Igualmente a tensão de alimentação do espelho de corrente pode ser controlada. Por outro lado, o divisor capacitivo é implementado como uma matriz de capacitores a fim de ser robusto as variações de processo. Além disso, o roteamento dos caminhos de sinal é feito usando a camada topo de metal evitando capacitâncias e resistências parasitas consideráveis. Por último, capacitores $M O S$ são conectados entre a alimentação e o 
substrato, e na porta dos transistores de comutação a modo de reduzir alguns ruídos gerados pelas fontes de tensão.

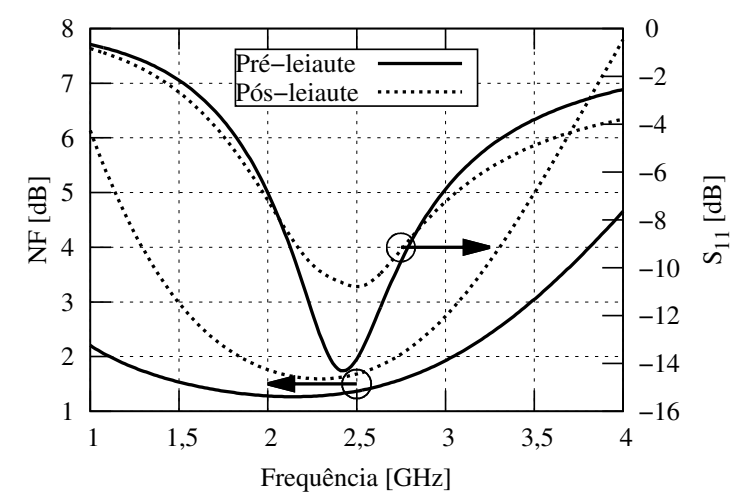

(a)

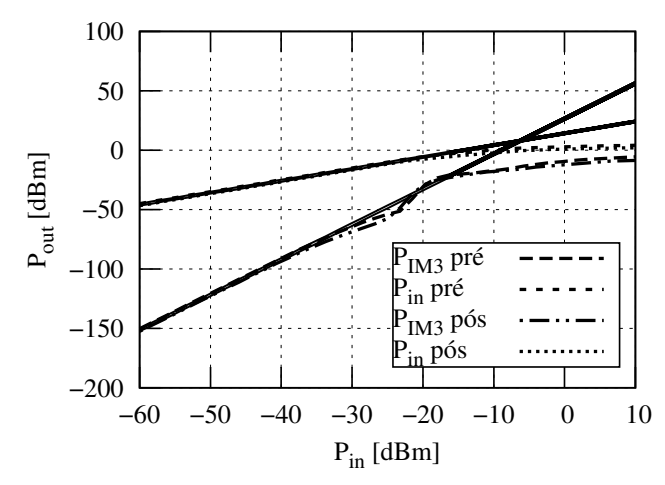

(c)

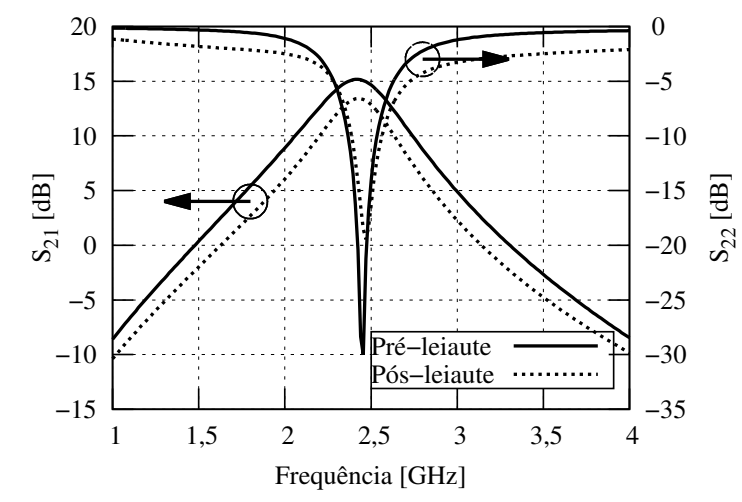

(b)

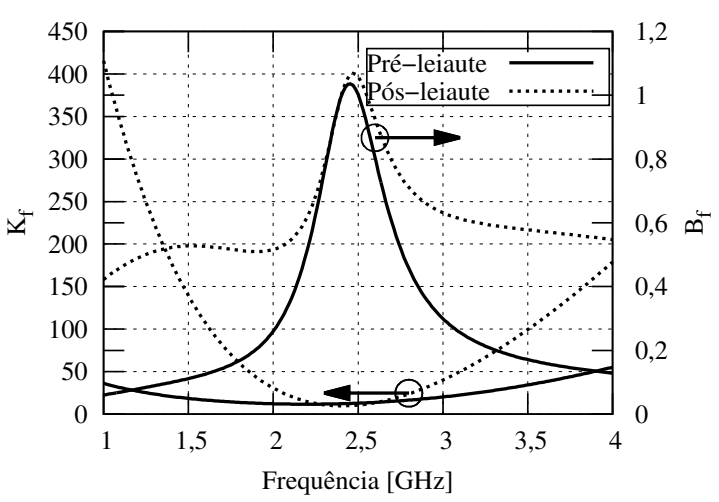

(d)

Figura 4.13: Resultados pós-layout do $L N A$ de banda estreita projetado no processo da $X F A B$ : (a) Figura de ruído e coeficiente de reflexão da entrada; (b) Ganho e coeficiente de reflexão da entrada; (c) Interceptação de terceira ordem; (d) Fator e medida de estabilidade.

Na figura 4.13 são apresentados os gráficos dos resultados pré e pós-layout para os principais parâmetros de desempenho do amplificador de baixo ruído, em adição ao gráfico da análise de estabilidade. Nas figuras observa-se uma boa concordância entre os resultados e é possível analisar como os parasitas afetam cada um desses parâmetros para em seguida concluir sobre a importância de um desenho adequado de layout para radiofrequência.

\section{Resultados pós-layout do $L N A$ de banda estreita usando o processo de $0,18 \mu \mathrm{m}$ da TowerJazz}

O segundo LNA é projetado e implementado utilizando o processo ts018sl da TowerJazz com a opção de cinco camadas de metal e sem metal espesso no topo $(5 M 1 L)$. O circuito é projetado considerando a capacitância do pad e os efeitos do emcapsulamento, que consistem de um capacitor entre a pad e terra e um bondwire entre o pad e o pino do emcapsulado. $\mathrm{O}$ 
dimensionamento do circuito é mostrado na tabela 4.10, onde pode-se observar que o transistor não tem multiplicidade porque permite ter um número elevado de dedos de acordo com as restrições indicadas na tabela 4.1. Como no projeto anterior, os indutores não correspondem por causa da indutância do bondwire e da capacitância do pad, desprezadas durante a formulação do PG. Neste processo, por causa da ausência de metal espesso na camada superior, os indutores projetados alcançam fatores de qualidade inferiores de oito. A comparação dos resultados é mostrada na tabela 4.11 onde é importante notar que as simulações pós-layout são feitas sem considerar o anel de pads devido a problemas com as estruturas do kit de projeto durante o processo de verificação. Também é importante considerar que neste projeto os pads usados não são especialmente projetados para aplicações de radiofrequência, pelo que a sua capacitância pode afetar os resultados consideravelmente. No entanto, para tratar com essa possibilidade os pads foram seleccionados para poder ligar e desligar as proteções do anel externamente sem afetar a alimentação do core.

Tabela 4.10: Dimensionamento do LNA de banda estreita em TowerJazz.

\begin{tabular}{|c|c|c|c|c|c|c|c|c|}
\hline Transistor & $W_{t}[\mu \mathrm{m}]$ & $n_{f}$ & $W_{f}[\mu \mathrm{m}]$ & $\mathrm{m}$ & $\mathrm{L}[\mu \mathrm{m}]$ & $L_{g}[\mathrm{nH}]$ & $L_{S}[\mathrm{nH}]$ & $L_{d}[\mathrm{nH}]$ \\
\hline$\overline{M_{1}}$ & 368 & 46 & 8 & 1 & 0,18 & $62^{\mathrm{a}} 78^{\mathrm{b}}$ & $08^{\mathrm{a}} \quad 1^{\mathrm{b}}$ & 5 \\
\hline$M_{2}$ & 96 & 12 & 8 & 1 & 0,18 & $0,2^{u} \quad 1,8$ & $0,8^{\circ} \quad 1$ & 5 \\
\hline
\end{tabular}

${ }^{\mathrm{a}} \mathrm{PG}$.

b Ajustado nas simulações.

Tabela 4.11: Resultados de projeto do $L N A$ de banda estreita em $0,18 \mu \mathrm{m}$ da TowerJazz.

\begin{tabular}{||c||ccccccc||}
\hline Resultado & $\mathrm{NF}[\mathrm{dB}]$ & $S_{11}[\mathrm{~dB}]$ & $S_{21}[\mathrm{~dB}]$ & $S_{12}[\mathrm{~dB}]$ & $S_{22}[\mathrm{~dB}]$ & $P_{D}[\mathrm{~mW}]$ & $P_{I I P 3}[\mathrm{dBm}]$ \\
\hline \hline PG & 1 & -32 & 13,6 & NA & NA & 8,3 & NA \\
Sim. Pré & 1,4 & $-23,2$ & 14,4 & $-39,1$ & $-23,1$ & 8,2 & -5 \\
Sim. Pós & 1,48 & $-25,7$ & 13,4 & $-39,9$ & -18 & 8,1 & -5 \\
Corner $^{\mathrm{a}}$ & 1,43 & $-20,8$ & 13,8 & $-36,8$ & -9 & 8,9 & -6 \\
Corner $^{\mathrm{b}}$ & 1,44 & $-26,4$ & 12,7 & $-44,1$ & $-15,3$ & 9,5 & -6 \\
Corner $^{\mathrm{c}}$ & 1,48 & $-19,7$ & 13 & $-37,1$ & -18 & 6,2 & $-8,74$ \\
Corner $^{\mathrm{d}}$ & 1,39 & $-26,8$ & 14,1 & $-42,7$ & $-18,1$ & 11,4 & $-7,5$ \\
\hline
\end{tabular}

${ }^{\text {a }}$ Pior caso de potência.

b Pior caso de velocidade.

c Pior indutor com transistor rápido.

${ }^{\mathrm{d}}$ Melhor indutor com transistor lento.

O layout do circuito é mostrado na figura 4.14, ocupando uma área de $2,17 \mathrm{~mm}^{2}$ principalmente por causa das enormes estruturas dos pads que têm em torno de $300 \mu \mathrm{m}$ de comprimento. Como no caso anterior é usada a comutação digital de capacitores e as mesmas considerações durante o roteamento do layout. Finalmente, na figura 4.15 são mostrados os resultados das simulações pré e pós-layout para este $L N A$. 


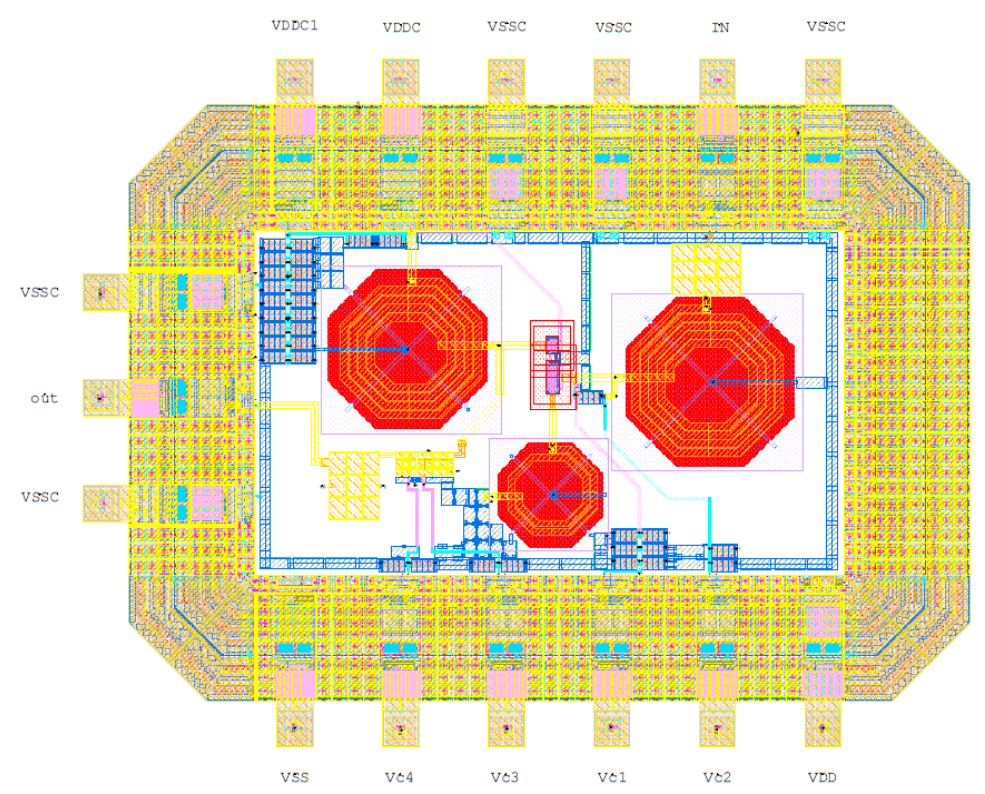

Figura 4.14: Layout do LNA de banda estreita usando o processo TSO18SL-5M1L da TowerJazz.

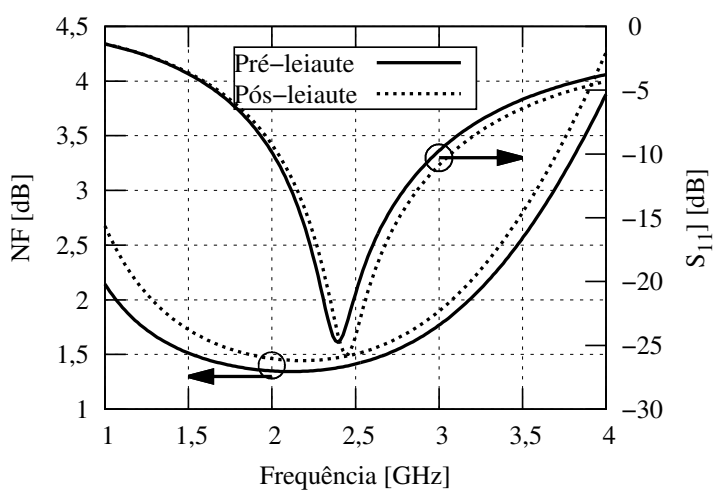

(a)

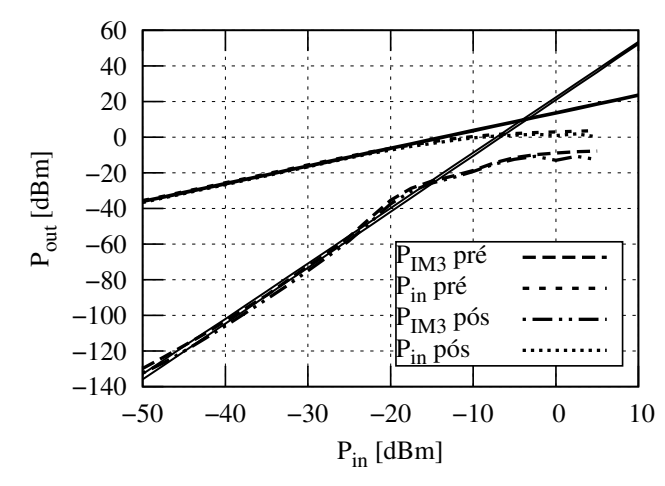

(c)

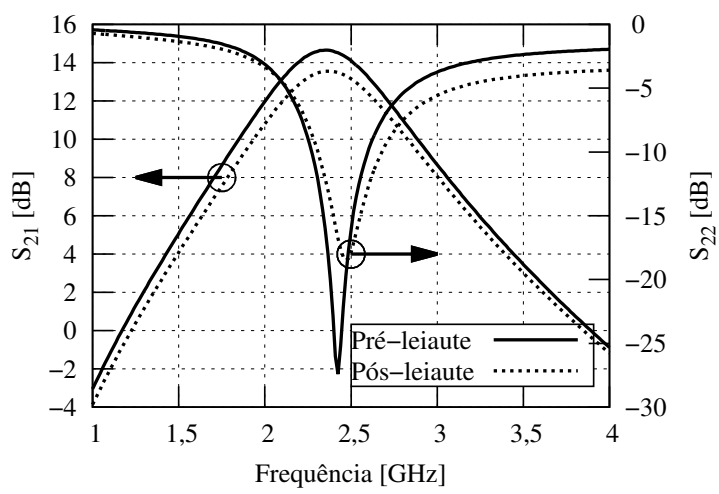

(b)

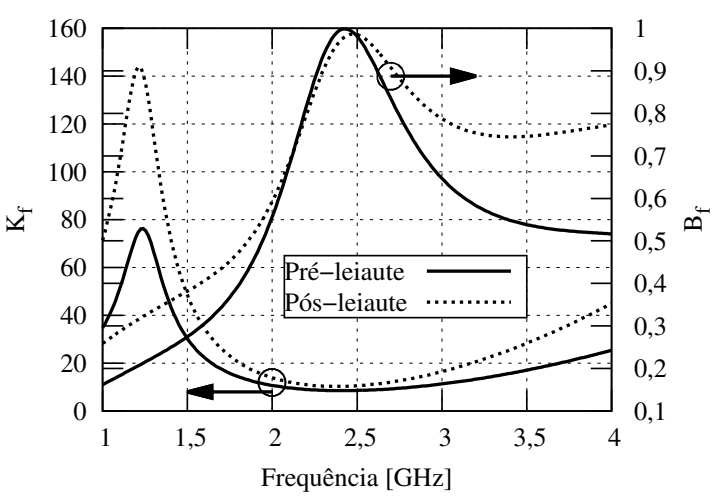

(d)

Figura 4.15: Resultados pós-layout do LNA de banda estreita projetado no processo da TowerJazz: (a) Figura de ruído e coeficiente de reflexão da entrada; (b) Ganho e coeficiente de reflexão da entrada; (c) Interceptação de terceira ordem; (d) Fator e medida de estabilidade. 


\subsubsection{Resultados pós-layout dos blocos $L N A$-misturador de banda larga usando o processo de $0,18 \mu \mathrm{m}$ da $I B M$}

Além dos blocos de banda estreita, dois protótipos de blocos $L N A$-misturador (ou misturador de baixo ruído) de banda larga foram fabricados, baseados na proposta apresentada em [54]. O bloco é mostrado na figura 4.16, e está formado por três estágios: um estágio de transcondutância com cancelamento de ruído, um estágio de comutação, e um esquema de cancelamento do oscilador local $L O$ proposto. A idéia deste bloco é integrar as funções dos dois circuitos. Assim, o estágio de entrada composto pelos transistores $M_{1}$ até $M_{3}$, deve ter bom casamento da impedância de entrada em radiofrequência, com baixo ruído e um ganho alto, enquanto a célula Gilbert ou estágio de comutação faz a mistura, alternando os transistores do par diferencial $M_{3}$ e $M_{4}$. Também uma técnica para cancelar o componente do oscilador local presente no sinal de saída é apresentada mediante o estágio composto pelos transistores $M_{5}$ até $M_{9}$. Essa técnica consiste em gerar uma corrente através dos transistores $M_{6}$ e $M_{7}$, defasada 180 graus respeito às correntes que fluem através $M_{4}$ e $M_{5}$, a fim de cancelar a componente do oscilador local na saída. Os circuitos foram projetados usando o processo $c m r f 7 s f$ da $I B M$, que é um processo com melhorias para projetos de radiofrequência.



Figura 4.16: Vista esquemática completa do bloco $L N A$-misturador de banda larga projetado.

O dimensionamento para ambas as versões do bloco é mostrado na tabela 4.12. A diferença entre as duas versões do circuito está na utilização do indutor $L_{d}$ (em cor cinza na figura 4.16), que permite atingir uma maior largura de banda. No esquemático, as resistências $R_{1}$ e $R_{3}$ são usadas como fontes de corrente. Os capacitores $C_{i n}, C_{L O}, C_{1}$ and $C_{2}$ são usados para desacoplar 
em $D C$. Além disso, $C_{1}$ e $C_{2}$, também ajudam a melhorar o casamento da impedância de entrada e o ruído do estágio de transcondutância. Os resistores $R_{\text {bias }}$ são usados para bloquear os sinais $A C$ no ramo de polarização. Finalmente $M_{m}$ e $R_{r e f}$ formam um espelho de corrente para polarizar $M_{2}$ e $M_{3}$.

Tabela 4.12: Dimensionamento dos blocos $L N A$-Misturador em $I B M$.

\begin{tabular}{||c||ccccc||cc||}
\hline Transistor & $W_{t}[\mu \mathrm{m}]$ & $n_{f}$ & $W_{f}[\mu \mathrm{m}]$ & $\mathrm{m}$ & $\mathrm{L}[\mu \mathrm{m}]$ & Resistências \\
\hline \hline \multicolumn{8}{|c||}{ Estágio de transcondutância } \\
\hline$M_{1}$ & 60 & 6 & 10 & 1 & 0,18 & $R_{1}[\Omega]$ & $R_{2}[\Omega]$ \\
$M_{2}$ & 50 & 5 & 10 & 1 & 0,18 & 404 & $1,74 \mathrm{~K}$ \\
$M_{3}$ & 160 & 16 & 10 & 1 & 0,18 & & \\
\hline \multicolumn{8}{|c||}{ Estágio de conmutação } \\
\hline$M_{4}$ & 200 & 10 & 10 & 2 & 0,18 & $R_{L}[\Omega]$ \\
$M_{5}$ & 200 & 10 & 10 & 2 & 0,18 & 340 \\
\hline \multicolumn{7}{|c||}{ Estágio de cancelamento de $L O$} \\
\hline$M_{6}$ & 60 & 5 & 6 & 2 & 0,18 & $R_{3}[\Omega]$ \\
$M_{7}$ & 60 & 5 & 6 & 2 & 0,18 & \\
$M_{8}$ & 600 & 6 & 10 & 6 & 1 & 85 \\
$M_{9}$ & 600 & 6 & 10 & 6 & 1 & \\
\hline \hline
\end{tabular}

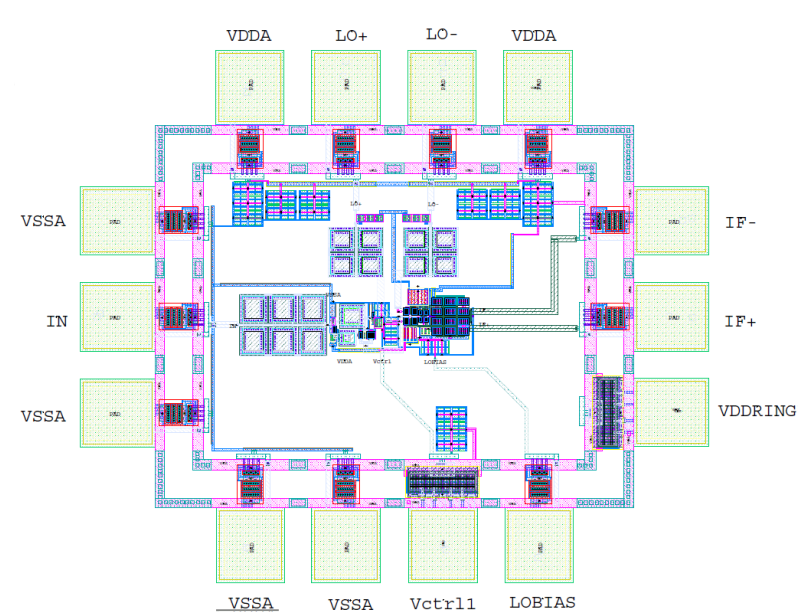

(a)

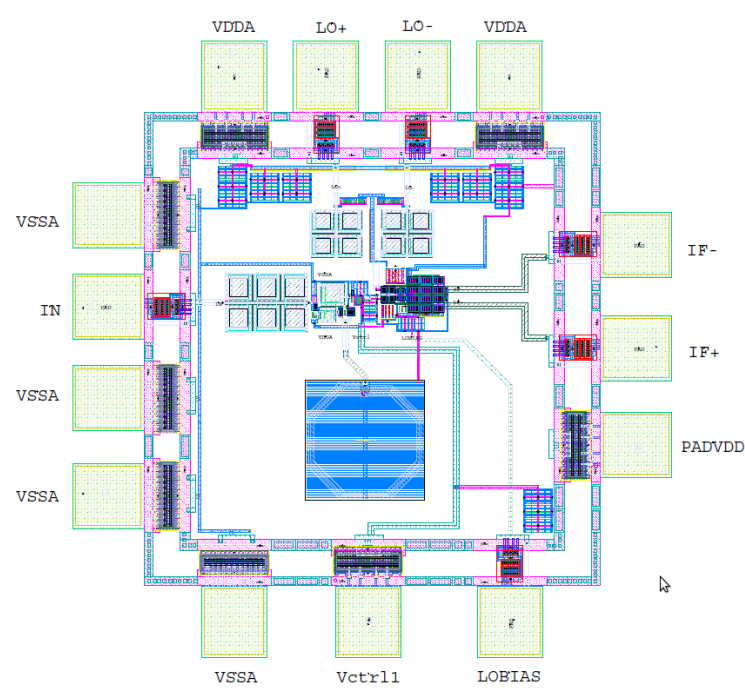

(b)

Figura 4.17: Layouts dos protótipos dos blocos LNA-misturador de banda larga usando o processo $c m r f 7 s f$ da IBM: (a) Versão sem indutor; (b) Versão com indutor.

Na figura 4.17, são mostrados os layouts para ambos os protótipos. O primeiro protótipo (mostrado na figura 4.17 (a)) ocupa uma área de $0,85 \mathrm{~mm}^{2}$. O segundo protótipo (mostrado na figura 4.17(b)) ocupa uma área de $1 \mathrm{~mm}^{2}$. No segundo protótipo o indutor é projetado para ressonar em uma frequência perto da frequência de $-3 \mathrm{~dB}$ da versão sem indutor.

O layout deste bloco precisa de ser desenhado com muito cuidado, pois existem três 
frequências diferentes através dele. A frequência de entrada (RF), a frequência do oscilador local $(L O)$, ea frequência intermediária $(I F)$. Portanto, deve-se evitar o acoplamento desses sinais evitando quanto seja possível caminhos onde eles se cruzam, e se tiverem de passar umas sobre as outras, túneis são necessários para isolar-os. Além das considerações anteriores no roteamento, o layout do par diferencial (estágio de comutação) precisa de ter casamento entre os dispositivos para garatir simetria, mas por tratar-se de um circuito de radiofrequência a matriz de casamento tem poucos dispositivos, já que o roteamento introduz capacitâncias e resistências não desejadas que podem alterar a frequência de operação. Adicionalmente, os pads de entrada e saída de sinal usados e as protecções de ESD (Electrostatic Discharge), são projetadas de forma a reduzir a capacitancia adicionada. Finalmente, tal como nos layouts anteriores foram adicionados capacitores entre o nó da alimentação e a terra a fim de filtrar alguns ruídos.

Tabela 4.13: Resultados pós-layout dos blocos $L N A$-misturador de banda larga em $0,18 \mu \mathrm{m}$ da $I B M$.

\begin{tabular}{||c||ccccccc||}
\hline Protótipo & Freq.[GHz] & $\mathrm{NF}_{S S B}[\mathrm{~dB}]$ & $A_{v}[\mathrm{~dB}]$ & $S_{11}[\mathrm{~dB}]$ & $P_{D}[\mathrm{~mW}]$ & $P_{I I P 3}[\mathrm{dBm}]$ & Área[mm $\left.{ }^{2}\right]$ \\
\hline \hline $\mathrm{V} 1^{\mathrm{a}}$ & $0,5-6$ & $7,4-9,1$ & 21,5 & $\leq-6$ & 14,4 & $\geq-12,4$ & 1 \\
$\mathrm{~V}^{\mathrm{b}}$ & $0,5-5,5$ & $7,4-10,3$ & 19,8 & $\leq-7,6$ & 14,4 & $\geq-12,3$ & 0,85 \\
\hline
\end{tabular}

${ }^{a}$ Versão com indutor.

b Versão sem indutor.

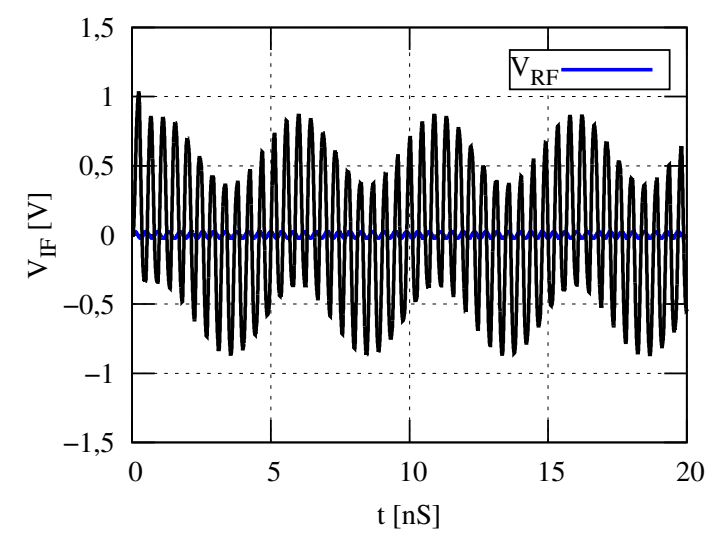

(a)

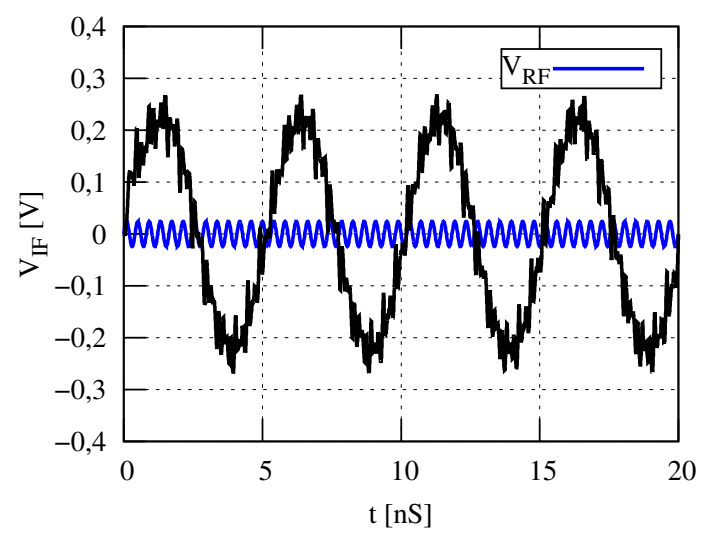

(b)

Figura 4.18: Resposta transiente dos blocos $L N A$-misturador de banda larga: (a) Sinal de sáida sem cancelamento do $L O$; (b) Sinal de sáida com cancelamento do $L O$

Os resultados para ambas as versões são apresentados na tablela 4.13, e nas figuras 4.18 e 4.19. Ambos os circuitos têm uma frequência intermediária de $200 \mathrm{MHz}$, e nas figuras 4.18(a) e 4.18(b) são apresentados os dois tipos de resposta transiente para demonstrar o efeito do circuito de cancelamento de oscilador local em uma célula Gilbert única. Nas figuras, o sinal de entrada $\left(V_{R F}\right)$ tem uma frequência 2,45 GHz. Também, na figura 4.19 pode-se observar que 
a versão com indutor tem uma figura de ruído mais achatada e maior largura de banda. Neste caso, a largura da banda de operação da versão com indutor não é limitada pelo ganho, mas pelo casamento da impedância de entrada.

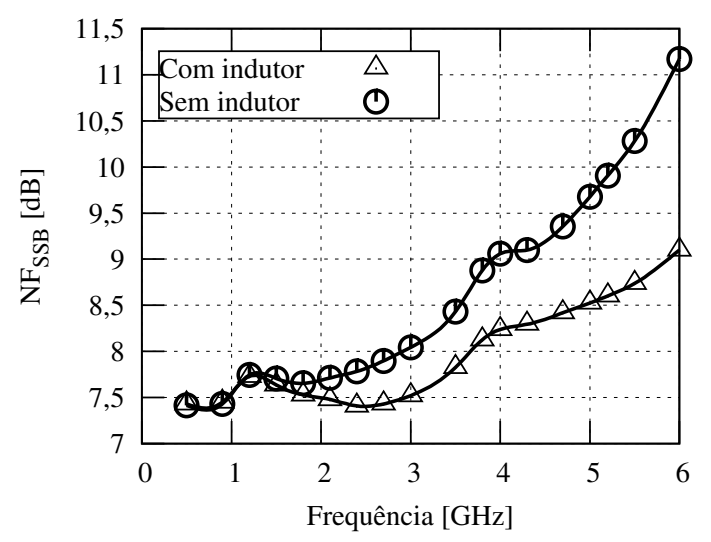

(a)

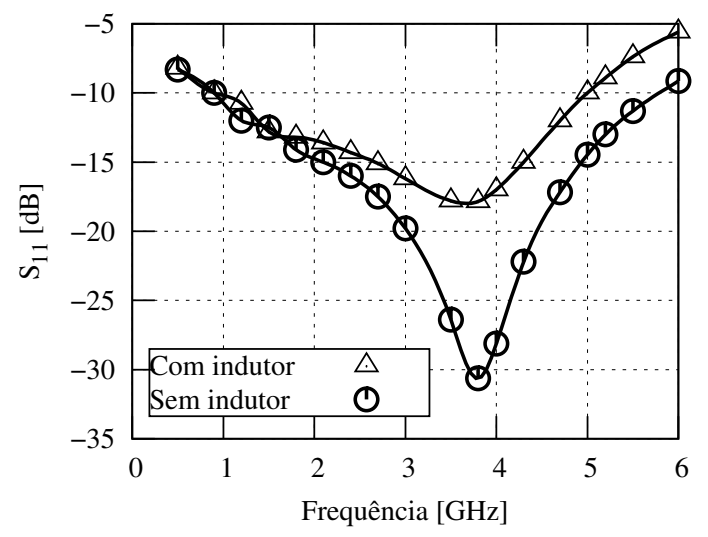

(c)

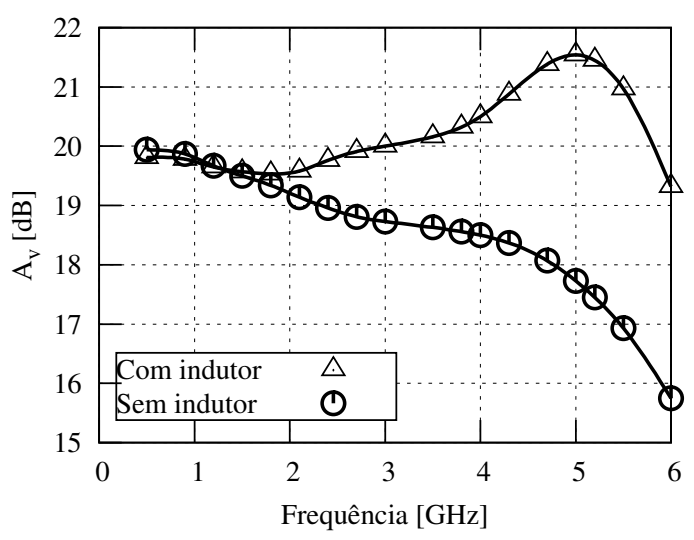

(b)

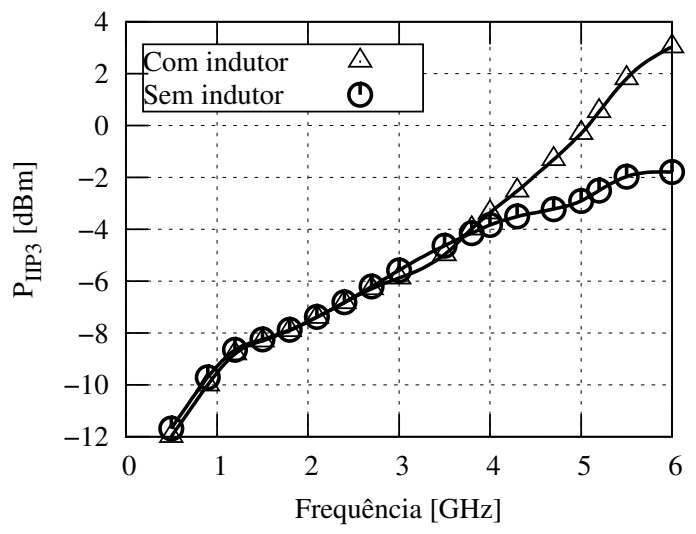

(d)

Figura 4.19: Resultados pós-layout dos blocos $L N A$-misturador de banda larga projetadas no processo da IBM: (a) Figura de ruído de banda lateral única; (b) Ganho de tensão; (c) Coeficiente de reflexão da entrada; (d) Interceptação de terceira ordem.

\subsection{Chips fabricados}

Nas figuras 4.20 e 4.21 são apresentadas as microfotografias dos chips fabricados. Os quatro circuitos foram fabricados e apenas um deles foi encapsulado (o LNA da TowerJazz). No entanto, o encapsulado usado não é feito especialmente para aplicações de radiofrequência e portanto fazer algumas medições de radiofrequência usando esta versão é inútil, mas um teste inicial de polarização é feito e o circuito opera na corrente esperada. Para os quatro protótipos serão feitas placas e o bondwire a fim de realizar as medições Chip-On-Board. Além disso, os blocos de banda estreita foram projetados considerando a possibilidade de utilizar pontas de 
teste de radiofrequência. Todas as medições serão feitas seguindo as orientações e os passos propostos em [52].

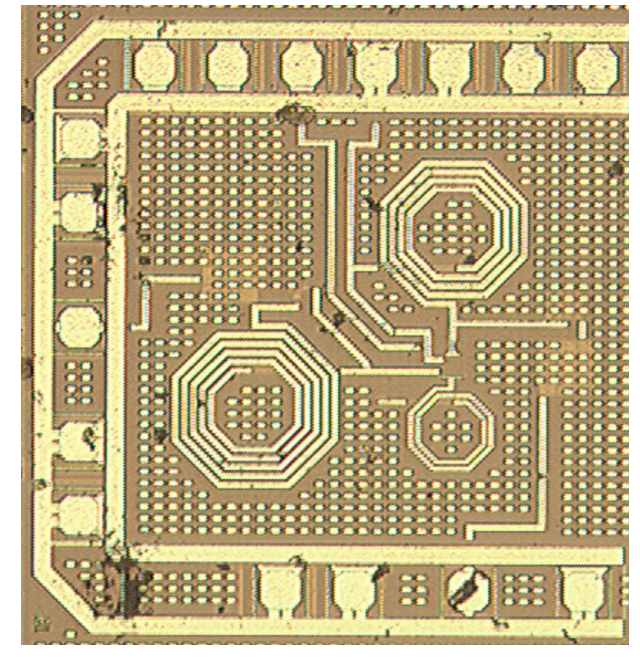

(a)

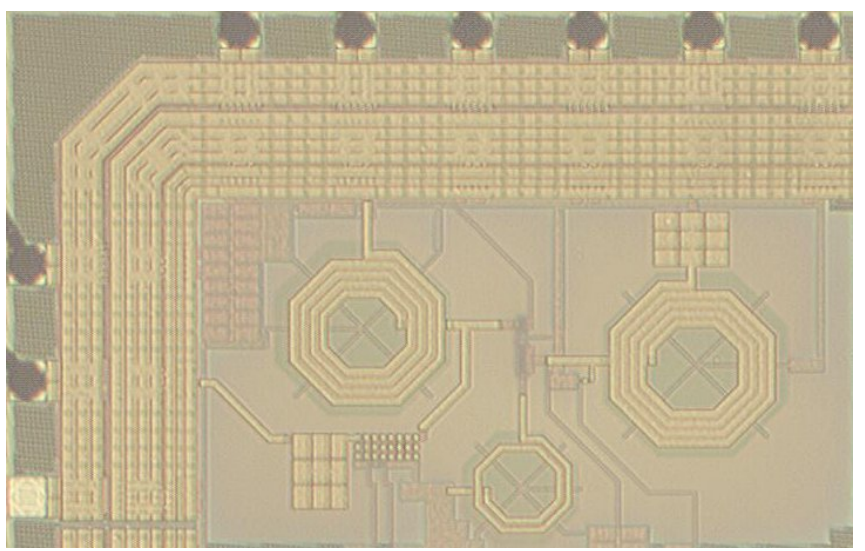

(b)

Figura 4.20: Microfotografia dos $L N A$ s de banda estreita: (a) XFAB; (b) TowerJazz.

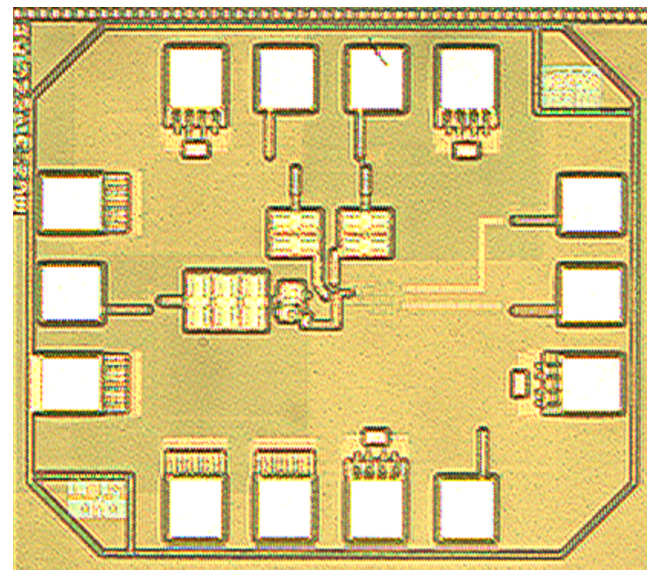

(a)

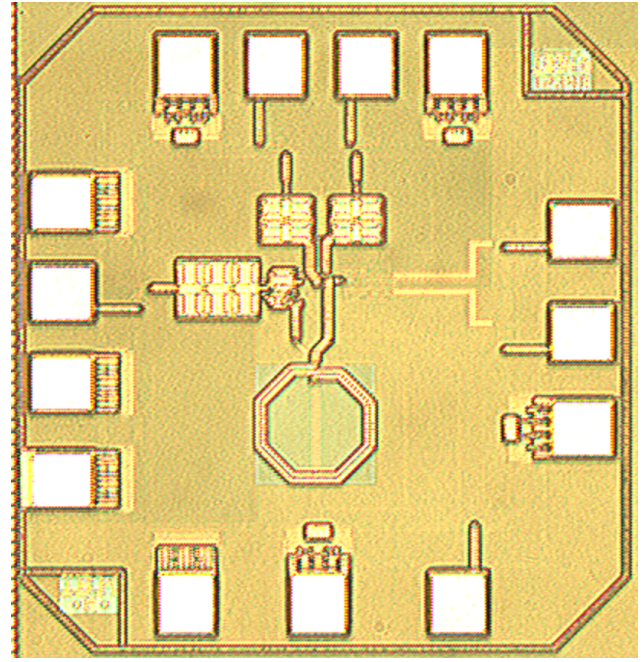

(b)

Figura 4.21: Microfotografia dos blocos $L N A$-misturador de banda larga usando o processo da $I B M$ : (a) Versão sem indutor; (b) Versão com indutor.

\subsubsection{Resultados parciais de medida dos $L N A$ s de banda estreita}

Para os dois $L N A$ s banda estreita de algumas medidas parciais foram feitas usando micro pontas de teste para radiofrequência de forma a obter alguns resultados e verificar a funcionalidade básica (Consumo de potência e parâmetros S.). Para o chip da TowerJazz as micro pontas de teste foram posicionadas através do encapsulado e os bondwires dos pads de entrada e saída de 
sinal foram retirados para testar apenas o núcleo do circuito como mostrado na figura 4.22(c). Para o chip da $X F A B$ duas amostras foram testadas com a configuração mostrada na figura $4.23(\mathrm{c})$.



(a)



(b)

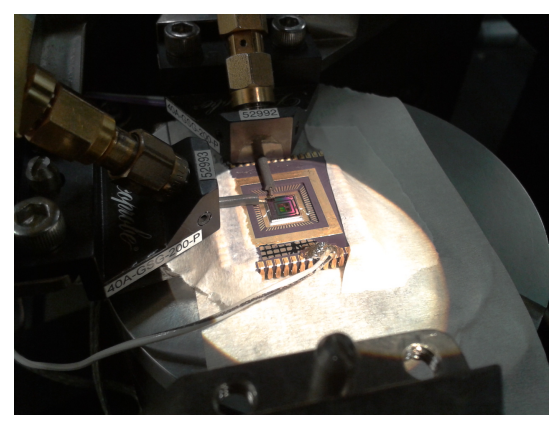

(c)

Figura 4.22: Resultados experimentais parciais do LNA da Towerjazz: (a) Figura de ruído e coeficiente de reflexão da entrada; (b) Ganho e coeficiente de reflexão da saída; (c) Set up de medida.

Dos resultados obtidos durante os testes do chip da TowerJazz, a polarização do circuito foi como o esperado mas o circuito não funcionou na frequência como era suposto. Em seguida, depois de analisar detalhadamente o layout do bloco foi detectado que o problema foi uma interpretação incorrecta dos pinos de conexão do pad de entrada e saída de sinal fornecido pela foundry. Consequência disso, a entrada do sinal foi ligado num pino onde este sinal flui através de um resistor de $600 \Omega$ antes de entrar no LNA o que atenua totalmente o nível do sinal. O mesmo erro foi detectado no pad de saída, portanto, qualquer sinal residual na saída também é atenuada pela resistência do pad (figura 4.22(b)).

Os resultados parciais dos testes feitos neste bloco são apresentados na tabela 4.14, onde pode ser visto que a corrente de polarização é próxima da corrente obtida durante a fase de simulação, mas o circuito está atenuando o sinal de entrada (parâmetro $S_{21}$ na tabela) produto da má interpretação dos pinos do pad feita. Esse problema também afeta o casamento das impedâncias de entrada e saída como se mostra na tabela e nas figuras 4.22(a) e 4.22(b). 
Tabela 4.14: Resultados parciais das medidas do chip da TowerJazz.

\begin{tabular}{||c||ccc||}
\hline Resultado & $P G$ & Pós-layout & Medidas \\
\hline \hline $\mathrm{NF}[\mathrm{dB}]$ & 1 & 1,48 & NA \\
$\mathrm{S}_{11}[\mathrm{~dB}]$ & -32 & $-25,7$ & -6 \\
$\mathrm{~S}_{21}[\mathrm{~dB}]$ & 13,6 & 13,4 & $-9,2$ \\
$\mathrm{~S}_{12}[\mathrm{~dB}]$ & $\mathrm{NA}$ & $-39,9$ & -33 \\
$\mathrm{~S}_{22}[\mathrm{~dB}]$ & $\mathrm{NA}$ & -18 & $-4,8$ \\
$I I P 3[\mathrm{dBm}]$ & $\mathrm{NA}$ & -5 & $\mathrm{NA}$ \\
$P_{D}[\mathrm{~mW}]$ & 8,3 & 8,1 & 8,5 \\
\hline
\end{tabular}

Por outro lado, os testes do chip da $X F A B$ são bem sucedidos. O valor da corrente de polarização é adequado, e o circuito se comporta na frequência muito próximo do esperado. Como mostrado nas figuras 4.23(a) e 4.23(b), o circuito tem casamento das impedâncias de entrada e saída adequado, e o ganho é próximo do ganho simulado. No entanto, a diferença no valor de ganho é produto das estruturas dummy presentes no centro dos indutores. Estas estruturas podem reduzir o fator de qualidade do indutor à metade ou até uma terceira parte afetando principalmente o ganho e a figura de ruído.

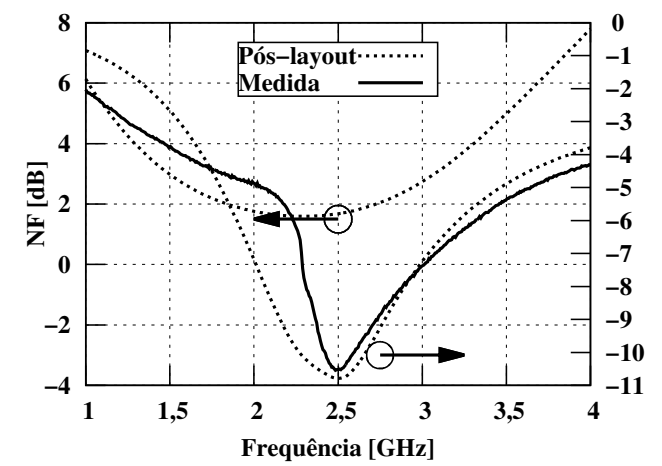

(a)

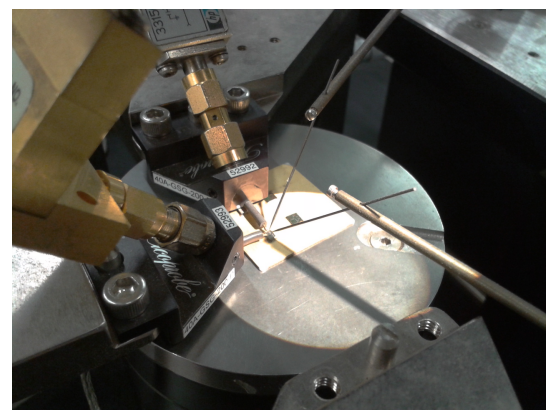

(c)

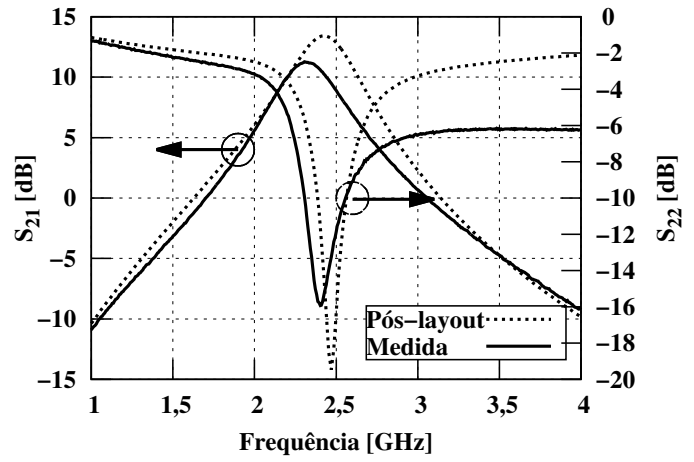

(b)

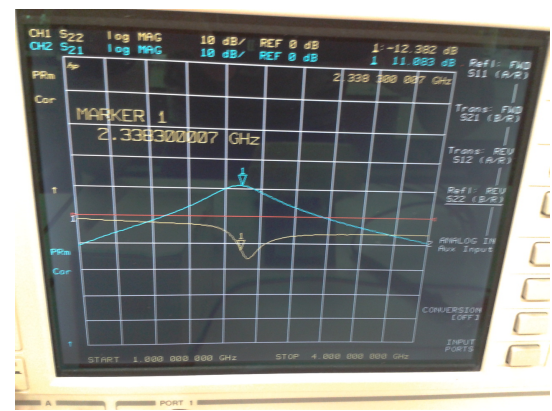

(d)

Figura 4.23: Resultados experimentais parciais do $L N A$ da $X F A B$ : (a) Figura de ruído e coeficiente de reflexão da entrada; (b) Ganho e coeficiente de reflexão da saída; (c) Set up de medida; (d) Vista do analisador de redes.

Na figura 4.23(d) é apresentada a medição do ganho e o coeficiente de reflexão da saída 
obtida no analisador de redes para este chip. Finalmente, na tabela 4.15 são apresentados e comparados os resultados parciais das medições com os resultados das simulações.

Tabela 4.15: Resultados parciais das medidas do chip da XFAB.

\begin{tabular}{||c||ccc||}
\hline Resultado & $P G$ & Pós-layout & Medidas \\
\hline \hline $\mathrm{NF}[\mathrm{dB}]$ & 1,1 & 1,64 & NA \\
$\mathrm{S}_{11}[\mathrm{~dB}]$ & -27 & -11 & $-10,4$ \\
$\mathrm{~S}_{21}[\mathrm{~dB}]$ & 13,4 & 13,4 & 10 \\
$\mathrm{~S}_{12}[\mathrm{~dB}]$ & $\mathrm{NA}$ & $-40,2$ & -25 \\
$\mathrm{~S}_{22}[\mathrm{~dB}]$ & $\mathrm{NA}$ & $-17,8$ & $-14,3$ \\
IIP3 $[\mathrm{dBm}]$ & $\mathrm{NA}$ & $-6,8$ & $\mathrm{NA}$ \\
$P_{D}[\mathrm{~mW}]$ & 3,8 & 3,84 & 4,1 \\
\hline
\end{tabular}

Para as medições de todos os parâmetros do LNA (incluindo a linearidade e a figura de ruído), o circuito da $X F A B$ será testado Chip-On-Board como mencionado no início desta seção. Para o chip TowerJazz não serão feitos mais testes por causa do problema detectado na ligação dos pads usados. 


\section{Conclusões e trabalhos futuros}

Esta dissertação teve como principal objetivo realizar o estudo para formulação do problema de projeto de amplificadores de baixo ruído para radiofrequência utilizando programação geométrica. O estudo começou com a documentação de algumas técnicas e topologias propostas para melhorar os parâmetros de desempenho do bloco, com o objetivo de atualizar o estado-daarte em relação aos trabalhos anteriores.

Em seguida, foi feito um estudo da topologia mais comum para $L N A$ s de banda estreita, formulando rigorosamente os principais parâmetros de desempenho. Alguns efeitos normalmente desprezados, como a capacitância porta-dreno e os indutores não ideais foram incluídos.

Posteriormente, foram feitas algumas considerações para formular o problema de projeto do bloco, como um problema de otimização usando cinco processos de fabricação diferentes, dos quais dois foram enviados para fabricação.

Finalmente, uma topologia para estágio de transcondutância usada em LNAs de banda larga foi estudada, formulada e usada no projeto de um bloco LNA-Misturador. Nesse caso, a programação geométrica foi aplicada no estágio de transcondutância mencionado, ajudando no processo de dimensionamento para garantir baixo ruído e o casamento de impedância. Esse protótipo foi também enviado para fabricação em duas versões diferentes.

A aplicação da programação geométrica na topologia de fonte comum com degeneração indutiva, ajudou na obtenção de projetos iniciais otimizados em curto tempo. A inclusão da capacitância porta-dreno na formulação, permitiu garantir o casamento da impedância de entrada em cinco processos diferentes, já que à medida que os processos de fabricação diminuem a largura do canal do transistor e as frequências aumentam, esta capacitância tornase consideravel. Também é importante notar que considerar esta capacitância no programa geométrico, permite tratar de melhor maneira a relação entre a figura de ruído e o acoplamento da impedância de entrada descrito no primeiro capítulo.

A criação de modelos precisos para os principais parâmetros do transistor mencionados no 
segundo capítulo, permitem a obtenção de uma melhor correspondência entre os resultados da otimização e as simulações, diminuindo o tempo de projeto e a quantidade de ajustes necessários.

O fato de considerar a resistência parasita associada ao indutor CMOS durante a formulação do projeto, permite uma melhor estimativa do ruído e do casamento de impedância na entrada. Além disso, é importante notar que os indutores $C M O S$ são uma boa opção em aplicações de banda estreita, quando é necessário garantir ressonância em frequências maiores do que a frequência de ganho unitário do transistor. Em aplicações de potência ultra-baixa, são usados para manter as quedas de tensão baixas em um ramo. Por outro lado, a principal desvantagem dos indutores $C M O S$, é o seu consumo de área elevado que não é escalável, e também, dependendo da tecnologia, seu desempenho de ruído.

O desenvolvimento de scripts para evitar ou reduzir alguns dos processos iterativos durante o fluxo de projeto, permitiu também a criação de ferramentas para a automação do projeto.

Neste trabalho, o projeto do amplificador de baixo ruído de banda estreita usando programação geométrica foi totalmente automatizado, reduzindo o tempo de desenvolvimento e alguns trabalhos tediosos para o projetista, além de forneçer ferramentas para fazer algumas varreduras das variáveis de projeto, e ter a opção de usar diferentes simuladores. É importante notar que neste caso em particular, a automação de projeto não implica que, um usuário que não tenha conhecimento prévio sobre amplificadores de baixo ruído, obterá um projeto otimizado, introduzindo especificações aleatoriamente. A redução do tempo de projeto e a segurança que o problema possa ser resolvido usando programação geométrica, depende das especificações introduzidas e do espaço de projeto explorado. Esses parâmetros são definidos adequadamente, à medida que o usuário tenha experiência prévia no projeto do bloco.

Estudou-se e demonstrou-se a característica de cancelamento de ruído da topologia selecionada para o LNA de banda larga. Com esta topologia é possível utilizar um amplificador de porta comum como estágio de entrada, para obter o casamento da impedância de entrada de banda larga, sem aumentar consideravelmente o ruído. Também, foi demonstrado que a programação geométrica pode ser aplicada para obter um ponto inicial no projeto desse bloco. Por outro lado, as análises do bloco foram focadas na obtenção do casamento de impedâncias na entrada e garantir o cancelamento do ruído. No entanto, a largura de banda pode ser melhorada através da utilização de alguns dispositivos passivos, como mostrado no bloco LNA-Misturador de banda larga que foi proposto e fabricado.

Utilizando programação geométrica foi possível descrever o projeto de amplificadores de ruído baixo para aplicações de banda estreita e banda larga, e resolvê-lo em menos de 20 
minutos mantendo-se erros inferiores a $10 \%$ entre as equações e os resultados das simulações. Demonstrando-se que esta técnica permite a obtenção de pontos de partida muito bons em curto tempo e com pouca intervenção do projetista durante o processo.

Como trabalhos futuros, recomenda-se abordar mais profundamente o projeto de amplificadores de baixo ruído de banda larga e banda ultra larga, e fazer um estudo da inclusão de ferramentas $C A D$ usando algoritmos não tão restritivos como a programação geométrica. Também, recomenda-se considerar desde o início do projeto os efeitos da fabricação, o empacotamento, e o acondicionamento para medição do circuito. Por outro lado, faz-se necessário uma análise mais profunda sobre as constantes de ruído, a fim de estudar se elas realmente mudam com os processos da forma como é relatado, e também estudar o efeito da fonte de ruído do canal em dispositivos de canal curto.

Uma última recomendação importante é o estudo de aplicação de blocos de radiofrequência unidos ou mistos e blocos que possuem circuitos digitais, com a finalidade de aumentar a escalabilidade, melhorar o desempenho desses circuitos e seguir a tendencia do estado-da-arte. 


\section{APÊNDICE A - Exploração do espaço de projeto do $L N A$ de banda estreita}

Durante o desenvolvimento desse trabalho, foi necessário fazer algumas simulações a fim de descrever a relação entre a tensão de polarização e o ponto de interceptação de terceira ordem conforme descrito no capítulo 2. Para isso, foi criado um script que permite acoplar as impedâncias de entrada e saída de um LNA fonte comum com degeneração indutiva para cada ponto de tensão de polarização, e depois extrair o parâmetro de linearidade. Além disso, o script permite fazer a varredura da relação entre o dispositivo de transcondutância e o transistor $M_{2}\left(W_{1} / W_{2}\right)$, permite usar indutâncias reais (geradas no ASITIC) e ideais, considerar uma saída casada a $50 \Omega$, ou apenas o tanque ressonante como saída, e até mesmo incluir os efeitos do bondwire e dos pads. O script funciona seguindo a metodologia descrita no diagrama de fluxo da figura A.1.

É importante notar a diferença entre esse script e os scripts desenvolvidos durante a abordagem usando programação geométrica. O fluxo usando PG irá conduzir a um resultado em minutos utilizando apenas as expressões matemáticas. Este resultado é um excelente ponto de partida e alguns ajustes são necessários durante as simulações a fim de obter o projeto final. Por outro lado, o script mencionado neste apêndice irá criar uma matriz (através de simulações usando o Eldorf da Mentor Graphics) com todos os LNAs com casamento de impedâncias que existem no interior do espaço de projeto de acordo com um passo definido. A geração desta matriz poderá levar dias ou mesmo semanas dependendo do tamanho do espaço, o passo definido, e a capacidade de processamento. Em seguida, um outro script é necessário para definir uma figura de mérito e selecionar um ou vários pontos no interior da matriz.

Neste apêndice são mostrados alguns gráficos obtidos durante os testes realizados para o processo de $0,35 \mu \mathrm{m}$ da $A M S$ e cujos resultados foram úteis no desenvolvimento de uma tese de doutorado [55]. Nos testes apresentados são considerados comprimento de canal mínimo no transistor, indutor de carga de $5 \mathrm{nH}$, e os indutores como uma indutância com uma resistência em série. $\mathrm{O}$ fator de qualidade dos indutores é assumido de 4,5 e constante na frequência. 


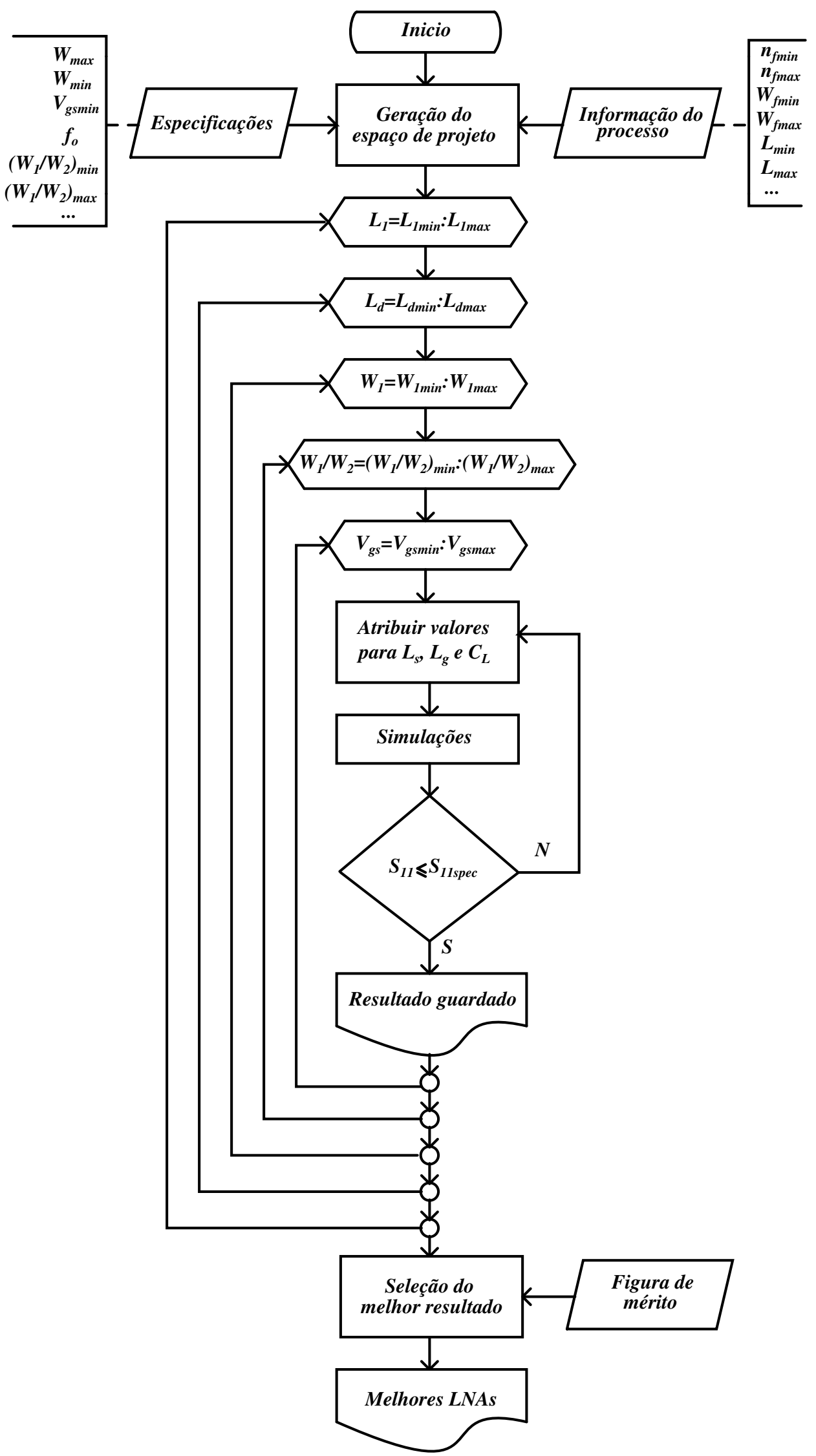

Figura A.1: Metodologia proposta para a exploração automática do espaço de projeto do $L N A$ de banda estreita. 
Mesmo que os gráficos apresentados nas figuras A.2 até A.10 estão em função da tensão de polarização, com todos os dados obtidos é possível plotar muitas outras possibilidades (inclusive as fronteiras de Pareto) de forma a observar diferentes compromissos entre as variáveis de projeto e os parâmetros de desempenho. Por exemplo, assumindo uma tensão de polarização fixa, pode-se plotar os parâmetros de desempenho em função da largura do canal do transistor do estágio de transcondutância $\left(W_{1}\right)$, para diferentes frequências ou tipos diferentes de indutâncias. Também é possível varrer outras variáveis, como o comprimento do canal do transistor e a indutância de carga. No entanto, quanto maior o número de variáveis envolvidas, maior será o tempo de processamento, tornando inviável a execução desse script em um computador pessoal comum. Finalmente, o script pode ser adaptado para trabalhar com outras tecnologias e simuladores, mesmo com tecnologias que incluem indutores no seu kit de projeto.
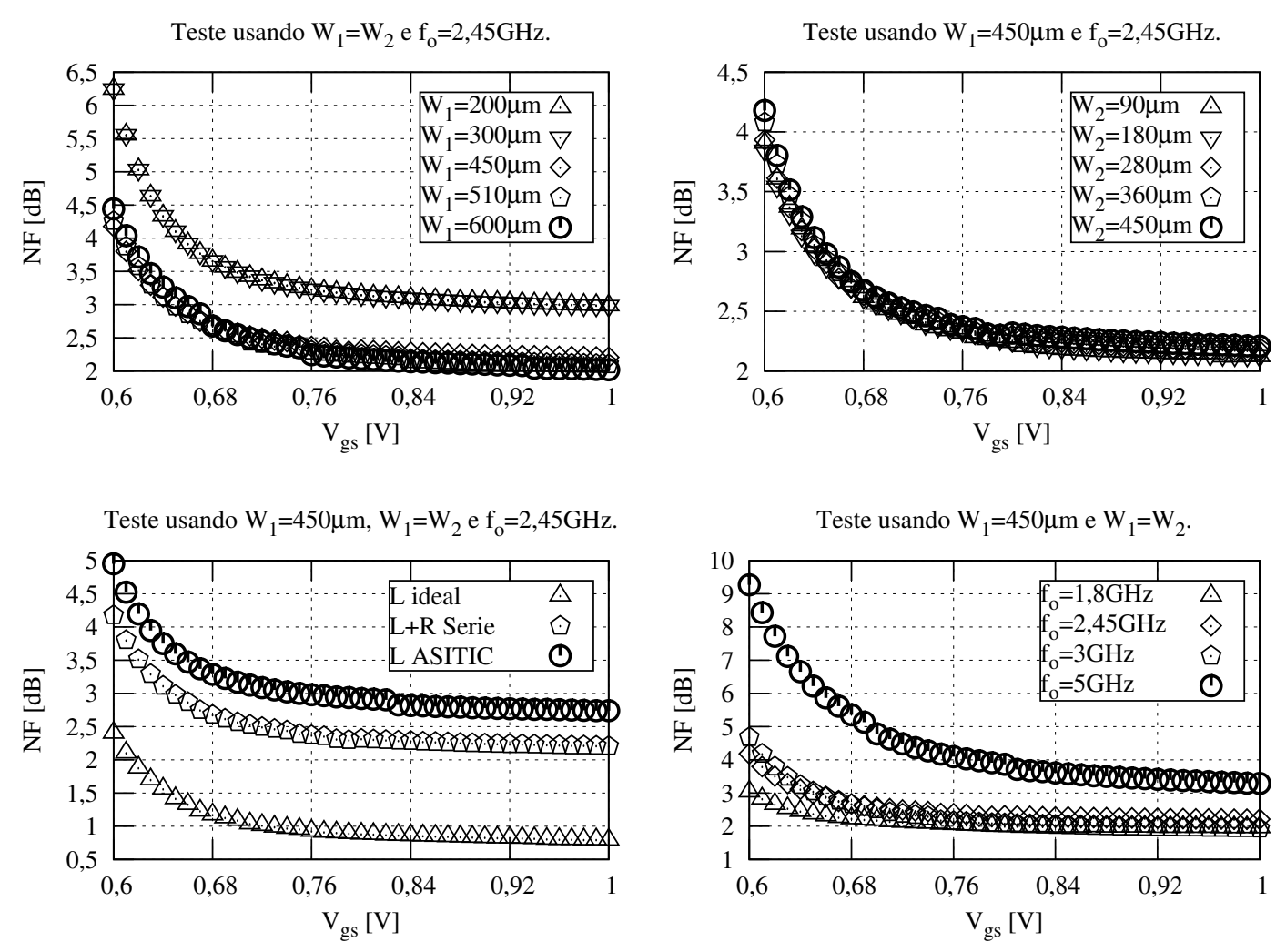

Figura A.2: Figura de ruído resultado de diferentes simulações. 

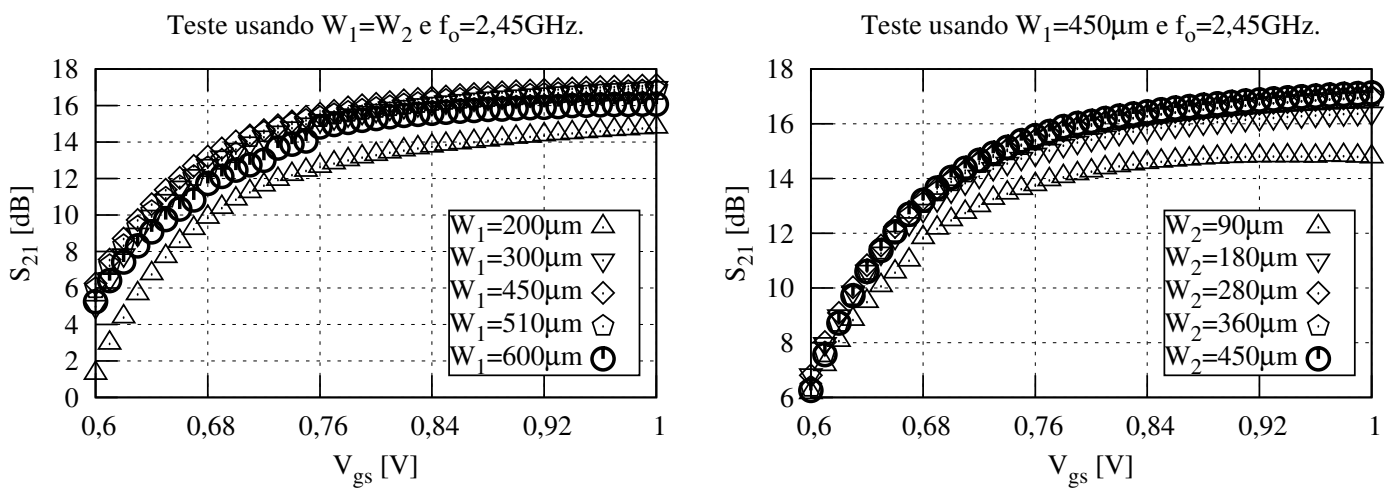

Teste usando $\mathrm{W}_{1}=450 \mu \mathrm{m}, \mathrm{W}_{1}=\mathrm{W}_{2}$ e $\mathrm{f}_{\mathrm{o}}=2,45 \mathrm{GHz}$.


Figura A.3: Ganho resultado de diferentes simulações.
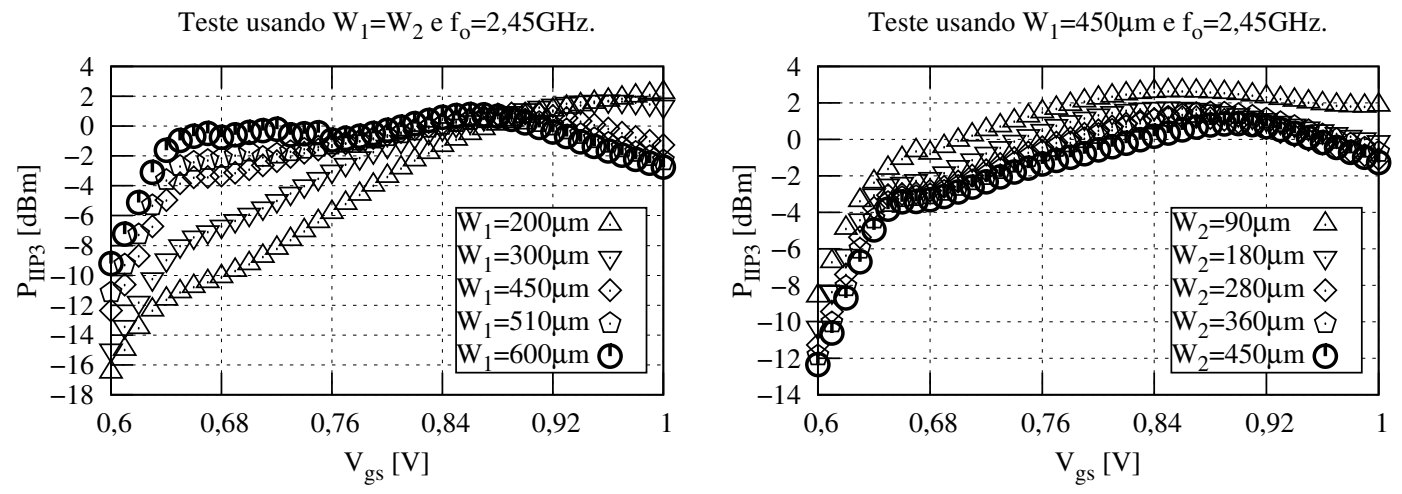

Teste usando $\mathrm{W}_{1}=450 \mu \mathrm{m}, \mathrm{W}_{1}=\mathrm{W}_{2}$ e $\mathrm{f}_{\mathrm{o}}=2,45 \mathrm{GHz}$.

Teste usando $\mathrm{W}_{1}=450 \mu \mathrm{m}$ e $\mathrm{W}_{1}=\mathrm{W}_{2}$.
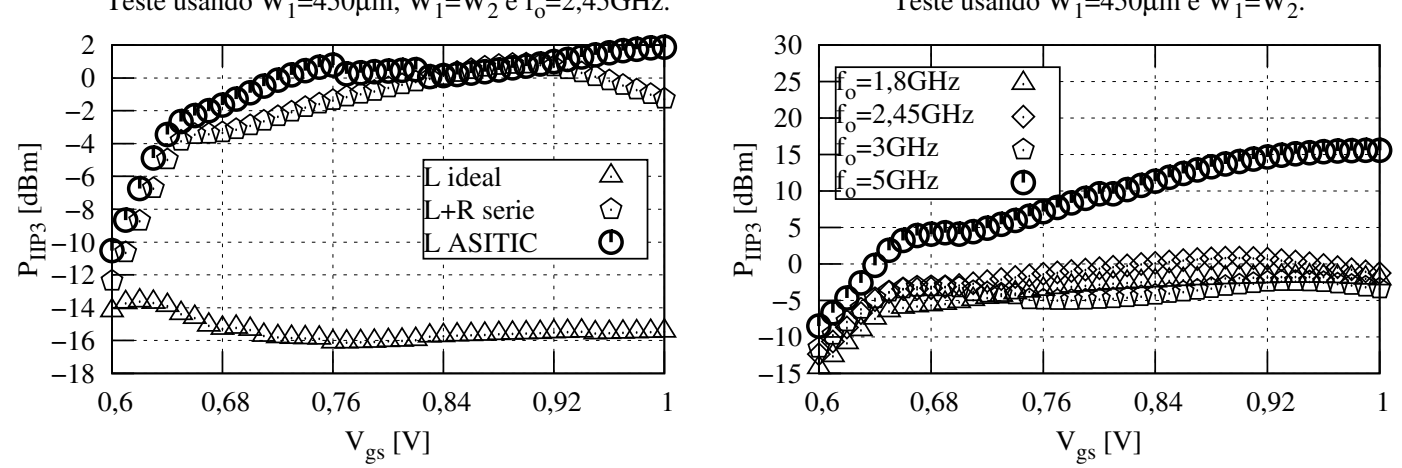

Figura A.4: Interceptação de terceira ordem resultado de diferentes simulações. 
Teste usando $\mathrm{W}_{1}=\mathrm{W}_{2}$ e $\mathrm{f}_{\mathrm{o}}=2,45 \mathrm{GHz}$.

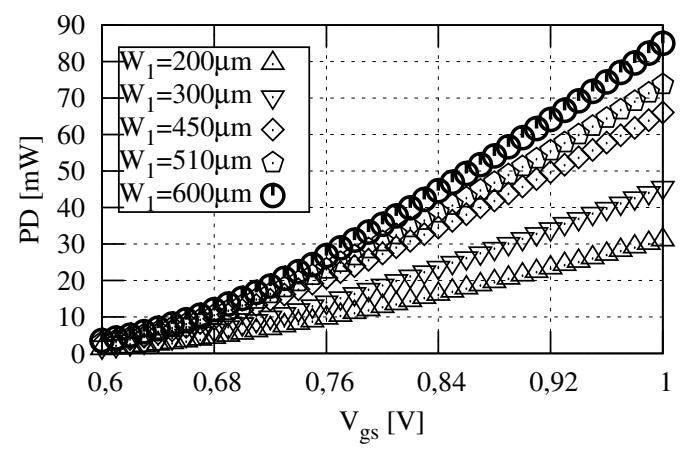

Teste usando $\mathrm{W}_{1}=450 \mu \mathrm{m}, \mathrm{W}_{1}=\mathrm{W}_{2}$ e $\mathrm{f}_{\mathrm{o}}=2,45 \mathrm{GHz}$.

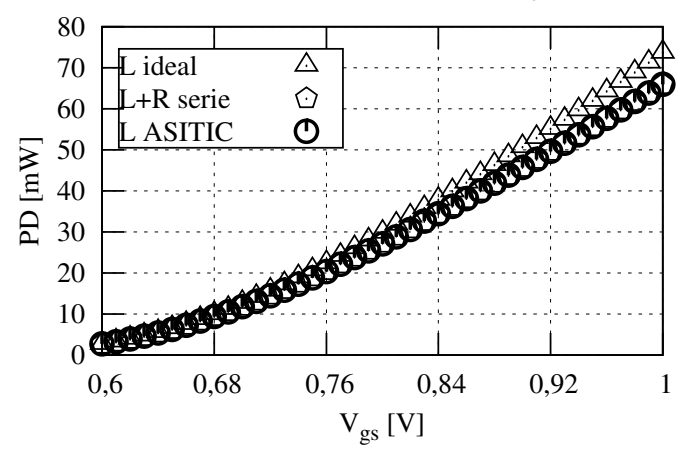

Teste usando $\mathrm{W}_{1}=450 \mu \mathrm{m}$ e $\mathrm{f}_{\mathrm{o}}=2,45 \mathrm{GHz}$.

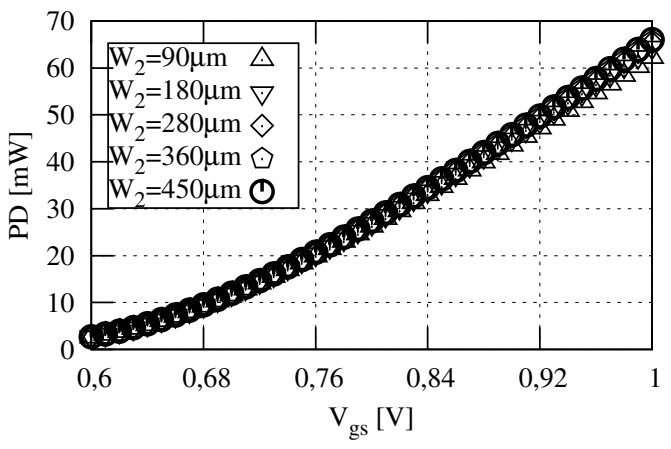

Teste usando $\mathrm{W}_{1}=450 \mu \mathrm{m}$ e $\mathrm{W}_{1}=\mathrm{W}_{2}$.

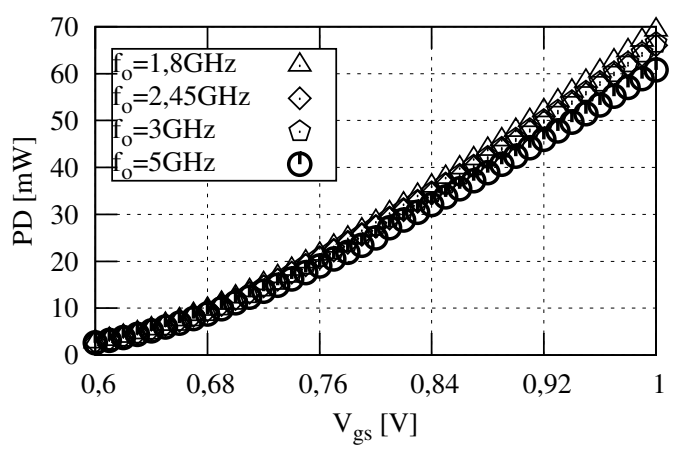

Figura A.5: Consumo de potência resultado de diferentes simulações.
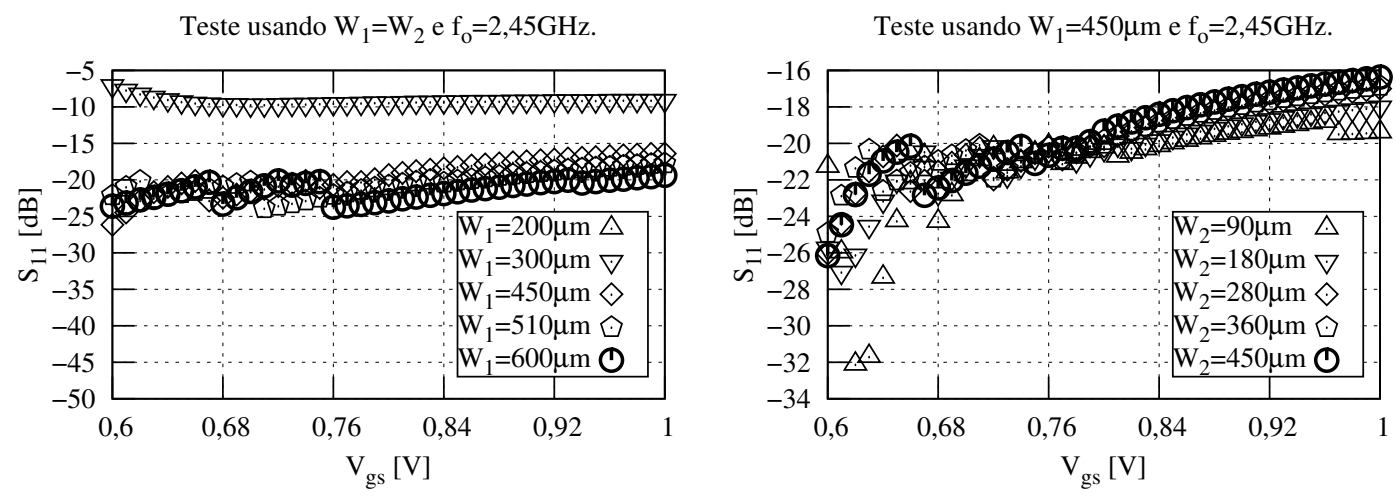

Teste usando $\mathrm{W}_{1}=450 \mu \mathrm{m}, \mathrm{W}_{1}=\mathrm{W}_{2}$ e $\mathrm{f}_{\mathrm{o}}=2,45 \mathrm{GHz}$. Teste usando $\mathrm{W}_{1}=450 \mu \mathrm{m}$ e $\mathrm{W}_{1}=\mathrm{W}_{2}$.
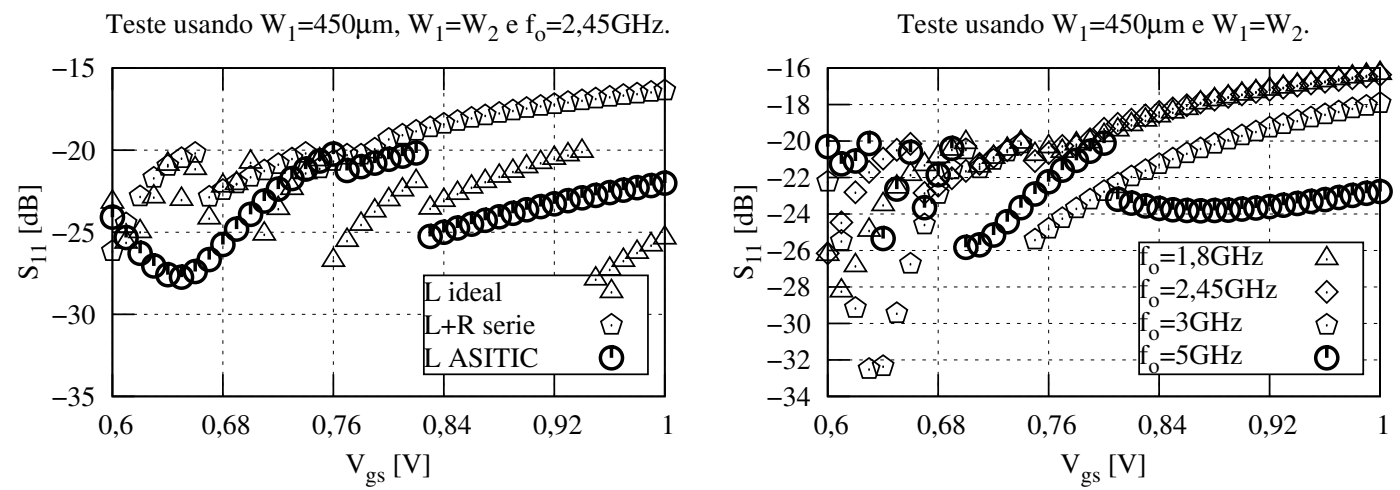

Figura A.6: Casamento da impedância de entrada garantido nas diferentes simulações. 

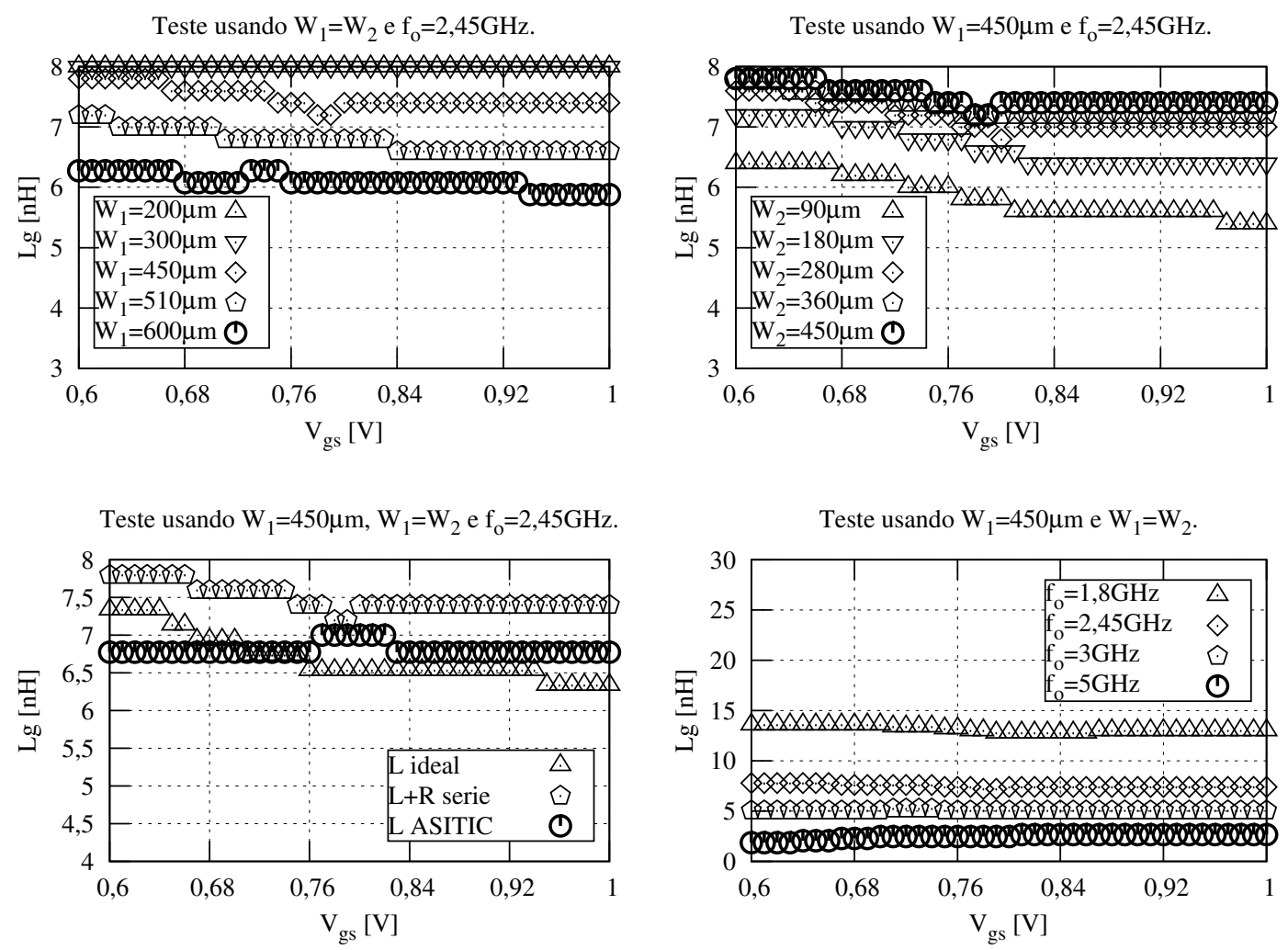

Figura A.7: Indutância de porta obtida para casar a impedância de entrada nas simulações.
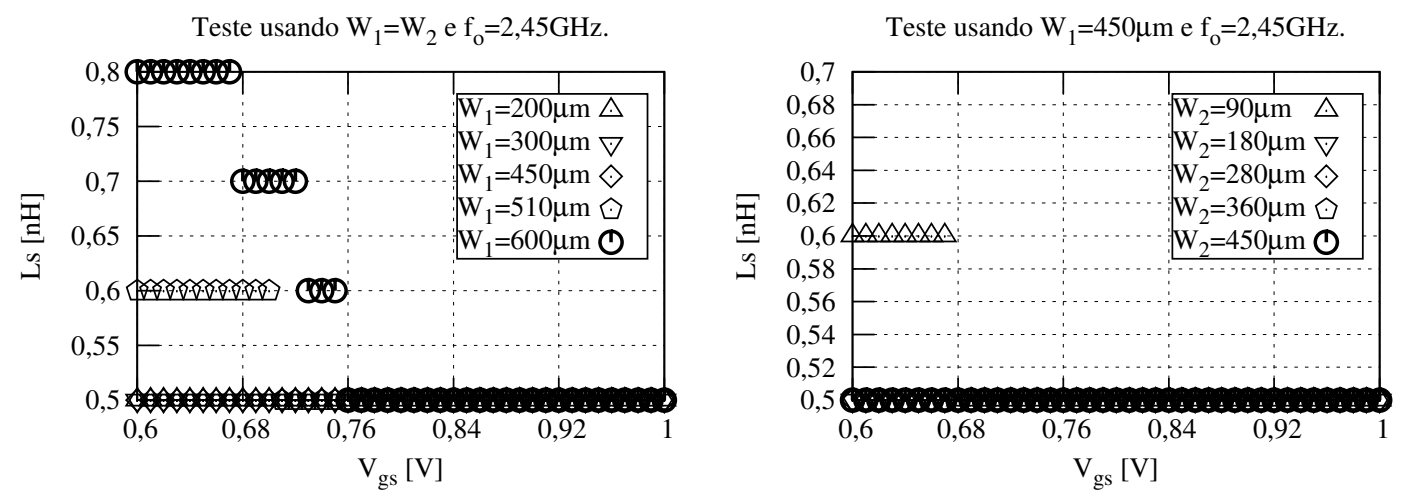

Teste usando $\mathrm{W}_{1}=450 \mu \mathrm{m}, \mathrm{W}_{1}=\mathrm{W}_{2}$ e $\mathrm{f}_{\mathrm{o}}=2,45 \mathrm{GHz}$.
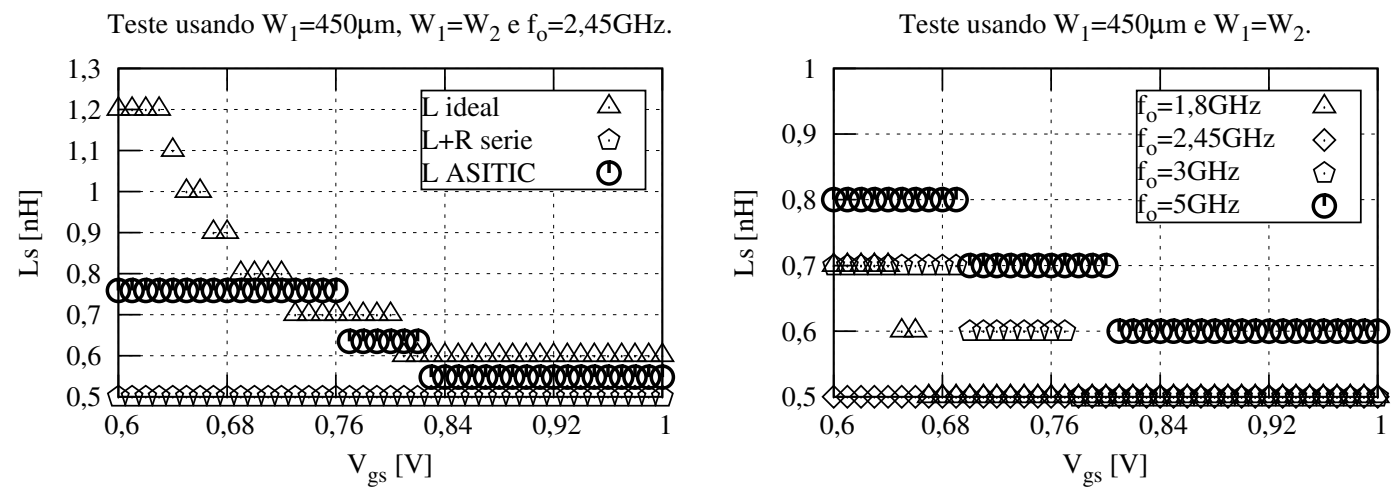

Figura A.8: Indutância de degeneração obtida para casar a impedância de entrada nas simulações. 
Teste usando $\mathrm{W}_{1}=\mathrm{W}_{2}$ e $\mathrm{f}_{\mathrm{o}}=2,45 \mathrm{GHz}$.

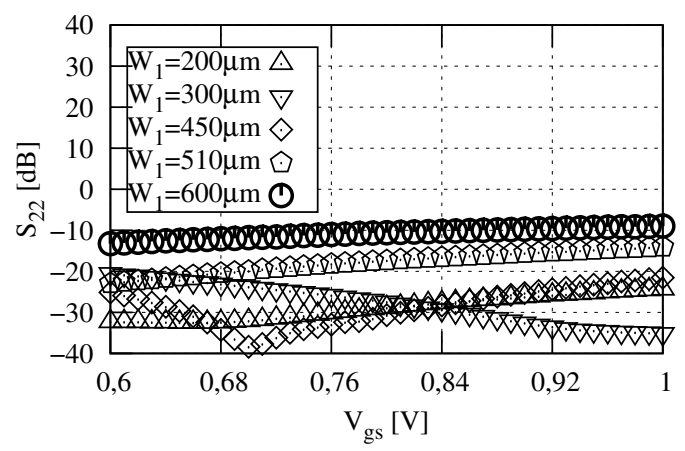

Teste usando $\mathrm{W}_{1}=450 \mu \mathrm{m}, \mathrm{W}_{1}=\mathrm{W}_{2}$ e $\mathrm{f}_{\mathrm{o}}=2,45 \mathrm{GHz}$.



Teste usando $\mathrm{W}_{1}=450 \mu \mathrm{m}$ e $\mathrm{f}_{\mathrm{o}}=2,45 \mathrm{GHz}$.

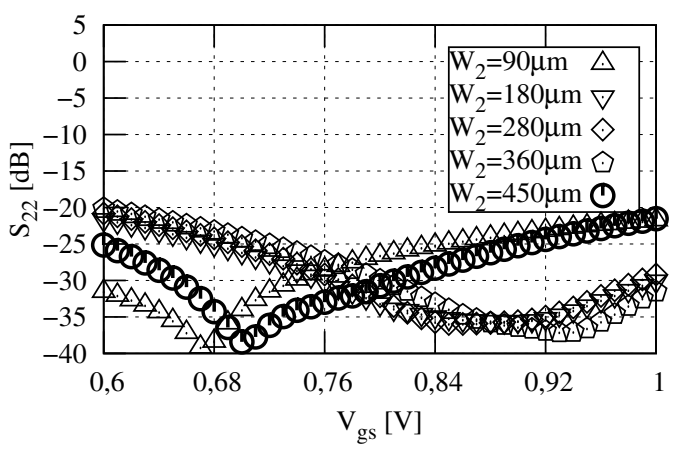

Teste usando $\mathrm{W}_{1}=450 \mu \mathrm{m}$ e $\mathrm{W}_{1}=\mathrm{W}_{2}$.

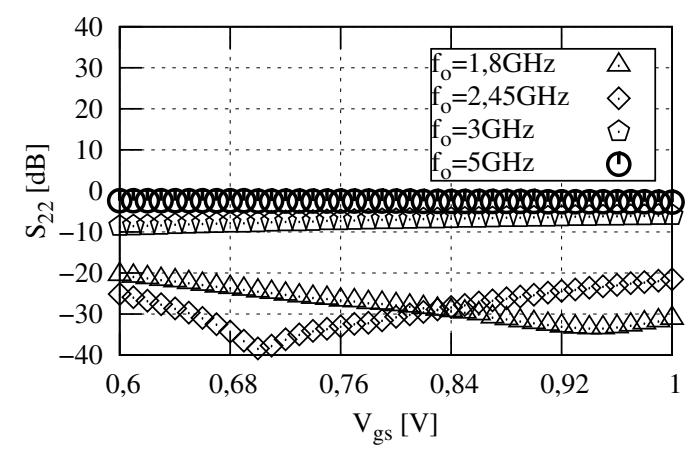

Figura A.9: Casamento da impedância de saída garantido nas diferentes simulações.
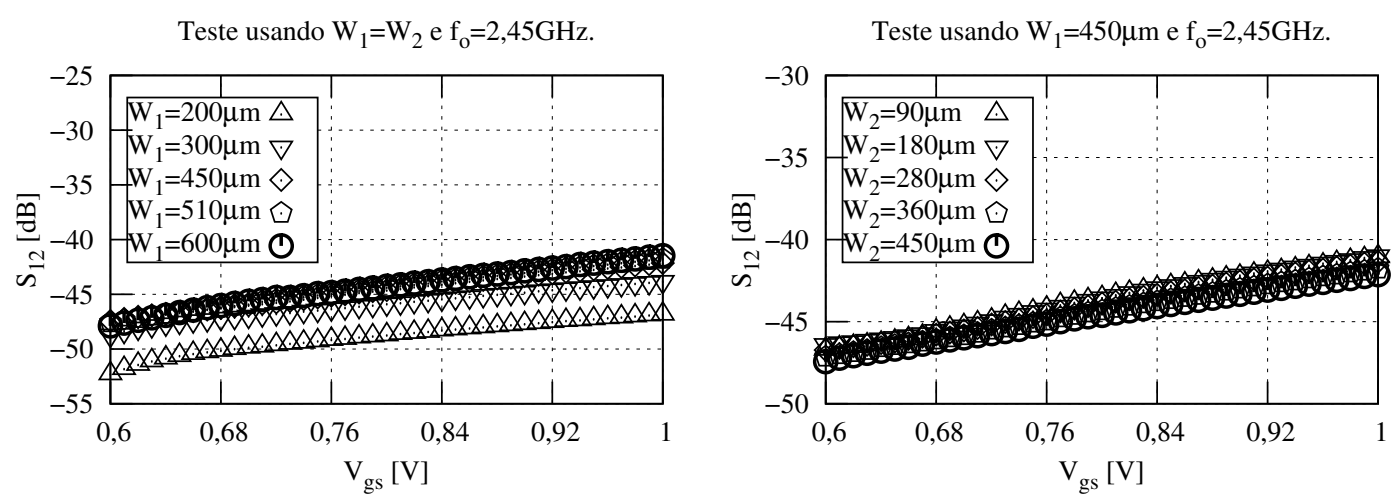

Teste usando $\mathrm{W}_{1}=450 \mu \mathrm{m}, \mathrm{W}_{1}=\mathrm{W}_{2}$ e $\mathrm{f}_{\mathrm{o}}=2,45 \mathrm{GHz}$.
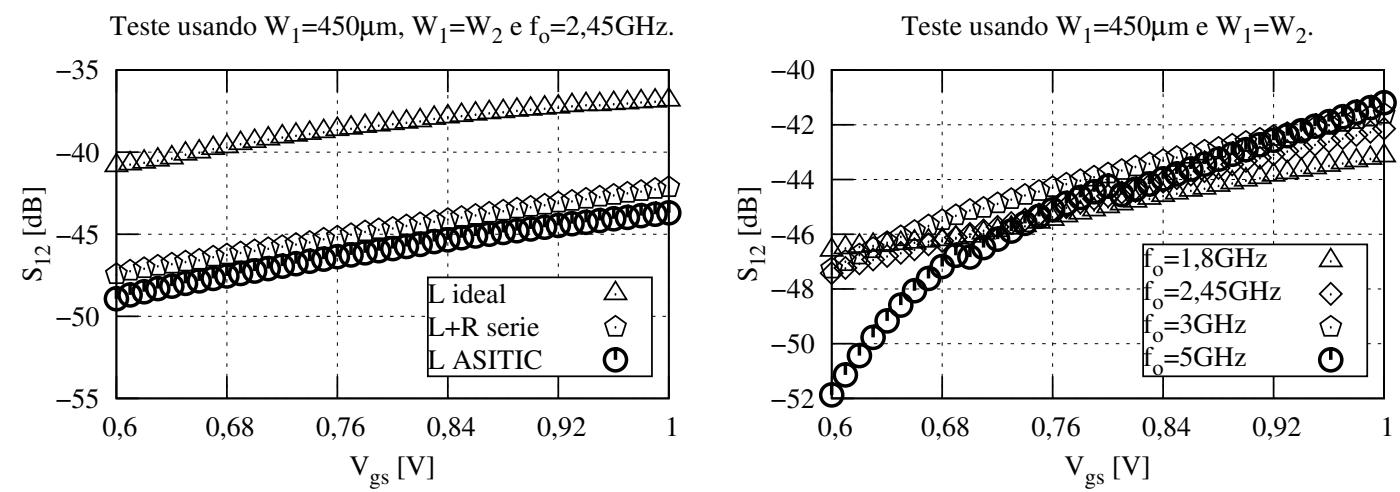

Figura A.10: Isolamento reverso resultado de diferentes simulações. 


\section{Referências Bibliográficas}

[1] ISHIHARA, N.; AMAKAWA, S.; MASU, K. RF CMOS Integrated Circuits: History, Current Status and Future Prospects. IEICE Transactions on Fundamentals of Electronics, Communications and Computer, E94, n. 2, p. 556-567, Feb. 2011. ISSN 739-8503.

[2] RAZAVI, B. Cognitive radio design Challenges and Techniques. IEEE Journal of SolidState Circuits, v. 45, n. 8, p. 1542-1553, Aug.. 2010. ISSN 0018-9200.

[3] STASZEWSKI, R. et al. All-digital TX Frequency Synthesizer and Discrete-Time Receiver for Bluetooth Radio in 130-nm CMOS. IEEE Journal of Solid-State Circuits, v. 39, n. 12, p. 2278-2291, Dec. 2004. ISSN 0018-9200.

[4] KIM, J.; YU, W.; YU, H.; CHO, S. A Digital-Intensive Receiver Front-End using VCO-based ADC with an embedded 2nd-Order Anti-Aliasing Sinc Filter in 90nm CMOS. In: IEEE International Solid-State Circuits Conference Digest of Technical Papers (ISSCC). New York, NY, USA: IEEE, 2011. p. 176-178. ISSN 0193-6530.

[5] KIM, J.; LEE, J.; CHO, S. Digital-Intensive Analog Circuits for Highly-Digitized RF Receivers. In: IEEE 54th International Midwest Symposium on Circuits and Systems (MWSCAS). New York, NY, USA: IEEE, 2011. p. 1-4. ISSN 1548-3746.

[6] KOBAYASHI, H.; KOUSAI, S.; YOSHIHARA, Y.; HAMADA, M. An all-Digital 8DPSK Polar Transmitter with Second-Order Approximation Scheme and Phase RotationConstant Digital PA for Bluetooth EDR in 65nm CMOS. In: IEEE International SolidState Circuits Conference Digest of Technical Papers (ISSCC). New York, NY, USA: IEEE, 2011. p. 174-176. ISSN 0193-6530.

[7] HE, X.; COLLADOS, M.; PAVLOVIC, N.; SINDEREN, J. van. A 1.2V, 17dBm Digital Polar CMOS PA with Transformer-based Power Interpolating. In: 34th European SolidState Circuits Conference, ESSCIRC. New York, NY, USA: IEEE, 2008. p. 486-489. ISSN 1930-8833.

[8] LEE, T. H. The Design of CMOS Radio Frequency Integrated Circuits. Cambridge: Cambridge University Press, 1998.

[9] RAZAVI, B. RF Microelectronics. New York, NY, USA: McGraw-Hill, 1998.

[10] DING, Y.; HARJANI, R. High-Linearity CMOS RF Front-End Circuits. Berlin: Springer, 2005.

[11] FAN, X.; ZHANG, H.; SANCHEZ-SINENCIO, E. A Noise Reduction and Linearity Improvement Technique for a Differential Cascode LNA. IEEE Journal of Solid-State Circuits, v. 43, n. 3, p. 588-599, Mar. 2008. ISSN 0018-9200. 
[12] CHANG, C.-P.; CHEN, J.-H.; WANG, Y.-H. A Fully Integrated 5GHz Low-Voltage LNA using Forward Body Bias Technology. IEEE Microwave and Wireless Components Letters, v. 19, n. 3, p. 176-178, Mar. 2009. ISSN 1531-1309.

[13] JOO, S.; CHOI, T.-Y.; JUNG, B. A 2.4-GHz Resistive Feedback LNA in 0.13- $\mu$ m CMOS. IEEE Journal of Solid-State Circuits, v. 44, n. 11, p. 3019-3029, Nov. 2009. ISSN 00189200 .

[14] LIN, C.; KALKUR, T.; MORIN, M. A 2.4GHz Common-Gate LNA using On-Chip Differential Inductors in a $0.18 \mu \mathrm{m}$ CMOS Technology. In: International Conference on Electrical, Communications, and Computers, CONIELECOMP. New York, NY, USA: IEEE, 2009. p. 183-188.

[15] JI, Y.; WANG, C.; LIU, J.; LIAO, H. 1.8 dB NF 3.6mW CMOS Active Balun Low Noise Amplifier for GPS. Electronics Letters, v. 46, n. 3, p. 251-252, April 2010. ISSN 00135194.

[16] FU, C.-T.; LAKDAWALA, H.; TAYLOR, S.; SOUMYANATH, K. A 2.5GHz 32nm $0.35 \mathrm{~mm}^{2} 3.5 \mathrm{~dB}$ NF $-5 \mathrm{dBm}$ P1dB Fully Differential CMOS Push-Pull LNA with Integrated 34dBm T/R Switch and ESD Protection. In: IEEE International Solid-State Circuits Conference Digest of Technical Papers (ISSCC). New York, NY, USA: IEEE, 2011. p. 56-58. ISSN 0193-6530.

[17] HAMPEL, S.; SCHMITZ, O.; TIEBOUT, M.; ROLFES, I. Inductorless 1-10.5GHz Wideband LNA for Multistandard Applications. In: IEEE Asian Solid-State Circuits Conference, A-SSCC. New York, NY, USA: IEEE, 2009. p. 269-272.

[18] CHANG, P.-Y.; HSU, S. A Compact 0.1-14-GHz Ultra-Wideband Low-Noise Amplifier in $0.13-\mu \mathrm{m}$ CMOS. IEEE Transactions on Microwave Theory and Techniques, v. 58, n. 10, p. 2575-2581, Oct. 2010. ISSN 0018-9480.

[19] HUNG, W.-H.; LIN, K.-T.; HSIEH, J.-Y.; LU, S.-S. A 2-6GHz Broadband CMOS LowNoise Amplifier with Current Reuse Topology utilizing a Noise-Shaping Technique. In: IEEE International Symposium on Circuits and Systems (ISCAS). New York, NY, USA: IEEE, 2011. p. 1291-1294.

[20] EL-NOZAHI, M.; HELMY, A.; SáNCHEZ-SINENCIO, E.; ENTESARI, K. An InductorLess Noise-Cancelling Broadband Low Noise Amplifier with Composite Transistor Pair in 90nm CMOS Technology. IEEE Journal of Solid-State Circuits, v. 46, n. 5, p. 1111-1122, May 2011. ISSN 0018-9200.

[21] CHEN, K.-H.; LIU, S.-I. Inductorless Wideband CMOS Low-Noise Amplifiers using Noise-Canceling Technique. IEEE Transactions on Circuits and Systems I: Regular Papers, v. 59, n. 2, p. 305-314, Feb. 2012.

[22] BRUCCOLERI, F.; KLUMPERINK, E.; NAUTA, B. Wide-band CMOS Low-Noise Amplifier exploiting Thermal Noise Canceling. IEEE Journal of Solid-State Circuits, v. 39, n. 2, p. 275-282, Feb. 2004. ISSN 0018-9200.

[23] CHEN, W.-H.; LIU, G.; ZDRAVKO, B.; NIKNEJAD, A. A Highly Linear Broadband CMOS LNA Employing Noise and Distortion Cancellation. In: IEEE Radio Frequency 
Integrated Circuits Symposium (RFIC). New York, NY, USA: IEEE, 2007. p. 61-64. ISSN 1529-2517.

[24] LIAO, C.-F.; LIU, S.-I. A Broadband Noise-Canceling CMOS LNA for 3.1-10.6-GHz UWB receivers. IEEE Journal of Solid-State Circuits, v. 42, n. 2, p. 329-339, Feb. 2007. ISSN 0018-9200.

[25] ZHUO, W.; EMBABI, S.; GYVEZ, J. de; SANCHEZ-SINENCIO, E. Using Capacitive Cross-Coupling Technique in RF Low Noise Amplifiers and Down-Conversion Mixer Design. In: Proceedings of the 26rd European Solid-State Circuits Conference, ESSCIRC. New York, NY, USA: IEEE, 2000. p. 77-80.

[26] ZHUO, W. et al. A Capacitor Cross-Coupled Common-Gate Low-Noise Amplifier. IEEE Transactions on Circuits and Systems II: Express Briefs, v. 52, n. 12, p. 875-879, Dec. 2005. ISSN 1549-7747.

[27] PERUMANA, B.; ZHAN, J.-H.; TAYLOR, S.; CARLTON, B.; LASKAR, J. ResistiveFeedback CMOS Low-Noise Amplifiers for Multiband Applications. IEEE Transactions on Microwave Theory and Techniques, v. 56, n. 5, p. 1218-1225, May 2008. ISSN 00189480 .

[28] WEBSTER, D.; HAIGH, D.; SCOTT, J.; PARKER, A. Derivative Superposition - A Linearisation Technique for Ultra Broadband Systems. In: IEE Colloquium, Wideband Circuits, Modelling and Techniques. New York, NY, USA: IEEE, 1996. p. 311-314.

[29] APARIN, V.; LARSON, L. Modified Derivative Superposition method for linearizing FET Low Noise Amplifiers. In: IEEE Digest of Papers, Radio Frequency Integrated Circuits (RFIC) Symposium. New York, NY, USA: IEEE, 2004. p. 105-108. ISSN 1529-2517.

[30] KIM, T.-S.; KIM, B.-S. Post-linearization of Cascode CMOS Low Noise Amplifier using Folded PMOS IMD Sinker. IEEE Microwave and Wireless Components Letters, v. 16, n. 4, p. 182-184, April 2006. ISSN 1531-1309.

[31] PARK, C.-W.; JEONG, J. Consideration of Linearity in Cascode Low Noise Amplifiers using Double Derivative Superposition Method with a Tuned Inductor. In: Korea-Japan Microwave Conference, KJMW. New York, NY, USA: IEEE, 2007. p. 21-24.

[32] ZHANG, F.; KINGET, P. Low-Power Programmable Gain CMOS Distributed LNA. IEEE Journal of Solid-State Circuits, v. 41, n. 6, p. 1333-1343, June 2006. ISSN 0018-9200.

[33] KIM, J.; HOYOS, S.; SILVA-MARTINEZ, J. Wideband Common-Gate CMOS LNA Employing Dual Negative Feedback with Simultaneous Noise, Gain, and Bandwidth Optimization. IEEE Transactions on Microwave Theory and Techniques, v. 58, n. 9, p. 2340-2351, Sept. 2010. ISSN 0018-9480.

[34] NAKAJIMA, T.; AMAKAWA, S.; ISHIHARA, N.; MASU, K. A Scalable Wideband Low-Noise Amplifier consisting of CMOS Inverter Circuits for Multi-Standard RF Receivers. In: 3rd International Conference on Signals, Circuits and Systems (SCS). New York, NY, USA: IEEE, 2009. p. 1-4.

[35] DUFFIN, R. J.; PETERSON, E. L.; ZENER, C. Geometric Programming - Theory and Applications. New Jersey, USA: John Wiley \& Sons Inc., 1967. 
[36] BOYD, S.; VANDERBERGHE, L. Convex Optimization. Cambridge: Cambridge University Press, 2004. http://www . stanford . edu/ boyd/cvxbook/.

[37] BOYD, S.; VANDERBERGHE, L.; HASSIBI, A. A Tutorial on Geometric Programming. 1997. http://www. stanford.edu/ boyd/papers/gp_tutorial.html.

[38] MOSEK. Specialized Solvers for Linear Programming, Mixed Integer Programming and many types of Nonlinear Convex Optimization Problems. http: //www . mosek . com.

[39] GRANT, M.; BOYD, S. CVX: Matlab Software for Disciplined Convex Programming, version 1.21. April 2011. http://www. stanford. edu/ boyd/cvx/.

[40] TOMLAB. Optimization Environment for Fast and Robust Large-Scale Optimization in MATLAB. http://tomopt. com/tomlab.

[41] HERShenson, M. del M. CMOS Analog Circuit Design via Geometric Programming. Tese (Doutorado) — Stanford University, California, 1999.

[42] HERSHENSON, M. del M. Design of Pipeline Analog-to-Digital Converters via Geometric Programming. In: Proceedings of the 2002 IEEE/ACM international conference on Computer-aided design. New York, NY, USA: ACM, 2002. (ICCAD '02), p. 317-324. ISBN 0-7803-7607-2. Disponível em: $<$ http://doi.acm.org/10.1145/774572.774620>.

[43] COLLERAN, D. et al. Optimization of Phase-Locked Loop Circuits via Geometric Programming. In: Proceedings of the IEEE Custom Integrated Circuits Conference. New York, NY, USA: IEEE, 2003. p. 377-380.

[44] CHEUNG, W.-T.; WONG, N. Optimized RF CMOS Low Noise Amplifier Design via Geometric Programming. In: International Symposium on Intelligent Signal Processing and Communications, ISPACS. New York, NY, USA: IEEE, 2006. p. 423-426.

[45] HERSHENSON, M. del M.; MOHAN, S. S.; BOYD, S. P.; LEE, T. H. Optimization of Inductor Circuits via Geometric Programming. In: Proceedings of the 36th annual ACM/IEEE Design Automation Conference. New York, NY, USA: ACM, 1999. (DAC '99), p. 994-998. ISBN 1-58113-109-7. Disponível em: $<$ http://doi.acm.org/10.1145/309847.310112>.

[46] OLIVEROS, J. Aplicação da programação geométrica no projeto de filtros Gm-C para receptores RF CMOS. Dissertação (Mestrado) - Escola politénica da Universidade de São Paulo, São Paulo, 2010.

[47] CABRERA, D. Automação e otimização do projeto de um oscilador controlável por tensão para aplicações em rádio frequência. Dissertação (Mestrado) - Escola politénica da Universidade de São Paulo, São Paulo, 2010.

[48] SAENZ, J. Metodologia para a otimização do rendimento e desempenho dos circuitos analógicos usando programação geométrica. Dissertação (Mestrado) - Escola politénica da Universidade de São Paulo, São Paulo, 2012. 
[49] CHAPARRO, S.; AYALA, A.; ROA, E.; NOIJE, W. V. A Merged RF CMOS LNAMixer Design using Geometric Programming. In: Proceedings of the 22nd Annual Symposium on Integrated Circuits and System Design: Chip on the Dunes. New York, NY, USA: ACM, 2009. (SBCCI '09), p. 16:1-16:5. ISBN 978-1-60558-705-9. Disponível em: <http://doi.acm.org/10.1145/1601896.1601917>.

[50] SHAEFFER, D. K.; LEE, T. H. A 1.5-V, 1.5-GHz CMOS Low Noise Amplifier. IEEE Journal of Solid-State Circuits, v. 32, p. 745-759, 1997.

[51] ROA, E. Metodologia de projeto para amplificadores de baixo ruído en CMOS. Dissertação (Mestrado) — Escola politénica da Universidade de São Paulo, Sao Paulo, 2003.

[52] AYALA, A. Projeto de um bloco LNA-Misturador para radiofrequência em tecnologia CMOS. Dissertação (Mestrado) - Escola politénica da Universidade de São Paulo, Sao Paulo, 2009.

[53] ASITIC: Analysis and Simulation of Spiral Inductors and Transformers for ICs. http: //rfic.eecs. berkeley.edu/ niknejad/asitic.html.

[54] HO, S.; SAAVEDRA, C. A CMOS Broadband Low-Noise Mixer with Noise Cancellation. IEEE Transactions on Microwave Theory and Techniques, v. 58, n. 5, p. $1126-1132$, May 2010. ISSN 0018-9480.

[55] ANJOS, A. dos. Integração de blocos RF CMOS com indutores usando tecnologia flip chip. Tese (Doutorado) — Escola politénica da Universidade de São Paulo, São Paulo, 2012. 